\title{
First Lopy
}

UITRASONIC IENSES AND TRANSMISSION PLATES

Thesis

submitted for the Degree of Ph.D.

to the University of Glasgow

by

Paul J. ERNST, Ph.D. (Vienna), Associate Professor of Physics Villanova College,Villanova, $\mathrm{Pa}$ :

New York, September 1946. 
ProQuest Number: 13850496

All rights reserved

INFORMATION TO ALL USERS

The quality of this reproduction is dependent upon the quality of the copy submitted.

In the unlikely event that the author did not send a complete manuscript and there are missing pages, these will be noted. Also, if material had to be removed, a note will indicate the deletion.

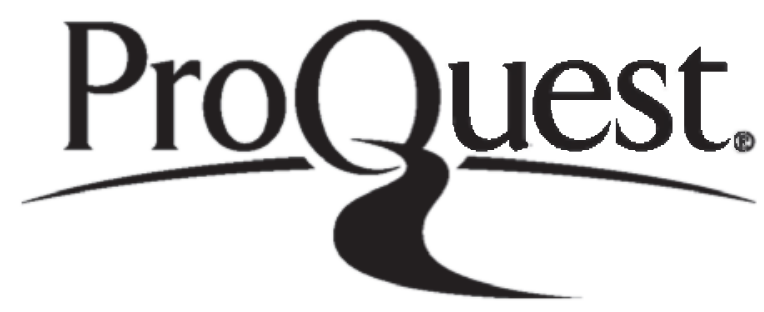

ProQuest 13850496

Published by ProQuest LLC (2019). Copyright of the Dissertation is held by the Author.

All rights reserved.

This work is protected against unauthorized copying under Title 17, United States Code Microform Edition @ ProQuest LLC.

ProQuest LLC.

789 East Eisenhower Parkway

P.O. Box 1346

Ann Arbor, Ml $48106-1346$ 
Contents.

Preface

List of Previous Publications

I. The Apparatus

(a) Introduction . • • • . . • 6

(b) The Ultrasonic Generator • . . . 9

1. The Electric Power Generator . • . 9

2. The Ultrasonic Oscillator . . . 12

3. The Crystal • . . . . . . 13

Quartz Crystals • . . . . . 13

Rochelle Salt Crystals • . • . 15

(c) The Longitudinal and Pure Transverse

Piezoelectric Effects in Crystals \&c.. . 16

(d) L-Cuts of Rochelle Salt Crystals . • . 20

II. The New Devices

(a) Solid Suspended U.S.Lenses of • • • 22

I. Plastics • . • • • • 22

2. Metals . • . • . . . . 23

(b) UItrasonic Contact Lenses . • • . 24

(c) Ultrasonic Transmission Plates . : . 25

III. Proofs of the Effect

(a) Mathematical Part . . . . . . 25

(b) Investigation of Ultrasonic Fields • • 33

1. Mechanical Methods . . . . - 33

2. Thermal Methods • • • • . 36

3. Electrical Method . . . . . 37 
Shadow Projection

Secondary Interferences . . . . 43

Diffraction Method . • . . . . 48

(c) Specification and Measurement of Ultrasonic Lenses \&c.

(d) Improvement of Bergmann's Method . . . 56

IV. Conclusion and Discussion . • • • . 58

Problems awaiting final solution . . . . 67

Phase-Reversal Zone-Plate - . . 68

Effect on a Binary Mixture . . . . . 72

Blackening Effect on Photo-

sensitive Emulsions . • . . 77

Bibliography

80 
Preface.

The research described in this thesis was carried out in the laboratories of the Departments of Applied Physics and Natural Philosophy in the University of Glasgow during the sessions 1942/43 - 1945/46, when I was Lecturer there.

In a Programme of Research, submitted in 1942, I set myself the problem "to design appliances which are simpler and more effective than the existing means of focusing ultrasonic waves." The main results of my investigations are summarised in a paper: Ultrasonic Lenses and Iransmission Plates, Journal of Scientific Instruments, Vol. 22, p.238 (1945), and in several other articles ready for publication.

The developments of solid ultrasonic lenses, ultrasonic contact lenses and transmission plates are original. They are analogues of optical appliances, but have not previously been used for ultrasonic work. The applications, to crystals of lithium potassium tartrate, potassium dihydrogen phosphate and kindred substances, of Cady's proof for the existence of a longitudinal piezoelectric effect in Rochelle salt crystals are new, and also that by Stamford for the positions of cuts of Rochelle salt crystals showing a pure transverse piezoelectric effect. "L-cuts" of Rochelle salt crystals are here actually used for the first time. + )

In addition, Bergmann's method for the determination of the velocities of ultrasonics in liquids has been improved, some inconsistencies revealed with results of previous investigators, and several erroneous opinions rectified. The observation of a particular ultrasonic effect on a binary mixture of 
Iiquids and its connexion with the velocity of sound therein are also original.

The recommendation of a new point source of light has appreciably simplified and improved the optical methods of rendering ultrasonic waves and fields visible. Perfect diaphragms with circular apertures for the light diffraction effect of ultrasonic waves have been made photographically for the first time. A very convenient specification and measurement of ultrasonic lenses and transmission plates is suggested in most stringent analogy to those used in optics. If nothing to the contrary is explicitly stated, the experiments have been elaborated and carried out, the apparatus contrived and set up by myself. I also have drawn the diagrams as well as the graphs, and taken, developed and printed the photographs.*)

Most of the experiments described here can be used as problems for students laboratory work in practical acoustics or in lecture demonstrations for the new field in the teaching of physics for which the name "Phonoptics" has been suggested by schilling $(60)$. They could constitute a special chapter appropriately called "Ultra-Phonoptics".

Moreover a number of new problems have been raised but not yet solved, either because they were beyond the scope of this work or leading too far away from its main line. 'the investigations, however, will be resumed as soon as the opportunity arises. itwo have already been started in the last chapter.

10 prints $(4,14,15,17,18,19,20,22,26,27)$ have been made by a photographer as they had been spoiled during the removal and my photographic equipment has not yet been set up here. 
A list of my previous publications is added to produce evidence of my having always been active in research work from my college-days till the invasion of Austria. Those eight papers distinguished by "c.p." (conjoint papers) after their titles have been worked out conjointly with research students under ny supervision. Those six marked with an asterisk are attached for mere inspection to estimate their general standard.

The first two deal with acoustic subjects. The third is the result of special studies in descriptive geometry. 'the patent specification relates analogues to soret's Zone-Plate and Wood's Phase-Reversal Zone-Plate applied to U.H.F.electric waves. In a similar way these devices are also applicable to uItrasonic waves. The fifth is a short report of a visit to the Northern Light Ubservatory at Tromsp. The last is a conjoint paper. Why share in this work was: choosing the subject, developing the new technique and applying it to the analysis of the bark of black alder-tree, dosigning the apparatus, supervising the experiments and checking the results obtained by a research student of mine, iuiss G. Weiner. For the actual and reliable performance of the difficult investigations and laborious measurements the Legree of Ph.D. was conferred on her by the University of Vienna. Parts of the paper are cited verbatim in the standard handbook on the subject by zechmeister and cholnoky and its translation into English ${ }^{++1}$.

\section{+1 The}

Liebermann (30) as have recently found application by Groth and city of sound. Labaw's (72) microphones contain Rochelle salt crystals cut in the orthodox way.

$++)$ Zechreister, I. and Cholnoky, L.: Principles and practice of Chromatography, translated by Bacharach, A.I. and Robinson, H'.N., Chapman and Hall Ltd., London (194I) p.296-300. 
Iist of Publications.

Zur Addition und Subtraktion mit Hilfe des logarithmischen Rechenschiebers. Z.M.u.Ph. 53 (1906).

+ Petzvals Guitharfe. Z.f.Realschw. 32 (1907).

Die einfachste Behandlung des Spieckerschen Kreises. Z.f.Rschw. $\frac{32}{\left(5 y^{n}\right.}(1907)$.

synthetischer Beweis einiger Eigenschaften des Heuerbachschen Kreises. Z.f.Rschw. 32 (.2907).

Uber das küppersche Konoid. Honatsh.iv.u.Ph. 17 (1907). $18(1908)$.

Ein Analogon zur wannheimschen kurve. Wonh. W. U. Fh.

Sur la courbe d'inversion de Raimondi. Giorn.mat.45. Die Radiale einer ebenen Kurve. Arch.M.u.Ph. 14 ( $\overline{1908)}$

+ Bemerkungen zu retzvals Theorie der Tonsysteme. Z.M. u.Ph. 57 (1909).

$15(1909)$.

Die Clairautschen wltiplicatrixkurven.Arch.M.u.Ph.III.

ZZusammenhang zwischen dem Küpperschen und Plückerschen Konoid. Monatsh.li.u.Ph. 19 (I909).

Mechanische trzeugung der Zissoiden vierter Ordnung. Monatsh. N.u.Ph. 19 (1909).

Die Aoustsche Resultantenkurve. 35.Jahrber. R.XV. (1909)

Die Axoidale zweier eb. Kurven. 35.Jahrber. R.XV. (1909)

+ Darstellend geornetrische Behandlung der Dupinschen ZykIiden. 36.Jahrber.R.XV.(1910).

Die allgemeine tuannheimsche Kurve. Monh. M.u.Ph.23(1913)

Die Kinematographie in ihrer Bedeutung für Wissenschaft und Schule. 85. Vers. d. Naturf. u. Mrzte, Wien(1913).

Die Trajectorien der schleifschieberbewegung als Orthogonalprojektionen etc... Arch. M.u.Ph. III. 22 (1913).

24 (1914).

Die Mannheimsche Kurve von Raumkurven. Honatsh. M.u.Ih.

Die einfachste Konstruktion der Tangente an Kissoiden und Konchoiden etc. .. Arch.M.u.Ph.III. 23 (1914).

Kinematograph und Esychologie. Iichtbildkunst, 3 (1914).

Der Wert des Kinetophons. Lichtbildk. 3 (1914).

Die Lichtpause in Unterricht der darstēllenden Geometrie Schultechnik 3 (1914).

Iichtbildapparat und kinematograph in der Schule. Das Kind in der schule. Bugra (1914).

Zur Erinnerung an Karl Wolf-Czapek. Filmw. II (1914).

$25(1915)$.

Einige Anwendungen der Rollenkoppel. Wonatsh. H.u.Ph.

Moderne Lichtreklame und künstliches Tageslicht. H'rohes schaffen, 3 (1926).

Von unsichtbarem Licht. Fr.Sch. 4 (1927).

Zur Erklärung des Schattenkreuzphänomens in der vrookeschen Röhre. Z.ph.ch.Unterr. 40 (1927). (c.p.)

Eine einfache versuchsanordnung zum Nachweis der elektro-optischen Loppelbrechung. Z.m.natw.Unterr. 41 (1929) (c.p.)

Miethes fluorographisches verfahren zur Thotographie von versteinerungen. Das Bild, 5 (1928). 
feeh. I (1928).

Der Werdegang einer Iichtreklame-Leuchtröhre. Wr.Kaf-

Die Photographie in den physikalischen Schülerübungen. Das Bild, 5 (1928).

Dild. 5 (1928).
Lumineszenzproben für ichulversuche im Licht der AnaIysenquarzlampe. Z.math.natw.Unterr. 61 (1929).

Sensitometrische Prüfung von ryponpapier. Phot.Korr.

$63(1929)$. (c.p.)

Schulversuche über wärmewirkungen hochfrequenter

Wechselströme. Z.math.natw.Unterr. 6I (I929). (c.p.)

Die Ultraviolett-Kapillaranalyse der pharmazeutischen

Drogen. Pharm. Wonatsh. 10 (1929). (c.p.)

+ Vorrichtung züm sammeln und Zerstreuen, gerichteten

Senden und Empfangen elektrischer wellen. Osterr.Pat.No.132272.

La Nordlumobservado on Troms $\phi$. Austr.Esper. 7 (1930).

Die Technik der Polarforschung von gestern uñd heute. Radio talk, Jan 15, 1931.

Naturfarbeneufnahmen von Lumineszenzerscheinungen in gefiltertem UItraviolettlicht. Phot.Korr. 67 (1931).

Das Rätsel des Polarlichts. H'r.Sch. 8 (1931).

Die Quarzlanpe und ihre gewerblich-iñdustrielle verwendung. Wochsch. N.O.Gew.ver. 92 (1931). $68(193 \stackrel{+}{2})$.

+ Die Photographie in der Nordlichtforschung. Hhot.Kor.

Der Blick ins Innere der Waterie. Radio talk (1932).

Das Lichtbild ohne Licht. Radio talk, Jan.15, 1933.

Der Blick ins Innere der waterie, t'r.Sch. IOn(1933).

Aktuelle t'lugereignisse. Radio talk (1933).

Dasxmagische 'tahlendreieck. H'r.Sch.10 (1933).

Kostenlose selbstherstellung von wodellphotozellen.

Ph.u.Ch. 34 (1934).

Spektrographie mit schulmäßigen Mitteln. Schulphot.

3 (1934).

$5(1934)$.

Aufgaben für photographische Schülerübungen. Schulph.

Die Synchronuhr. Der Uhrm. 8 (1935).

Zur UItraviolett-Kapillaranālyse der pharmazeutischen

Drogen. Pharm.ilonatsh. 16 (1935). (c.p.)

Unterscheidung frischgetrockneter und abgelagerter cortex Frangulae. Pharm.Monatsh. I7 (1936). (c.p.)

+ Chromatogramme und UItrachromatogramme pharmazeutischer Drogen. Sci.Pharm. 8 (1937). (c.p.)

22, $238(1945)$.

Ultrasonic Lensés and Transmission Plates. J.Sc.Instr. 
Introduction.

Whenever a lens is mentioned in acoustics usually one of two individual apparatus is meant: either the large collodion lens filled with carbon dioxide by means of which, almost 100 years ago, Sondhauss (63) demonstrated the validity for sound waves of the laws of refraction: or the hemispherical lens of wire-gauze stuffed with down or small chips of ebonite which in 1890 Hesehus (32) used for the determination of the velocities of sound in these substances. Later Lubcke applied an air lens of $1.5 \mathrm{~m}$. diameter immersed in water to an experimental test of a remarkable diffraction phenomenon predicted by Lord Rayleigh (5\%). Host probably also a few further applications to acoustical research of lenses could be found in literature; but, to the best of my knowledge, no practical use whatever of acoustic lenses has been published.

Still more surprising is the fact that lenses have not yet been introduced in ultrasonic work. Here the uneconomical amount of power required presents a challenge to improve the efficiency of ultrasonic waves by concentrating them towards a focus, and yet lenses to answer this purpose can be designed of quite a manageable size.

A device serving as a means to this end is that given by Gruetzmacher's (31) "concave piezoelectric quartz"; this method has been successfully applied recently to physiological work (44, The chief problem of making ultrasonic lenses was tackled by Pohlmann(55) in 1939, but was only partially and unsatisfactorily solved. 
When ultrasonic waves travel from one medium into another through a plane boundary perpendicular to the direction of propagation of the waves, the reflectivity of the separating plane, that is, the ratio of reflected to incident ultrasonic energies ${ }^{+}$, is expressed by Boyle and Rawlinson's $(19,12)$ fundamental formula:

$$
\mathrm{R}=\frac{\left(\frac{\rho_{1} v_{1}}{\rho_{2} v_{2}}-\frac{\rho_{2} v_{2}}{\rho_{1} v_{1}}\right)^{2}}{4 \cot ^{2} \frac{2 \pi_{2}}{\lambda_{2}}+\left(\frac{\rho_{1} v_{1}}{\rho_{2} v_{2}}+\frac{\rho_{2} v_{2}}{\rho_{1} v_{1}}\right)^{2}},
$$

$\rho_{1}, \rho_{2}$ being the specific gravities of the two media, $\nabla_{1}, v_{2}$ the velocities of ultrasonic waves in them, $\mathrm{d}_{2}$ the thickness of the second medium, and $\lambda_{2}$ the wave length in the second medium. The product of $p v$ is called the "acoustic resistivity" and plays a similar part in diacoustics as the characteristic impedance in the theory of electric transmission lines; it will be denoted by $w$ in what follows. The ratio $m=w_{1 / w_{2}}$, on which the reflectivity depends, will be named "reflective index". The acoustical "refractive index" is known to be equal to the quotient of the velocities of sound waves in the two media concerned, i.e. $\mu=v_{1} / v_{2}$.

From the above expression Pohlmamdraws the conclusion that solids are unsuitable materials for ultrasonic lenses because of the great losses of energy, on passing into and emerging from a solid lens, of ultrasonic waves travelling through a liquid. He therefore devises "liquid lenses" consisting of carbon tetrachloride or chloroform filled into

$+T$ For this and the following definitions see International Critical Tables of Numerical Data, $\Phi$, p.450 (1929). 
biconvex cells of spherically curved copper foils of $0^{\circ} 01 \mathrm{~mm}$. thickness. With reference to water as the medium for the propagation of ultrasonic waves, their refractive indices are $1 \cdot 6$ and 1.5 respectively, and with reference to m-xylene 1.43 and 1.34. The lenses, "thin-skinned" as they are, reflect nevertheless twice $16 \%$ of the incident energy at the copper foils, so that, in the case of water, about $70 \%$ is transmitted; in the case of m-xylene, even less than $65 \%$ is transmitted.

As will be shown in what follows, yohlmann's reasoning does not hold true for all solid materials.

His paper, after all, was published under the title: "Uber die möglichkeit einer akustischen Abbildung in Analogie zur optischen" ("On the Possibility of rroducing an Acoustical Inage Analogue to the Optical") which gave no indication that the article contained anything on ultrasonic lenses.

Tumanski (68), on the other hand, gave his Russian paper a misleading title, which is, translated into English: "The lieneration of UItrasonic Uscillations by Piezo-Quartz Lenses." There was no lens whatever used by him. What he calls a quartz lens is a quartz crystal ground to the shape of a watch glass of throughout equal thickness. All that he did was checking Gruetzmacher's method and a little improving it. By means of a Hartley oscillator of $1 \mathrm{kw}$ power at $4000 \mathrm{~V}$ anode voltage, using lead foils as electrodes and an air cushion as support for the crystal and vaseline oil as liquid for the propagation, Tumanski, according to his paper, has produced a mound of $70 \mathrm{~cm}$. height measured from the upper surface of the crystal+1, + Cady (17), obviously by his translator's mistake, is citing on p.681: from the free surface of the liquid. 
The Ultrasonic Generator.

Ultrasonic waves can be generated in different ways: mechanically, thermally or electrically, utilizing magnetostriction or piezoelectric effects. The devices designed in this thesis are applicable to ultrasonics produced by anyone method, of course. To include the widest range of frequency, especially higher frequencies, a piezoelectric generator has been selected. This consists of an electric power generator and an ultrasonic oscillator.

The Electric Power Generator.

After almost all known types had been tried of small electric power generators used in ultrasonic work, a push-pull oscillator similar to those described by Porter (56) and by Bosch and Allée (9) was built and modified according to the requirements of this work and the means available in the Hlectronics Laboratory of the Physics vepartment.

Most of the apparatus of other investigators is used at power levels in the kilowatt range. Even the circuits of Yorter and of Bosch and Allée embody two valves of $250 \mathrm{~W}$ and $100 \mathrm{~W}$ respectively, while the set used here is built around two Mazda PA40 output triodes of $40 \mathrm{~W}$. power which were discarded from a used amplifier. 'lhey are, of course, not the right valves for a class $C$ oscillator but no others were at my disposal then. Fig.l is a photograph of the whole assembly, Fig.2 shows a schematic diagram of the simple circuit. The filament current is taken from the A.C. main supply by means of a step-down transformer 250:4, the anode voltage from the $500 \mathrm{~V}$ 
ע.C. main supply, using a potentioneter of $3000 \Omega$ resistance to vary the voltage continuously from 0 to 500 volts, and a choke imput smoothing filter. Both the transformer and filter are separately screened and placed at an appreciable distance from the oscillator portion of the apparatus.

Lwo variable air condensers of 150 pqu each and one of 15 pyut with vernier control are provided forthe tuning and a variable oil condenser of 2000 ppuF can be added when more capacitance is needed. 'L'O diminish "hand capacity" the condensers are fitted with crooks of glass of about $25 \mathrm{~cm}$. length as handles instead of ordinary knobs.

As a chief feature the interchangeable inductance coils possess four pairs of adjustable taps apart from the centre tap, two pairs going to the anodes and grids of the valves and one pair each to the tuning condensers and to the electrodes of the crystal. 'L'he positions providing optimum results are found by trial. As a rule the anode and condenser taps are on the same turn. since the reciprocal piezoelectric effect is proportional to the voltage applied to the crystal, the voltage is raised by means of a high frequency transformer (Tesla coil) replacing the fourth pair of tappings unless limited mechanical or dielectric strengths of the crystal make it impossible. A safety spark in parallel with the crystal and two fuse bulbs in series with it serve as protections from over voltage and excess current respectively. une moving coil L.C. voltmeter and two milliammeters control the imput, a high frequency voltmeter and milliammeter record the output. 


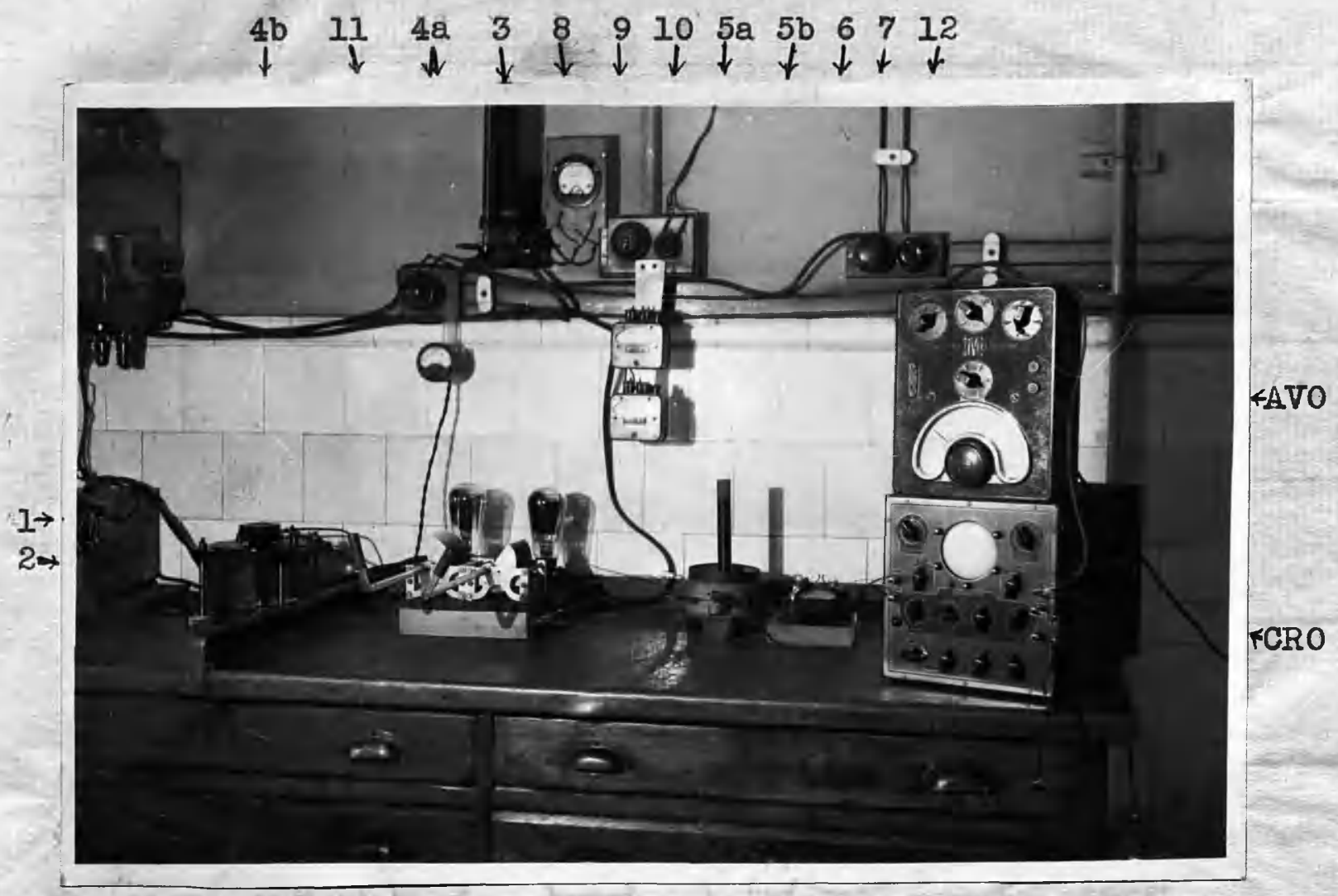

Fig. 1. The Electric Power Generator.

1 Transformer $250: 4$

2 Smoothing Filter

3 Resistance

4a Variable Air Condensers

4b Variable $0 i l$ Condenser

$5 a$ Induction Coil, primary

5b Induction Coil, secondary AVo-Oscillator
6 Spark Gapg

$7 \quad$ Fuse Bulbs

8 D.C. Voltmeter

9 Milliammeter for $1_{a}$

10 Milliarmeter for $i_{g}$

11 H. F. Voltmeter

12 H. F. Milliametetem

CRO-Oscilloscope 

The above condensers together with three exchangeable H.F.transformers cover the whole range of frequencies from about $50 \mathrm{kc} / \mathrm{sec}$. to $5000 \mathrm{kc} / \mathrm{sec}$. $+1$

'Lhe frequency was measured, when necessary, by comparison with a signal generator on a vossor cathode ray oscillograph (method of Lissajous' figures) or in the same way by means of an AVO-oscillator which had been checked before with the sig nal generator.

To make the most of the energy available very precise tuning to exact resonance with the oscillating crystal is important. Maximum power tranisor would be obtained by a fixed tuned pulse generating circuit or similar means, provided that the particular purpose permits their use. but that was not necessary in this case.

(38)

+) The coils were wound by myself according to Korndörfer's equations, measured by means of an inductance bridge and finally the frequencies checked. About korndörfer's equations see e.g. Rein $\bar{H}$. and $K$. Wirtz, kadiotelegraphisches rraktikum (58).

The Ultrasonic Uscillator.

The ultrasonic oscillator consists of an optically worked square glass cell containing the oscillating crystal imnersed in a dielectric fluid. vells of two different sizes were used, $5 \times 5 \times 16 \mathrm{~cm}$. or $16 \times 16 \times 16 \mathrm{~cm}$.

'l'he first design of the crystal holder was an improvement on that given by Hreundlich and his co-workers (26). Freundlich's "bed of lead" combined with Gruetzmacher's (31) "air-cushion" gave excellent results, especially with metal springs instead of glass hooks for fixing of the upper electrode, 
Later the idea of fixing an upper electrode at all was dropped, and transmission plates or contact lenses were used instead. +) Sliding of the quartz on the metal bed or of the plates or lenses on the crystal did not occur.

In view of the following work the considerations in

Freundich's paper, mentioned above, concerning the reasons for the advantages of lead as a support for the crystal and a "window" as an upper electrode seem rather doubtful. To these points will be returned later in discussing the conclusions.

\section{The Crystal.}

Different crystals were used with the circuit described: quartz wafers of different sizes and various cuts for length or thickness vibrations, and "pebbles" discarded from old spectacles, "L-cuts" and other slices of Rochelle salt crystals.++)

\section{Quartz Crystals.}

The first quartz crystal plate supplied by the University, an X-cut $2.54 \times 2.54 \times 0.476 \mathrm{~cm}$., corresponding to the frequency of $600 \mathrm{kc} / \mathrm{sec}$. in the thickness direction and $108 \mathrm{kc} / \mathrm{sec}$. in the length, was broken by a too powerful electric field during one of the first experiments. This crystal has been replaced by an identical one, which is still in use after having survived many thousand experiments. Thin silver electrodes are sputtered on in the conventional way. They are 1 smaller than the surface of the crystal on each side as a precaution against sparking ct Plano-parallel plate, plano-spherical or plano-
cylindrical fens in direct contact with the crystal, cf.pp.24,25.
++ "L-cuts" are cuts showing a maximum of longitu-
dinal piezoelectric effect, cf. pp.16ff.,20 $\mathrm{f}$. 
between them. Also the first plate was "rescued" to some extent. It was re-ground in the Geology Department and oscil-

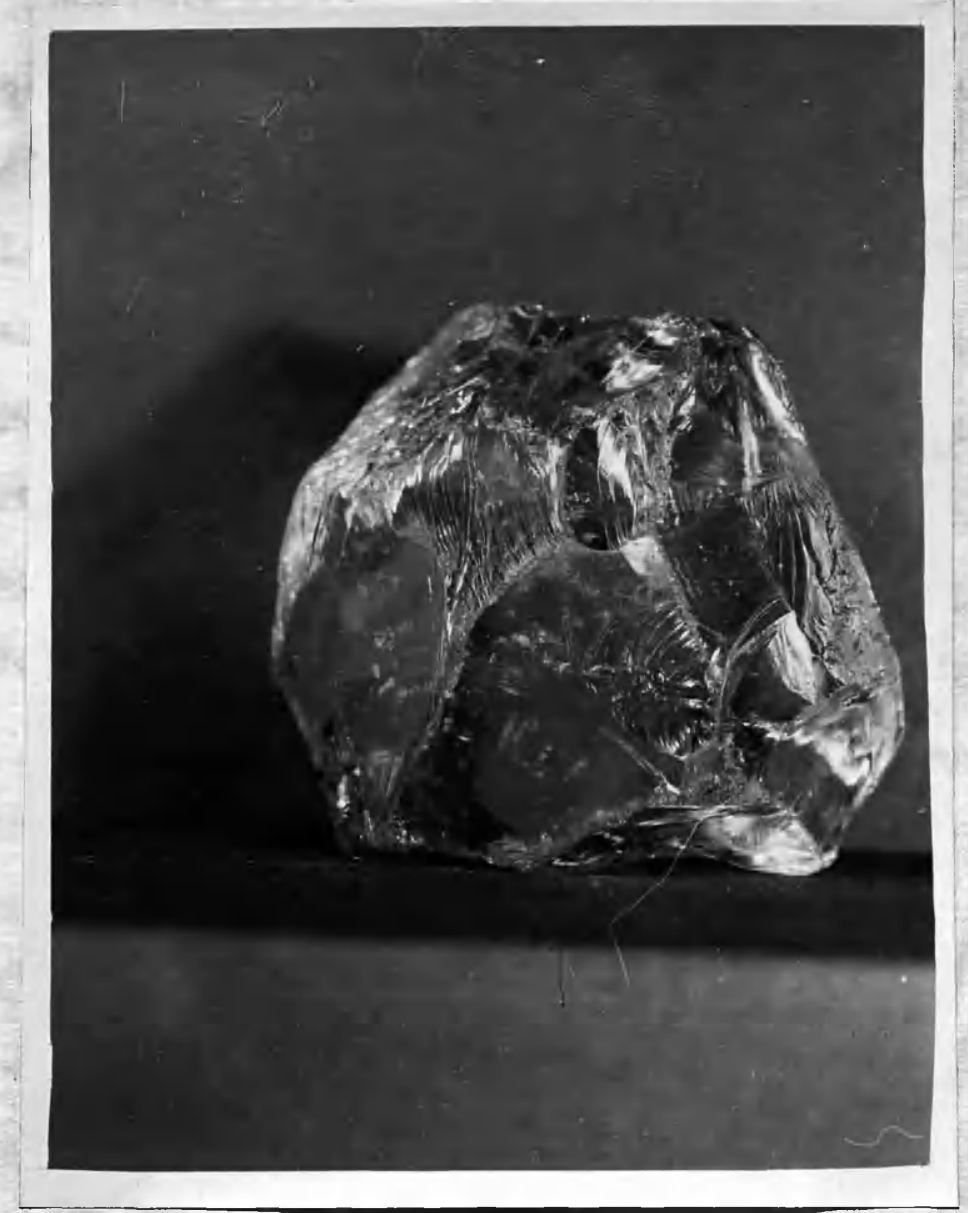

Fig.3. Iump of Citrine. lates again rather weIl a.s arrettangular plate in both thickness and length vibrations, $600 \mathrm{kc} / \mathrm{sec}$. and $136 \mathrm{kc} / \mathrm{sec}$. respectively.

Fig. 3 is the photograph of an irregular lump of citrine from the Hunterian Museum.+) This has offered the opportunity of studying various methods for the determination of

the piezoelectric axes of quartz crystals. When being washed in hot water after etching with hydrofluoric acid the crystal unfortunately cracked. It was thereafter cut along the main cracks by means of a carborundum disc on a milling machine and ground with carborundum powder in the ordinary manner. In this way some bigger and a number of smaller wafers have been obtained from the mother crystal, all of them accomplishing their objects very well. +I should like to thank Professor Trueman for his kind gift also here. 
Rochelle Salt Crystals.

Rochelle salt has been known for many years to be a cheap and easily replaceable substitute for quartz crystal as a good piezoelectric oscillator. The bibliography on this substance is very extensive. The references and short abstracts in Gmelin's Handbuch fill not less than 58 pages (28). There are different methods of growing Rochelle salt crystals: evaporation of a saturated solution at constant temperature under reduced air pressure, evaporation at constant temperature using concentrated sulphuric acid, slow cooling of a supersaturated solution in a thermostat, and combinations of these methods.

In these ways crystals were grown of about $8 \mathrm{~cm}$. in their longest direction; but they were sometimes streaky and not quite free from flaws. Contrary to the usual method of starting with miniature seed crystals it was found better to beginn with thin but large crystal plates. They grow much more quickly, and the solution can be cooled regularly from the very beginning. The diameter plate perpendicular to the electric axis has proved best.

A huge crystal $8 \times 3^{1} / 2 \times 30 \mathrm{~cm}$. was supplied by Messrs. Brush Crystal Company Ltd., London. They also gave information about machining methods, so that a fair number of excellent crystal plates could be cut and ground. After almost two years the crystals still work very well. The only precaution necessary to take is that they must be kept under a bell jar in air dried by calcium chloride. Too strong siccatives are not advisable as the crystal easily lopses its water of crystallisation. 
The Longitudinal and Pure Transverse Piezoelectric Effects in Ciystals of Potassium Dihydrogen Phosphate and some Isomorphs.

For more than forty years, sinee Pockels' (54) earliest measurements on the piezoelectricity of Rochelle salt crystals, only their transverse piezoelectric effeot was investigated and sometimes also practically applied. The existence of a longitudinal piezoelectric effect in Rochelle salt had escaped observation until it was, for the first time, discussed theoretically and proved experimentally in 1937 by Cady (16). His proof is based on Voigt's (69) general equatIon for the longitudinal piezoelectric effect and comprises all crystal classes for which all the piezoelectric moduli are zero, with the exception of $\mathrm{d}_{14}, \mathrm{~d}_{25}$ and $\mathrm{d}_{36}$. The maximum effect is produced by "I-cuts", as he calls them, which are equally inclined to all three crystallogigraphic axes.

In the same year Bahrs and Engl (2) investigated the piezoelectricity of ammonium chloride crystals at the transition point $-30^{\circ} 5^{\circ}$, using an "L-cut" of this salt. This particular case, where $\mathrm{d}_{14}=\mathrm{d}_{25}=\mathrm{d}_{36}$ and all other moduli are equal to zero, is, of course, included in Cady's proof; but Bahrs and Engl derived the piezoelectric properties of this cut by specialisation of Voigt's general equations, most probably quite independently of Cady.

In 1938 Busch $(14,15)$ described the 'Rochelle-electricity" of crystals of potassium dihydrogen phosphate $\left(\mathrm{KH}_{2} \mathrm{PO}_{4}\right)$ and three other isomorphous substances, potassium dihydrogen arsenate $\left(\mathrm{KH}_{2} \mathrm{AsO}_{4}\right)$, ammonium dihydrogen phosphate $\left(\mathrm{NH}_{4} \mathrm{H}_{2} \mathrm{PO}_{4}\right)$ and anmonium dihydrogen arsenate $\left(\mathrm{NH}_{4} \mathrm{H}_{2} \mathrm{AsO}_{4}\right)$. One year later 
Luidy (42) showed that for $\mathrm{KH}_{2} \mathrm{PO}_{4}$ crystals the value of the piezoelectric modulus $a_{36}$ varies with that of its dielectric constant. It increases greatly near the Curie point and reaches a maximum value at $123^{\circ}$ abs., which is more than (43) 5000 times its value at room temperature. Ludy still considered at that time, as he explicitily has stressed in his paper, that Rochelle salt could be excited piezoelectrically only by shearing forces, and assumed that the same was true for $\mathrm{KH}_{2} \mathrm{PO}_{4}$ crystals as well. But this assumption is erroneous.

According to Voigt, for crystals of the tetragonal scalenohedral class ( $V$ 19), to which the four substances mentioned above belong, of the piezoelectric moduli referred to the crystallographic axes only $a_{14}, d_{25}$ and $a_{36}^{+}(69)$ are different from zero. In addition $\mathrm{d}_{14}=\mathrm{d} 25$. Therefore Cady's proof applies equally to potassium dihydrogen phosphate and its isomorphs.

Consequently it follows that:-

1. Plates cut in any orientation except those parallel to one of the crystallographic axes show a longitudinal piezoelectric effect.

2. The effect is a maximum when the specimen is equally inclined to the three crystallographic axes.

Moreover, Stamford's (66) calculation of the correct orientation of Rochelle salt cuts for pure longitudinal oscillations is applicable, without alteration, to these substances so that:

3. Specimens cut parallel to one of the crystallographic axes $+13$

By an obvious misprint in Lüdy's paper the modulus $\mathrm{d}_{21 \text { is }}$ referred to instead of $\mathrm{d}_{25}$. 
and making angles of $45^{\circ}$ with the other two show a pure transverse piezoelectric effect.

Busch and Scherrer's schools (Zürich, Switzerland) (59)

have apparently not yet noticed the existence of a longitudinal piezoelectric effect in Kochelle-electrics. Luring the last few years Helv. Phys. Acta, wherein most of their articles appeared, were not easily obtainable. But neither in those papers read in the "Acta", nor in the reprints which were available, nor in any review of the articles concerned was any mention made of the longitudinal piezoelectric effect in crystals akin to Rochelle salt or even in Rochelle salt itself. ${ }^{+1++1}$

In a recent paper Fagan (24) recommends Iithium potassium tartrate crystals as substitute of Rochelle salt crystals. This mixed tartrate is isomorphic with Rochelle salt and therefore included in Cady 's and Stamford's proofs which fact is not mentioned in Fagan's article. Whether the lithium potassium tartrate crystal possesses the merits attributed to it by Fagan is rather doubtful as his conclusions are drawn from experiments performed with crystals of the dimensions of a few mm. and many of the other statements in his paper are obviously wrong.

+ on p.I claim is laid to the originality of the contents of this chapter.As the facts stated herein are briefly mentioned in Cady's book on piezoeleotricity (I7) published just a few weeks ago the priority of my thesis to or its independence of this book has to be proved.

Up to here this chapter had been written more than two years ago and sent on 7th June 1944 to Messrs. Macmillan \& Co.Ltd. for publication in "Nature",But in a letter of l4th June 1944 the editors of Nature "regretted they were unable to find space for the communication". On March 31, 1946 I sent the manuscript to Prof. W.G.Cady. His delayed answer was forwarded from Glasgow to my present address and is enclosed (p. 19) to explain how matters stand.

++ Even Bergmann still adheres to the wrong opinion. on p.25 of the 3rd ed. (1942) of his book (4) he is reiterating the statement: "... beim Seignettesalz sind einfache Dickenschwinger wie beirn Quarz oder Turmalin nicht möglich." 


\section{WESLEYAN UNIVERSITY}

MIDDLETOWN, CONNECTICUT

SCOTT LABORATORY

DEPARTMENT OF PHYSICS

May 2, 1946

Dr. Paul J. Ernst

Nat. Phil. Department

The University of Glasgow

Glasgow, Scotland

\section{Dear Doctor Ernst:}

Thanks for your letter of March 31 st with the enclosure. I must apologize for being so late in replying, but I wanted to discuss the subject matter of your enclosure with my colleague, Professor Van Dyke, and he has been away much of the time. If you are already on the way to the United States, I hope that this letter will be forwarded to you. Your conclusion that there is a longitudinal effect in the crystals that you mention, when cuts are suitably oriented, is entirely correct. I have already called attention to this fact in my book on "Piezoelectricity," which should be published this month by the McGraw-Hill Book Company. It was expected that the book would be out last January, but publication has been unavoidably delayed.

The possibility of a longituainal effect, not only in Rochelle salt and in the tetragonal class that you mention, but in two other crystal classes as well, is stated on page 204 of my book. This information will, therefore, be made known long before your paper could appear in any journal. I hope I am right in assuming that you would, for this reason, prefer not to have your paper submitted for publication. On the other hand, if you will soon have experimental data to publish, an account of such an investigation will be very worthwhile. Up to the present time, I have seen no experimental confirmation of the longitudinal effect in the classes mentioned, except in the case of Rochelle salt. I have long had it in mind to do some experimenting along this line of one of the ammonium salts, but so far have not found time. I should be greatly interested in hearing of your success.

With kindest regards and hoping to see you while you are in this country, I am,

Yours very sincerely,

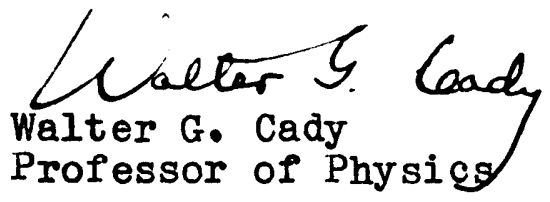

WGC: bw

Enc. 
Ihe Rochelle salt crystal used were mostly L-cuts+). Their correct position was secured by fixing the crystal on an

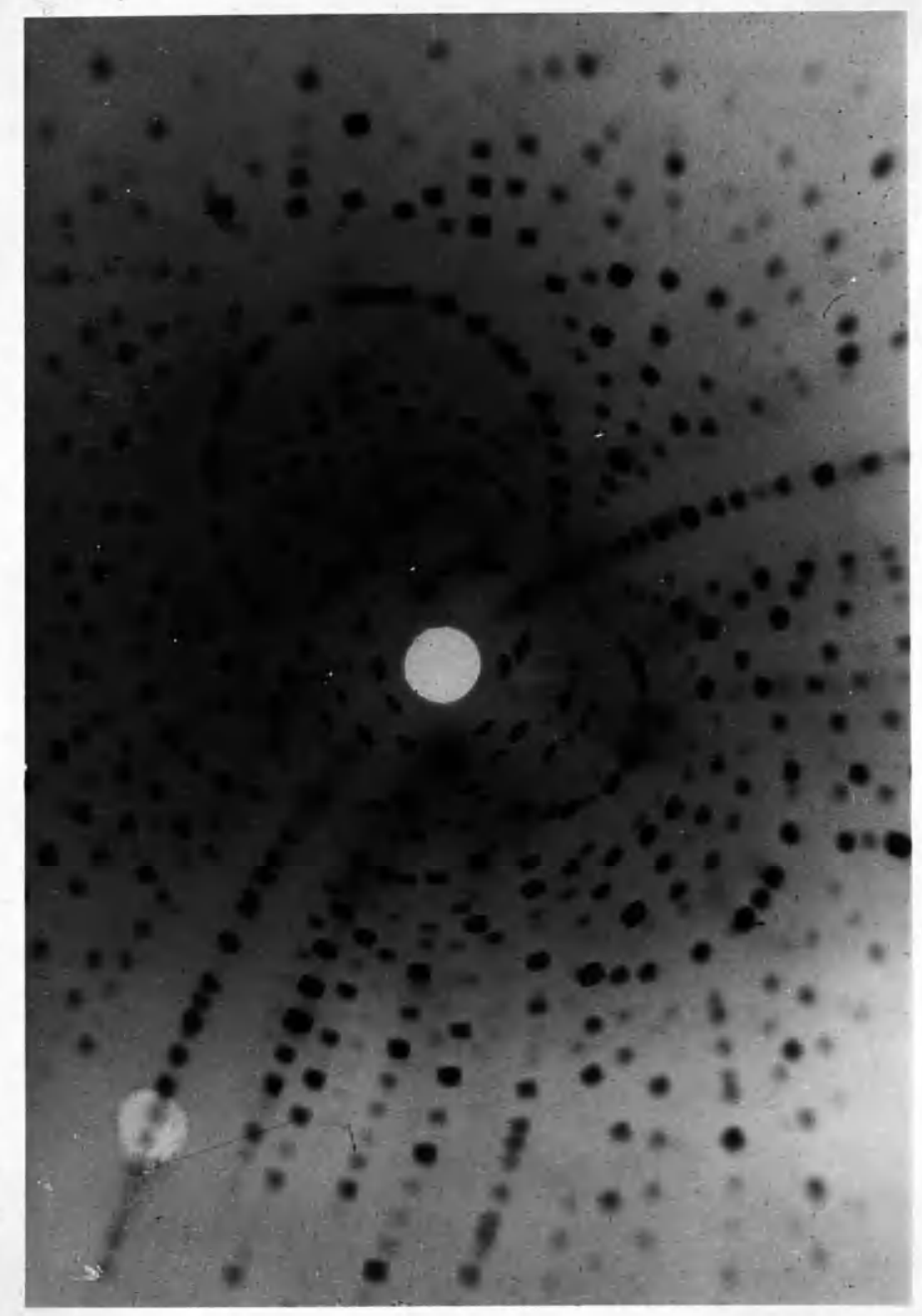

Fig. 4. Laue spot diagram of an L-cut of Rochelle salt. adjustable table when it was cut. Fig. 4 is

the Laue spot diagram of one of them. ${ }^{++}$Its interpretation seems to be fairly difficult. ordinary cuts were employed only for comparison with I-cuts. Square, rectangular, circular or irreguIarly shaped L-cut plates and rods were applied of sizes from a few $\mathrm{mm}^{2}$ to the inclined cross section of the crystal sketched in Fig. 5 and of thicknesses from 1 to $20 \mathrm{~mm}$. Circular discs did not work very satisfactorily, all other sorts were excellent resonators. Figg. 27,29-32 show the good performance of those in + I wish to express my thanks to Dr. W.S.Cormack, Principal of Stow College for Ingineering, Glasgow, for the permission to cut the crystal in the workshop of the college. ++ ) My thank is due to Professor J. M. Robertson of Glasgow who gave me the permission to use an $X$-ray spectrograph in the Chemistry Department. 
combination with lenses or transmission plates. Further details are given in the legends to the figures.

The I-cuts could not be excited in an oscillator cixcuit unless at least a small reaction was added. It is however,

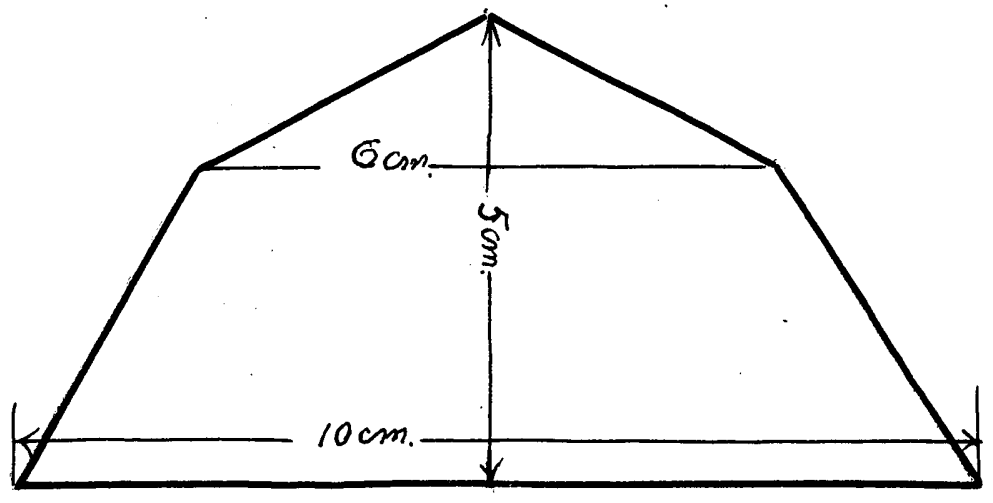

Fig.5. Sketch of the inclined cross section of an L-cut of Rochelle salt by experiment, quite

easily proved that in a

"modified Pierce circuit"

like that shown in Fig. 6

the crystal does control

the oscillations. +1

According to

Cady (16) L-cuts of Ro-

chelle salt do not stand up to a voltage higher than $1000 \mathrm{~V} / \mathrm{cm}$. Therefore, in a circuit controlled by a Rochelle salt L-cut, the use of a high frequency transformer (Tesla coil) is not advisable. Anyway, experiments showed that for the same volt-

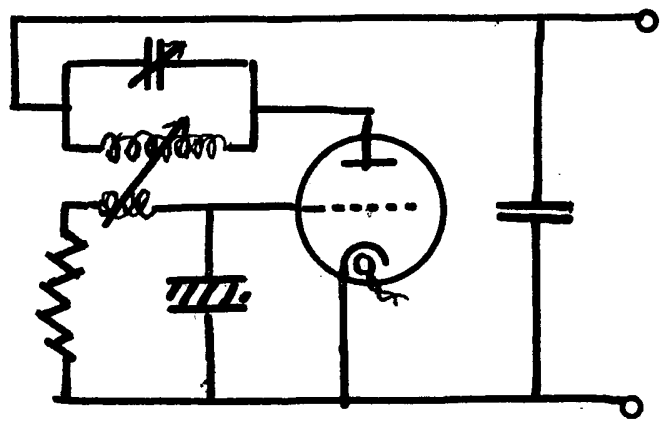

Fig.6. Modified Pierce Circuit. age applied the radiation from a.

Rochelle salt resonator crystal was stronger than from a quartz, all other conditions havj.ne been the same, cr.. Figg. 26 and 27 .

The small reaction was added at the suggestion of Mir. Heinz Bieberfeld, Radio Technician of Messrs, Ewing \& MCIntosh, Glasgow. He also assembled the apparatus and performed numerous measurements which corroborated vady's results, but are omitted here. 
Solid Lenses, suspended in a liquid.

From the simplified formula (1)

$$
R \leqslant\left\{\left(w_{1}-w_{2}\right) /\left(w_{1}+w_{2}\right)\right\}^{2},
$$

the transmittivity through one interface, that is the ratio of transmitted to incident ultrasonic energies, is found to be

$$
\mathrm{T}_{1} \geqslant 4 \mathrm{w}_{1} \mathrm{w}_{2} /\left(\mathrm{w}_{1}+\mathrm{w}_{2}\right)^{2}
$$

Introducing the reflective index, the percentage transmittivity is given by the formula

$$
\mathrm{T}_{1} \geqslant 100 \mathrm{~m}\left(\frac{1+m}{2}\right)^{-2} \text {. }
$$

Plastics.

In polystyrene of specific gravity $1^{\cdot 06}$ the velocity of ultrasonic waves is $2350 \mathrm{~m} . / \mathrm{sec}$; thus its acoustic resistivity is $24^{\circ} 9 \times 10^{4} \mathrm{~g} . \mathrm{om} .^{-2}$ sec. ${ }^{-1}$ (18). A lens of polystyrene, therefore, possesses a refractive index of 1.57 with reference to water and transmits $93.8 \%$ of the incident energy. Since, for ultrasonics, polystyrene is a rarer medium than water, it is necessary to use a concave lens for converging. Polymethyl methacrylate is also avajlable for ultrasonic work. Its specific gravity of $1 \cdot 18$ and ultrasonic velocity of $2070 \mathrm{~m} \cdot / \mathrm{sec}$. (73) give an acoustic resistivity of $24^{\cdot 4} \times 10^{4} \mathrm{~g} \cdot \mathrm{cm}^{-2} \mathrm{sec}^{-1}$. Consequently a lens of polymethyl methacrylate has a refractive index of $1 \cdot 38$ and a transmittivity of $89^{\circ} 9 \%$ with reference to water. With $x y-$ lene lenses of these two materials cannot be used since they are soluble in hydrocerbons; but amnng the large assortment of modern plastios available, a suitable lens material can generally be found for every liquid and for every required index of refraction. 
Another material useful for ultrasonic lenses, especially when the liquid is incompatible with plastics, is lithium. Where is nothing known about its ultrasonte properties. From Young's modulus for lithlum, $5 \times 10^{4} \mathrm{~kg} \cdot / \mathrm{cm}^{2}$, and its specific gravity, 0.534 , a value of $3000 \mathrm{~m} . / \mathrm{sec}$. for the velocity of longitudinal waves is obtained. Its acoustic resistivity is, therefore, about $16.0 \times 10^{4} \mathrm{~g} . \mathrm{cm} .^{-2} \mathrm{sec}^{-1}$. A lens of 1ithium in Iiquid paraffin should transmit $95.9 \%$, having a refractive index of $2 \cdot 26$. Experiments on lithium lenses gave results which confirmed the above calculation.

According to David (20) the velocity of sound in beryllium has the extremely high value of $12600 \mathrm{~m} . / \mathrm{sec}$.Therefore, among all solids, beryllium has the highest refractive index with reference to liquids: from 6.55 with reference to glycerine and 8.42 to water up to $13 \cdot 58$ with reference to carbon tetrachloride which values exceed all that is known in optics. In what way this extraordinary property can be used will become evident in due course. As X-ray tube windows of beryllium have been produced for twenty years chemically pure bertillum is commercially available. The ingots are usually $12^{\circ} 5 \mathrm{~cm}$. Iong and $2^{\circ} 5 \mathrm{~cm}$. dia. and containing less than $0.042 \%$ impurities.

The above results can only be taken as approximations, since important factors, such as absorption, dispersion and others have been neglected. On these very little preliminary work has been done. That their influence is considerable can be seen from the fact that e.g., according to Cochrane and Samsel (18), the attenuation factor by absorption of polystyrene is $1^{\circ} 2 \mathrm{db} . / \mathrm{cm}$. 


\section{UItrasonio Contact Lenses.}

*

Losses due to refledion at the ultrasonic lenses arise in addition to the inevitable loss on passing ultrasonic energy from the generating orystal to the medium of propagation. This loss, however, can be considerably diminIshed by the use of plano-spherical or plano-cylindrical lenses in direct contact with the generating crystal. In what follows they are named "Ultrasonic Contact Lenses" in analogy with the corresponding devices for the human eye.

Since aluminium and glass have almost the same acoustic resistivity as quartz, the reflectivity of a contact lens of these materials with reference to the generating crystal is negligibly small, while the loss on passing ultrasonic energy from these lenses to the medium of propagation is practically equal to that on passing it from the crystal. Thus the use of a contact lens of those materials does not cause any additional 10ss. As, on the other hand, the sound velocities in aluminium or glass are higher than $5000 \mathrm{~m} / \mathrm{sec}$, their refractive indices with reference to liquids are extraordinarily high, from $2^{\circ} 6$ (glycerine) to $5^{\circ} 5$ (carbon tetrachloride) approximately; the value for water is about $3^{\bullet} 4$.

The best results with ultrasonic lenses (ordinary and contact lenses) are obtained by using "single-wave quartz crystals" ( $71^{\circ}$ cuts) (67) which oscillate almost like pistons emitting/plane waves/very nearly/. Anyhow the photographs Figg. show that also ordinary quartz platea give results at least as good as optical lenses compared with the wave lengths. 
Transmission Plates.

While the loss due to reflesfion between the generating quartz or salt crystal and a medium for propagation of a different acoustic resistivity cannot be avoided in general, it can be considerably reduced by inserting plates with plane parallel faces of materials matching the two resistivities. In what follows these plates are called "Transmission Plates".

In a similar way, in optical work, reflection is diminished by coating glass with a thin film of cryolite or another material of a suitable refractive index. $(8,21,25,74)$.

Mathematioal Part.

The mathematical part of the problem is by no means difficult if one is satisfied with an approximate solution and there is no need for a greater accuracy in this investigation ${ }^{+}$. When $a$ transmission plate of the acoustic resistivity $x$ is inserted between two materials of the resistivities $w_{1}$ and $w_{2}$ respectively, the transmittivity is given by the formula (3) generalized for three media, i.e. for two boundaries,

$$
T_{2}=\frac{16 w_{1} x^{2} w_{2}}{\left(w_{1}+x\right)^{2}\left(w_{2}+x\right)^{2}}
$$

$T_{2}$ becomes a maximum when the function

$$
y=\frac{x}{\left(w_{1}+x\right)\left(w_{2}+x\right)}
$$

becomes a maximum, that is for

+ For a more thorough mathematical treatment cf. Deans J. (2I), an extensive bibliography is given in blodgett (8). 


$$
x=\mathbb{V}\left(w_{1} w_{2}\right)
$$

as a simple calculation shows. The substitution of (6) into (4) gives

$$
T_{2}(\max .) \geqslant 16 w_{1} w_{2}\left(V_{w_{1}}+\sqrt{w_{2}}\right)^{-4}
$$

and, by introducing $m$ again, as a percentage,

$$
\mathrm{T}_{2}(\max \cdot) \geqslant 100 \mathrm{~m}\left(\frac{1+\sqrt{m}}{2}\right)^{-4} \text {. }
$$

'l'o show what improvement a trensmission plate brings about, the values of $T_{1}(\max$.$) and T_{2}$ (max.) corresponding to those of $\mathrm{m}$ between $I$ and $I 00$ are giten in 1 rable $I$ and are graphically represented in Hig. 7 .

\begin{tabular}{|c|c|c|c|c|c|c|c|c|c|c|}
\hline $\mathrm{m}$ & 1 & 2 & 3 & 4 & 5 & 6 & 7 & 8 & 9 & 10 \\
\hline$\% T_{1}$ & .00 & $88^{\circ} \cdot 9$ & $5 \cdot 0$ & 4.0 & $5 \cdot 6$ & $49^{\circ} 0$ & $43^{\circ} 8$ & $39^{\circ} 5$ & $36^{\circ} 0$ & $33^{\circ}$ \\
\hline$\% \mathrm{~T}_{2}$ & 100 & $94^{\circ} 2$ & $86^{\circ} 1$ & $79 \cdot 2$ & $82 \cdot 9$ & $677^{\circ} 8$ & $68 \cdot 8$ & $59 \cdot 6$ & $56 \cdot 3$ & $53 \%$ \\
\hline$\% \mathrm{~T}_{3}$ & 100 & $96^{\circ} 1$ & $90^{\circ} 5$ & $85^{\circ} 3$ & $80^{\circ} 8$ & $76^{\circ} 8$ & $73^{\circ} 3$ & $70 \cdot 2$ & $67^{\circ} 5$ & $65^{\circ}$ \\
\hline
\end{tabular}

Table 1. Percentage maximum transmittivity for reflective index $m$ between $I$ and 100

\begin{tabular}{|c|c|c|c|c|c|c|c|c|c|c|}
\hline $\mathrm{m}$ & 10 & 20 & 30 & 40 & 50 & 60 & 70 & 80 & 90 & 100 \\
\hline$\% \mathrm{~T}_{1}$ & $33^{\circ} 1$ & $18^{\circ} 1$ & $12^{\circ} 5$ & $9^{\circ} 5$ & $7^{\circ} 7$ & $6^{\circ} 5$ & $5^{\circ} 6$ & $4^{\circ} 9$ & $4^{\circ} 3$ & $3^{\circ} 2$ \\
\hline$\% \mathrm{~T}_{2}$ & $53^{\circ} 3$ & $35^{\circ} 7$ & $27^{\circ} 3$ & $22^{\circ} 2$ & $18^{\circ} 9$ & $16^{\circ} 6$ & $14^{\circ} 6$ & $13^{\circ} 1$ & $11^{\circ} 9$ & $10^{\circ} 9$ \\
\hline$\% \mathrm{~T}_{3}$ & $65^{\circ} 0$ & $48^{\circ} 7$ & $40 \cdot 8$ & $34^{\circ} 3$ & $30^{\circ} 3$ & $27^{\circ} 2$ & $24^{\circ} 8$ & $22^{\circ} 9$ & $21^{\circ} 2$ & $19^{\circ} 9$ \\
\hline
\end{tabular}

The material best matching water to quartz $(m \neq 10)$ has to have an acoustic resistivity of $x=\sqrt{(15} \times 150)$, about 47.4. A lithium-magnesium alloy fulfills this condition near enough. substitution of $m=10$ in equation $\left(3^{+}\right)$and $\left(7^{+}\right)$ shows that such a transmission plate gives an increase of 


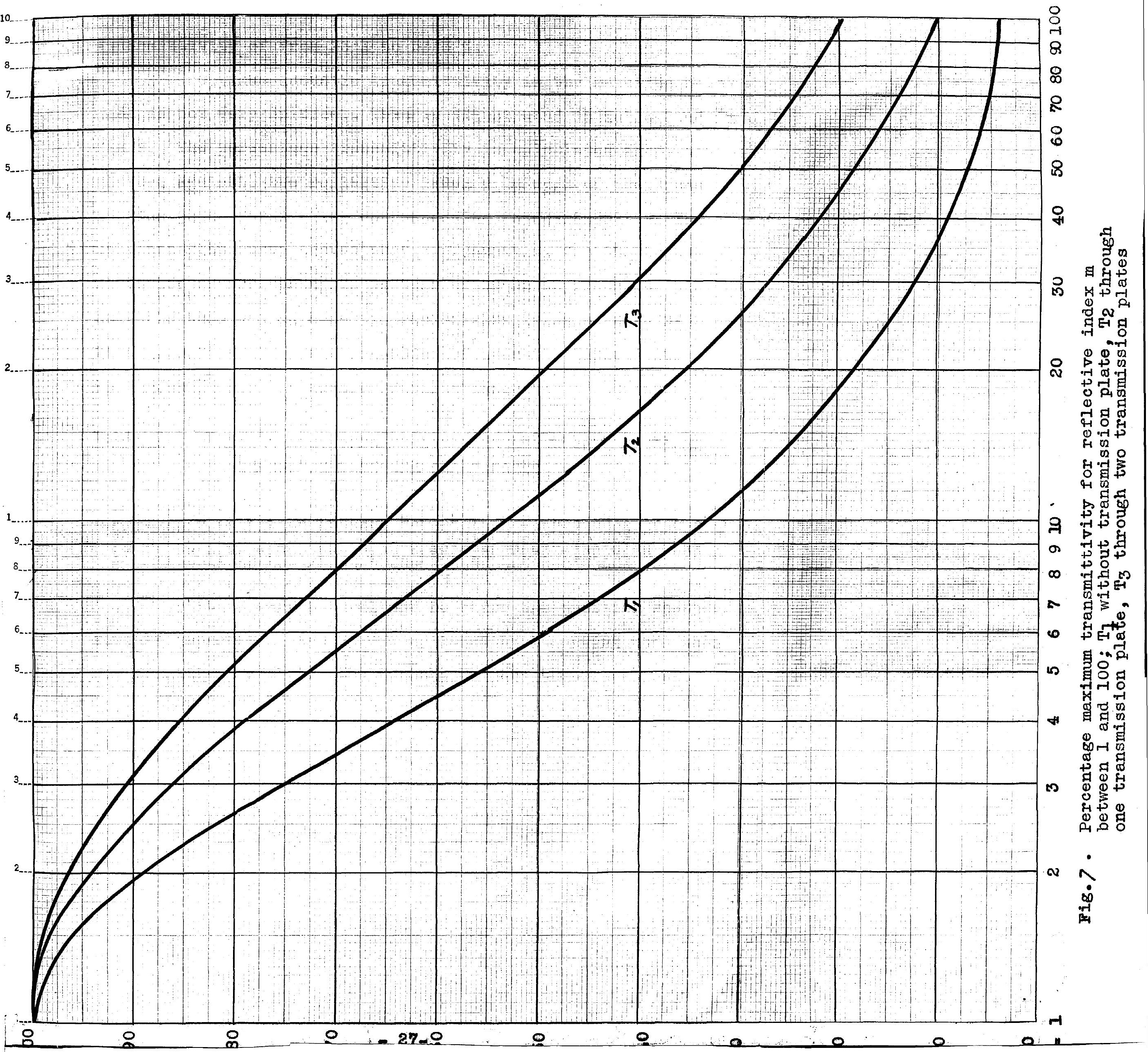


transmittivity of from $33 \cdot 1$ to $53 \cdot 3 \%$.

Optimum acoustic transmittivity in the matching material is not very critical. This is illustrated in Table 2 and in Fig.8. The percentage transmittivity is calculated from, and plotted against, the reflective index $m_{l}=w_{1} / x$ of the transmission plate for $m=10$, corresponding to quartz-water. The obtained flat curve proves that, for example, for the transmittivity of more than $50 \%$ instead of $53.3 \%$ any material will be suitable that has an acoustic resistivity lying between $31^{\circ} 3$ and $71^{\circ} 4 \mathrm{~g} . \mathrm{cm} \cdot{ }^{-2} \mathrm{sec}^{-1}$. Lure magnesium of acoustic resistivity $83 \cdot 5 \mathrm{~g} . \mathrm{cm} .^{-2} \mathrm{sec}^{-1}$ transmits still $47 \cdot 5 \%$.

Table 2. Percentage transmittivity for reflective index 10 through one transmission plate

\begin{tabular}{|c|c|c|c|c|c|c|c|c|c|c|c|}
\hline $\mathrm{m}_{1}$ & 1 & 2 & 3 & $3 \cdot 16$ & 4 & 5 & 6 & 7 & 8 & 9 & 10 \\
\hline$\% \mathrm{~T}_{2}$ & $33^{\cdot 1} 1$ & $49 \cdot 4$ & $53 \cdot 2$ & $53 \cdot 3$ & $52 \cdot 2$ & $49 \cdot 4$ & $45 \cdot 9$ & $42 \cdot 4$ & $39 \cdot 0$ & $35 \cdot 9$ & $33 \cdot 1$ \\
\hline
\end{tabular}

It is very natural now to raise the question whether further improvement can be accomplished by inserting more than one transmission plate. 'lhe formula for the transmittivity through two interposed plates (three interfaces) of acoustic resistivities $x$ and $y$ respectively is

$$
T_{3} \geqslant \frac{64 w_{1} x^{2} y^{2} w_{2}}{\left(w_{1}+x\right)^{2}(x+y)^{2}\left(y+w_{2}\right)^{2}}
$$

$\mathbf{T}_{2}$ becomes a maximum when the function

$$
z=\frac{x y}{\left(w_{1}+x\right)(x+y)\left(y+w_{2}\right)}
$$

becomes a maximum, that is, as could be expected, when 


$$
x=\left(w_{1} w_{2}\right)^{1 / 3} \text { and } y=\left(w_{1} w_{2}\right)^{1 / 3} \text {. }
$$

$w_{1}, x, y, w_{2}$ form a geometrical series with its quotient

$$
q=\left(w_{2} / w_{1}\right)^{1 / 3}=m^{1 / 3} \text {. }
$$

By substitution of (10) in (8) and introduction of (11)

it follows that the percentage maximum transmittivity

$$
\mathrm{T}_{3}(\max .) \geqslant 100 \mathrm{~m}\left(\frac{1+\mathrm{m}^{1 / 3}}{2}\right)^{-6}
$$

For an easy comparison of the corresponding values of $T_{I}$ (max.), $T_{2}(\max$.$) , and T_{3}(\max$.$) the values calculated from equation (12)$ are also tabulated in Table 1 and plotted in Fig. (p.27).

By further generalization the maximum transmittivity $+1$

in the case of $n$ interfaces is obtained by the formula

$$
\mathrm{T}_{\mathrm{n}}(\max .) \geqslant 100 \mathrm{~m}\left(\frac{1+\mathrm{m}^{1 / n}}{2}\right)^{-2 \mathrm{n}} \text {. }
$$

To illustrate also these conditions the values of $\mathrm{T}_{\mathrm{n}}$ (max.), corresponding to $1<n<100$ are tabulated in l'able 3 , and Fig.9. is a graph of them for $m=10$.

Table 3. Percentage maximum transmittivity for reflective index 10 through $n-1$ transmission plates

\begin{tabular}{|c|c|c|c|c|c|c|c|}
\hline $\mathrm{n}$ & 1 & 2 & 3 & 4 & 5 & 6 & 7 \\
\hline $\operatorname{Tn}(\max )$. & $33^{\circ} 1$ & $53^{\circ} 3$ & $65^{\circ} 0$ & $72^{\circ} 1$ & $76^{\circ} \cdot 9$ & $80^{\circ} 3$ & $82^{\circ} \cdot 8$ \\
\hline
\end{tabular}

\begin{tabular}{|c|c|c|c|c|c|c|c|}
\hline$n$ & 8 & 9 & 10 & 20 & 40 & 70 & 100 \\
\hline$T_{n}(\max \cdot)$ & $84 \cdot 7$ & $86 \cdot 3$ & $87 \cdot 5$ & $93 \cdot 6$ & $97 \cdot 0$ & $98 \cdot 2$ & $98 \cdot 6$ \\
\hline
\end{tabular}

The same improvement of transmittivity is also obtain+ i.e. n-1 transmission plates 


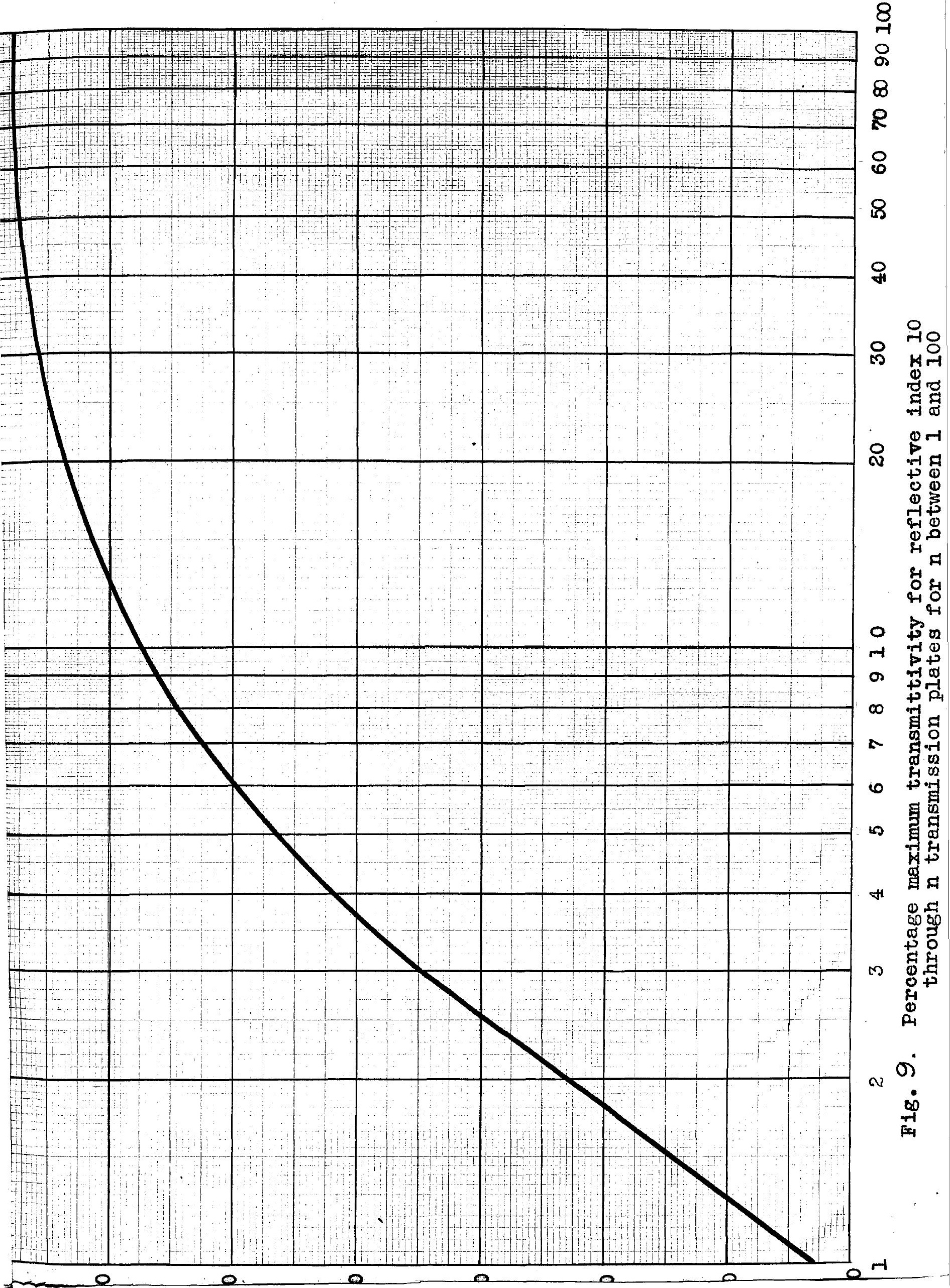


$a b l e$ in the case of contact lenses when using lenses of matching materials, but, of course, mostly at the cost of the refractive index.

"Matching down" from a higher acousticresistivity to a lower resistivity is not always desired; sometimes "matching up" is necessary. That will be the case, for example, in testing of materials according to sokoloff $s$ (62) method. If, say, iron has to be tested, the transmittivity improves with the use of a mercury film as a sound carrier instead of an oil film from 3 to $87 \%(3)$. This value is very near to the theoretical optimum attainable of $89 \cdot 7 \%$, using one transmission plate. Beryllium gives even a better result since its acoustic resistivity is almost exactiy equal to that required for maximum transmittivity. The employment of two transmission plates, one of tin $\left(\mathrm{w}=190 \mathrm{~g} \cdot / \mathrm{cm}^{2} \mathrm{sec}_{.}\right)$, the other of zinc $\left(\mathrm{w}=264 \mathrm{~g} \cdot / \mathrm{cm} .^{2} \mathrm{sec}.\right)$, enables a transmittivity to be reached of $90 \cdot 3 \%$ which is only $2: 2 \%$ short of the optimum obtainable $92 \cdot 5 \%$. According to formula (1), for special thicknesses of transmission plates the transmittivity still more improves.

As one face of a transmission plate is adjoining to a denser medium, the other face to a rarer medium maximum transmission occurs when its thickness is an odd number of quarterwave-lengths (thickness resonance). There are also thicknesses different from these showing maximum transmittivity. An explanation of this fact is given by Cremer" (19) "coincidence of bending waves" and, if the thickness of the partition becomes comparable with the rangtliength, by Götz's "general coincidence theory" (29): 
Methods of investigating vitrasonic fields.

Among the numerous mechanical, thermal, electrical and optical methods of investigating ultrasonic fields the optical proved to be the best for recording the effects of the devices developed in the foregoing chapters. On the following pages a brief summary is given of the experiments in question. Mechanical methods.

In search of demonstration material for experiments on polarized light, in a box containing discarded lenses, I have found 8 spectacle lenses of quartz. ") While 2 of these "pebbells;" cut almost perpendicularly to the optical axis, did not work either as oscillators or as resonators the other 6 were excellent specimens for ultrasonic experiments despite they were probably cut at random. They worked equally well as oscillators and resonators in thickness and length vibrations, had very many harmonics, but not well-marked natural frequencies.

On these pebbfos, excited in air in a Pierce circuit, Kundt's $(39,40)$ dust figures were produced by means of lycopodium powder. Five showed more or less complicated patterns similar to Chladni's acoustic figures on elliptic plates (75), the 6 th, cut at $90^{\circ}$ approximately, a node line just as the rod in Straubel's well-known experiment (67).

Kundt's method was also applied to cylindrical iods of metal or plastic oscillating lengthw1se. Plastics gave not very satisfactory results. The conventional arrangement was modified in order to surmount the difficulties of leading the rods

+) I am obliged to Dr.F.R.Storrie, Lecturer in Chemistry, for the loan of an excellent polarizing microscope (Leitz). 
through a hode in the wall of the ultrasonic oscillator cell. The rods employed were rectangularly bent, held by a thread and dipped at one end into the ultrasonic field. The ultrasonics were lead by the rod even round the bend, its radius having been large compared with the wave-length, and gave rise to ridges of lycopodium at distances of half a wavelength.on the horizontal part of the rod.

Boyle and Lehmann's method (II) using coke powder in a liquid was not tried at all in this work. This method is applicable only to fairly strong standing waves of moderate frequency and propagated horizontally. After each experiment the vessel has to be emptied and cleaned. The results are very coarse.

Oyama (51) has found that, in a Iiquid in which ultrasonic waves were propagated, vertically upward, the mound caused by the ultrasonics was directly connected with their intensity. A comparison of the photographs rigg. 10 and 11 demonstrates clearly the increase of intensity when an ultrasonic lens is used. A strong diffuse counter-Iight helped to show the mound standing out in bold relief against the surface of the liquid. (1000 c.p. Pointolite lamp through a ground glass plate of $40 \times 40$ om.att a distance of $60 \mathrm{~cm}$. from the lamp. The distance from the cell was $20 \mathrm{~cm}$. Further photographic data are given in the legend to the Figg. The lens was a polymethyl methacrylate lens and focused towards the surface of the liquid (Iiquid paraffin). In Fig. 10 the lens replaced by a square plate of the same material and thickness. The electric data for both photographs 


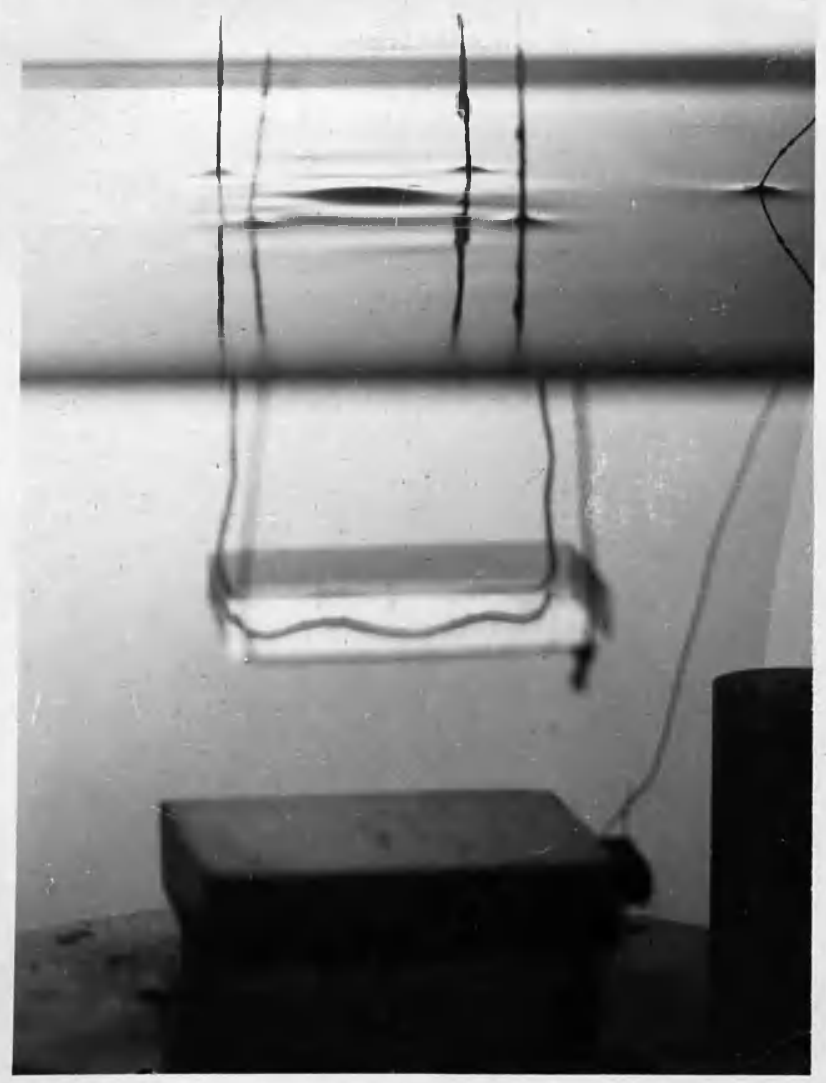

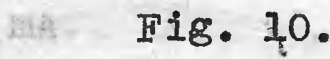

Photograph of a mound (camera inclined 300) HP3 Ilford Plates exposure $1 / 4$ sec. distance $30 \mathrm{~cm}$. Dogmar $18 \mathrm{~cm}$. $1: 4^{\circ} 5$ magnification $\times I^{\bullet} 4$ mound

surface of the liquid square plate of polymethyl methacrylate

־ transmission plate of aluminium

— quartz crystal

$\leftarrow$ lead bed

Fig. 11.

Photograph of a mound

mound

mirror image of mound

surface of the Iiquid $\vec{l}$ lens of poly methyl methacrylate

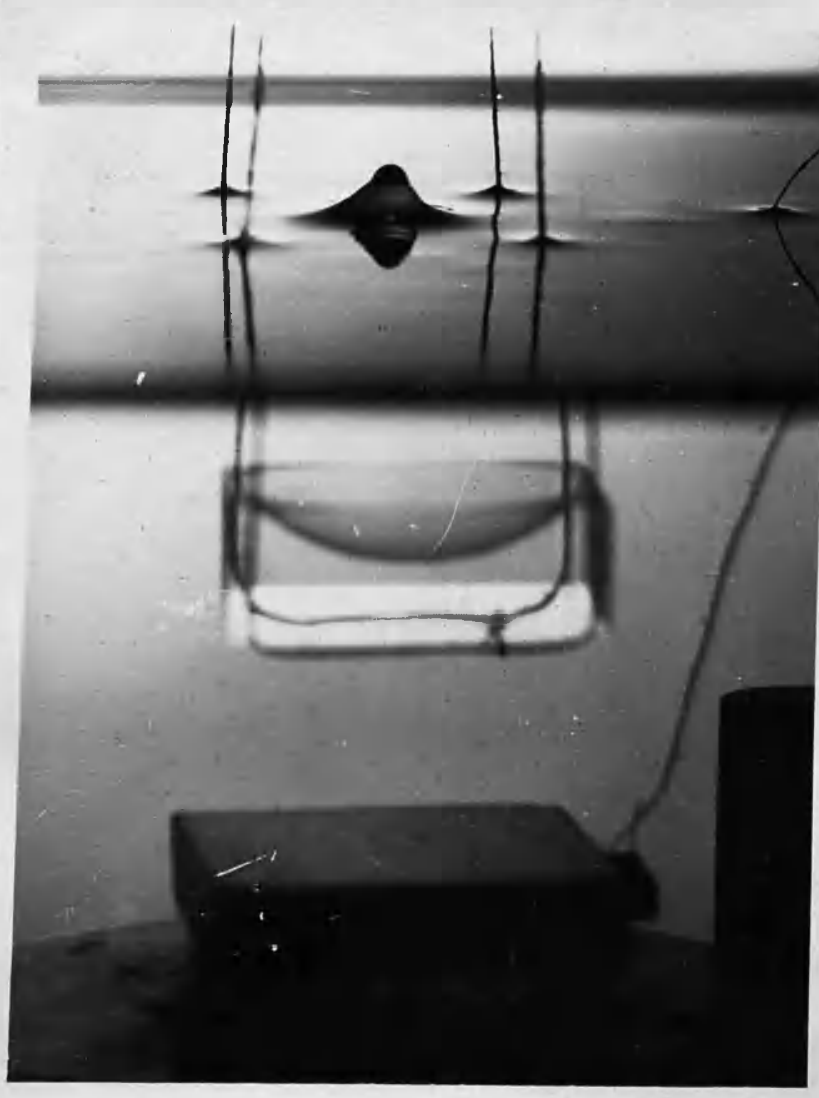

transmission plate $\rightarrow$ of aluminium quartz crystal 
are: D.C. $\nabla_{a}=350 \mathrm{~V},, i_{a}=250 \mathrm{~mA} ., i_{g}=26 \mathrm{~mA} .$,

A.C. $($ prim. $)=420 \mathrm{~V} ., 1_{\text {crystal }}=540 \mathrm{~mA}$.

Thermal methods.

The remarkable concentration of energy towards the focus of an ultrasonic lens was showed clearly by means of Gruetzmacher's (31) thermoscope ${ }^{+1}$.

The same effect was also proved by a thermopile $e^{++}$. A small block of polystyrene was provided with 24 holes arranged in two concentric circles of 12 and $18 \mathrm{~mm}$. diameter respectively. 12 copper-eureka thermocouples were passed through the holes and bent together as closely as possible without touching each other. The odd soldered joints formed the apex of the cone of wires. The effect was measured by the valve voltmeter of a wavemeter type 111\%. Identical conditions, for a series of experiments, were too difficult to secure for obtaining consistent results. The most striking proof of the phenomenon was furnished in the following very simple way: An ordinary mercury thermometer for chemical purposes, divided into tenths of a centigrade, was dipped into liquid paraffin propagating ultrasonics vertically upwards. The thermometer showed an increase in temperature of $1.3^{\circ} \mathrm{Cin} 60 \mathrm{sec}$. and did not change the reading during the following minutes, /1naldated/ ture of $18^{\circ} \mathrm{C}$. within $60 \mathrm{sec}$. When a lithium lens was inserted and its focus coincident with the bulb of the thermometer.

$+)$ I am much obliged to war. Lloyd in the Physics Dept. of Glasgow University for blowing this instrument. ++ ) Mr. H. Bieberfeld (see p. 2l) soldered the thermopile wert accurately and I am greatly indebted to him for his assistance. 
As an electrical receiver a crystal microphone was used. This microphone consisted of a tiny Rochelle salt crystal, an L-cut ground to the seme frequency as the transmitting quartz crystal. The receiver crystal was enclosed in an airfilled and water-tight magnesium box and rested on its bottom that constituted a transmission plate and, at the same time, one of the electrodes of the crystal. The other electrode was pressed against the opposite face of the crystal by a week spiral spring. A screened cable connected the crystal with the valve voltmeter of a wave meter (1II7) or alternately with the amplifier of a Cossor cathode ray oscillograph.

Here is a representative test result:

Transmitter: quartz crystal, $f=608 \mathrm{kc} / \mathrm{sec}$.

Receiver: I-cut Rochelle salt crystal, $f=608 \mathrm{kc} / \mathrm{sec}$., (as near as possible).

D.C. $\mathrm{V}_{\mathrm{a}}=150 \mathrm{~V} ., i_{\mathrm{a}}=180 \mathrm{~mA} ., i_{g}=10 \mathrm{~mA}$, , A.C. (primary) $V=200 \mathrm{~V}$., $i_{\text {crystal }}=280 \mathrm{~mA}$. Without lens: deflexion (using full gain) $80 \mu \mathrm{A}$. With lens: deflexion (a little less than full gain) $600 \mu \mathrm{A}$. Here, too, sufficient consistency of the results obtained under different conditions was not attainable.

Optical methods.

Three optical methods were applied representing the three chief principles used for the optical recording of ultrasonics: striation, secondary interferences, diffraction of light. 
The photographs are added to furnish illustrations of the functions of the ultrasonic lenses and transmission ilates.

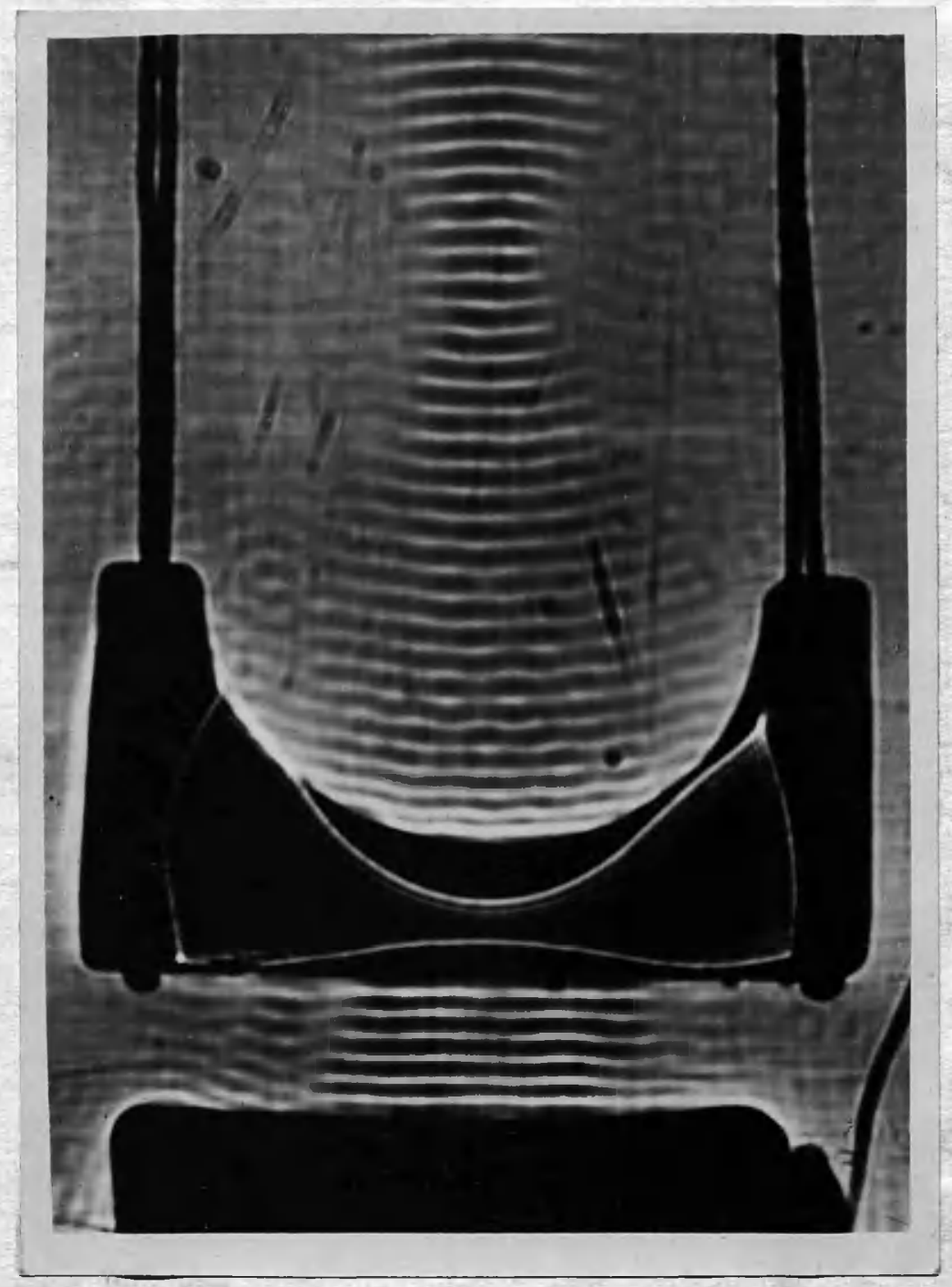

Fig.12. rlano-cylindrical polymethyl methacrylate lens suspended in liquid paraffin
Fig. 12 was made

by a simple sha-

dow projection

in the manner

described by

Bergmann and

Goehlich $(5,6)$,

using divergent

light without

any optical ap-

paratus.It shows

a plano-cylindrical

polymethyl meth-

acrylate lens of

$14 \mathrm{~mm}$. radius of

curvature suspended

in liquid paraffin

with its axis par-

allel to the cen-

tral beam of light. The projections of the striae, caused by the standing ultrasonic waves, are clearly visible. Between the upper electrode of the generating crystal and the plane bottom of the lens they are parallel lines, above the lens circular concentric ares converging to the projection of the line focus. (The wing-shaped bright figure on the photograph of the lens is obviously caused by the reflexion of light inside the transparent lens.l 
The experimental arrangement is given diagammatically

in the figure below.

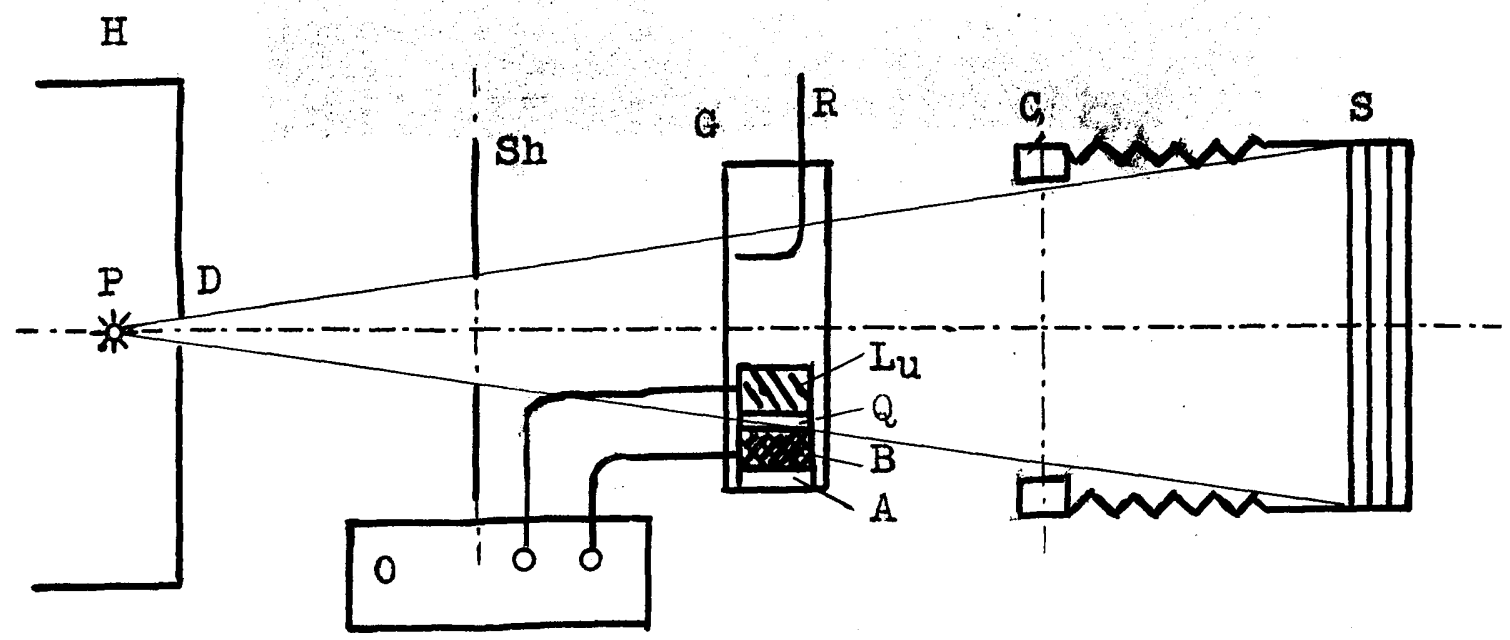

Iig.13. Experimental arrangement for rendering ultrasonic waves visible. (Bergmann and Goohlich's method).

$P$ is a $150 \mathrm{~W}$ lamp in a metal housing $H$ with a circular aiaphragm of about $1 / 2$ diameter on the front side. Sh is a shutter, $a$ antically worked glass cell $16 \times 16 \times$ $16 \mathrm{~cm} .$, filled with liquid paraffin, $\mathrm{C}$ a photographic camera $13 \times 18 \mathrm{~cm}$. Without lens, and $\mathrm{s}$ its screen or plate box.0 is the oscillator, A the air cushion, B the lead bed, $Q$ the quartz crystal, $I_{u}$ the ultrasonic lens and $R$ the reflector. Photo Fig.is was taken using the arrangement as described here. To improve the sharpness different sources of light were tried. Whe best results were obtained by means of a $1000 \mathrm{c} . \mathrm{p}$. Pointolite lamp and a double condenser of a small film projector (f $=25^{\circ} 4 \mathrm{~mm} ., 1 \div 1.9$ ) with a diaphragm $D$ of $0.5 \mathrm{~mm}$. circular aperture. Figg.14/5 photographs this effective yet simple arrangement. $\ldots$ 


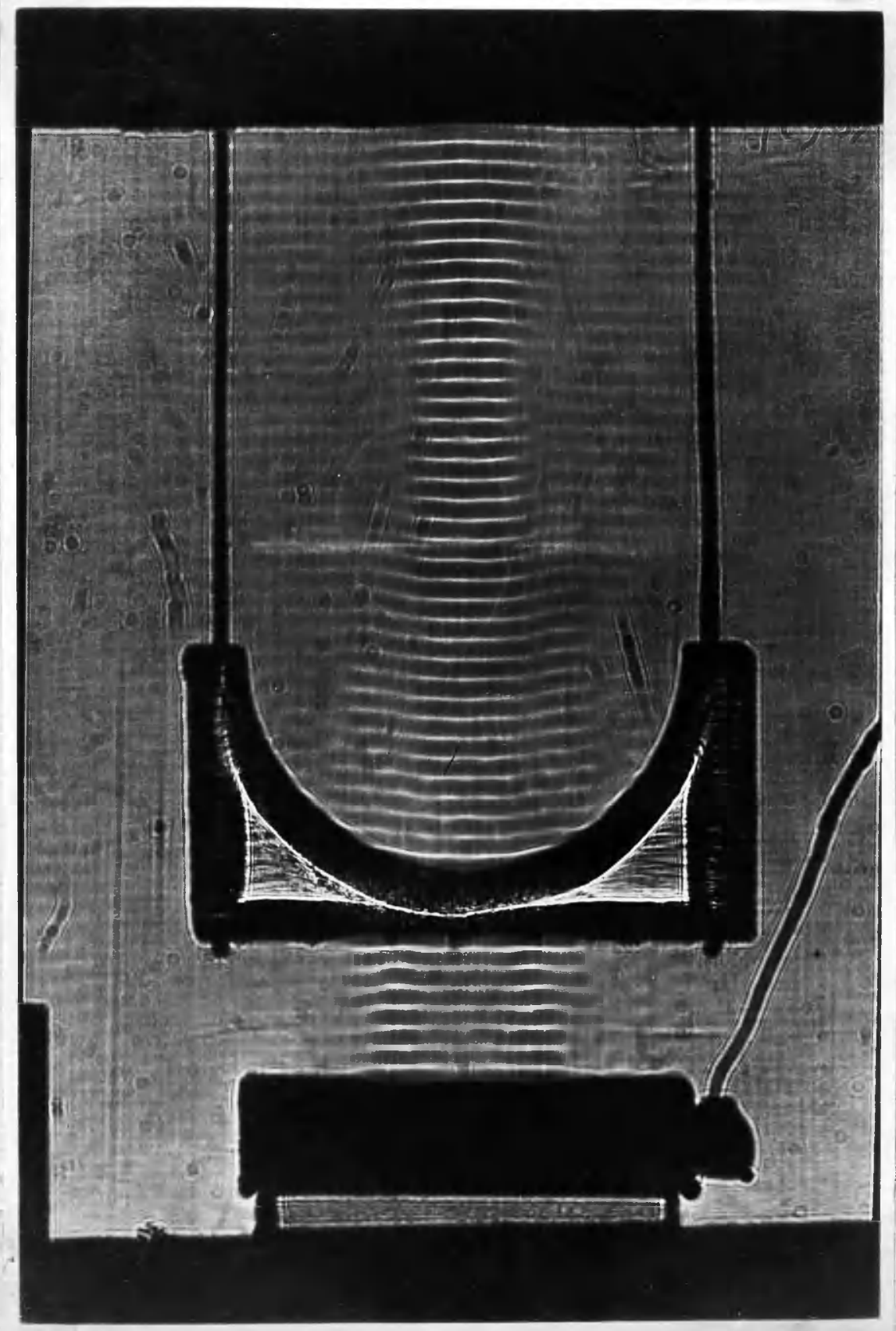

Fig. 14. Quartz crystal, aluminium transmission plate, plano-cylindrical lens of polystyrene suspended in Iiquid paraffin. Exposure immediately after switching on. 


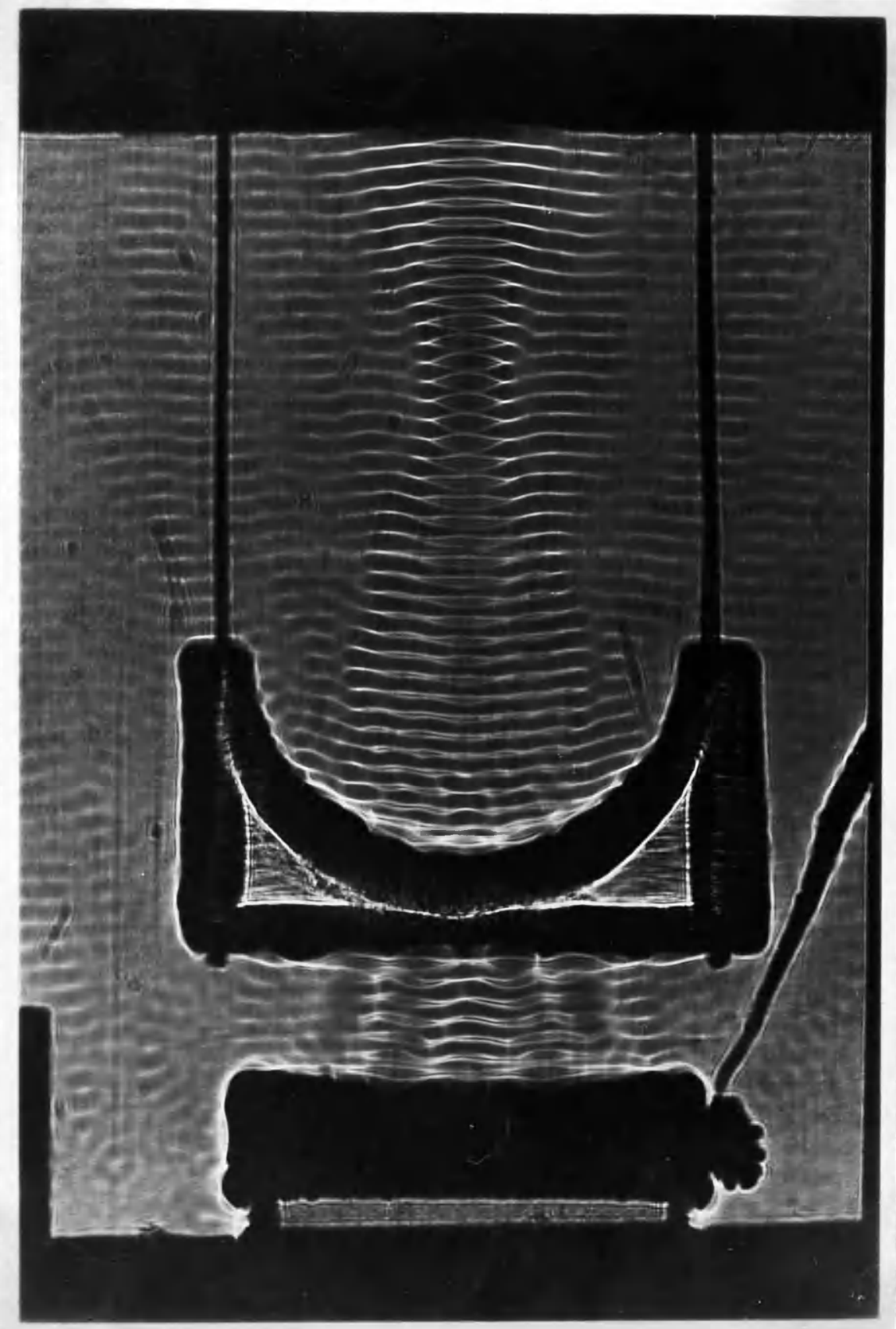

Fig. 15. Conditions the same as in Fig. 14. Exposure two minutes after switching on. The heat effect is clearly visible. 


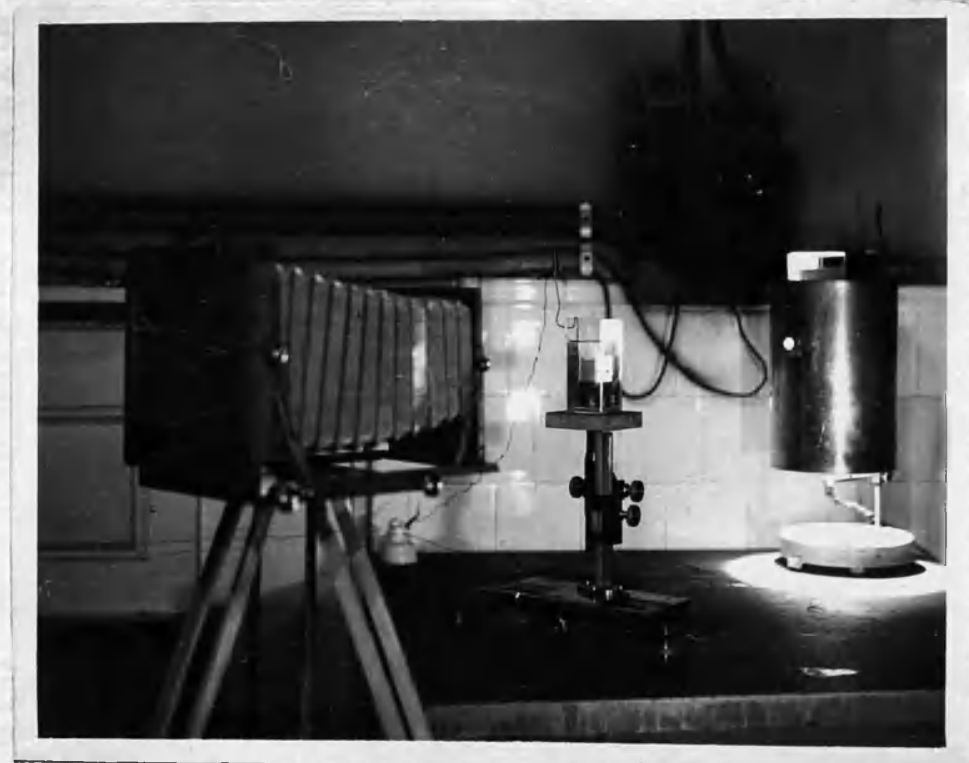
Fig 16.
Pointolite lamp in housing loon- denser and dia- phragm removed /, glass cell on stand, damera.

Doubtless the best light source for the purpose of this narrow beam projection and lensless photography is the "Concentrated-Arc Lamp". This new type of light source was developed by the Flectronics Research Laboratories of The Western Union Telegraph Company, Water Mill, Long Island,N.Y. It is described as an arc lamp provided with permanent electrodes which are sealed into a glass bulb filled with an inert ges. 'The source of the light is a small incandescent spot which forms on a specially prepared refractory oxide cathode. when the arc is established, the oxide surface is raised to its melting temperature and a brillant white light is emitted by the molten surface and a cloud of vaporized material which extends for a few thousandths of an inch from the cathode. This vapour returns to the cathode, thus renewing the surface and resulting in lamps which have a life of several hundred hours. A more detalled deseription is found in Buckingham and Deibert's recent paper. (13). 
Although the photographs obtained in Bergmann and Goohlich's mannervpoved quite satisfactory, it seemed advis-

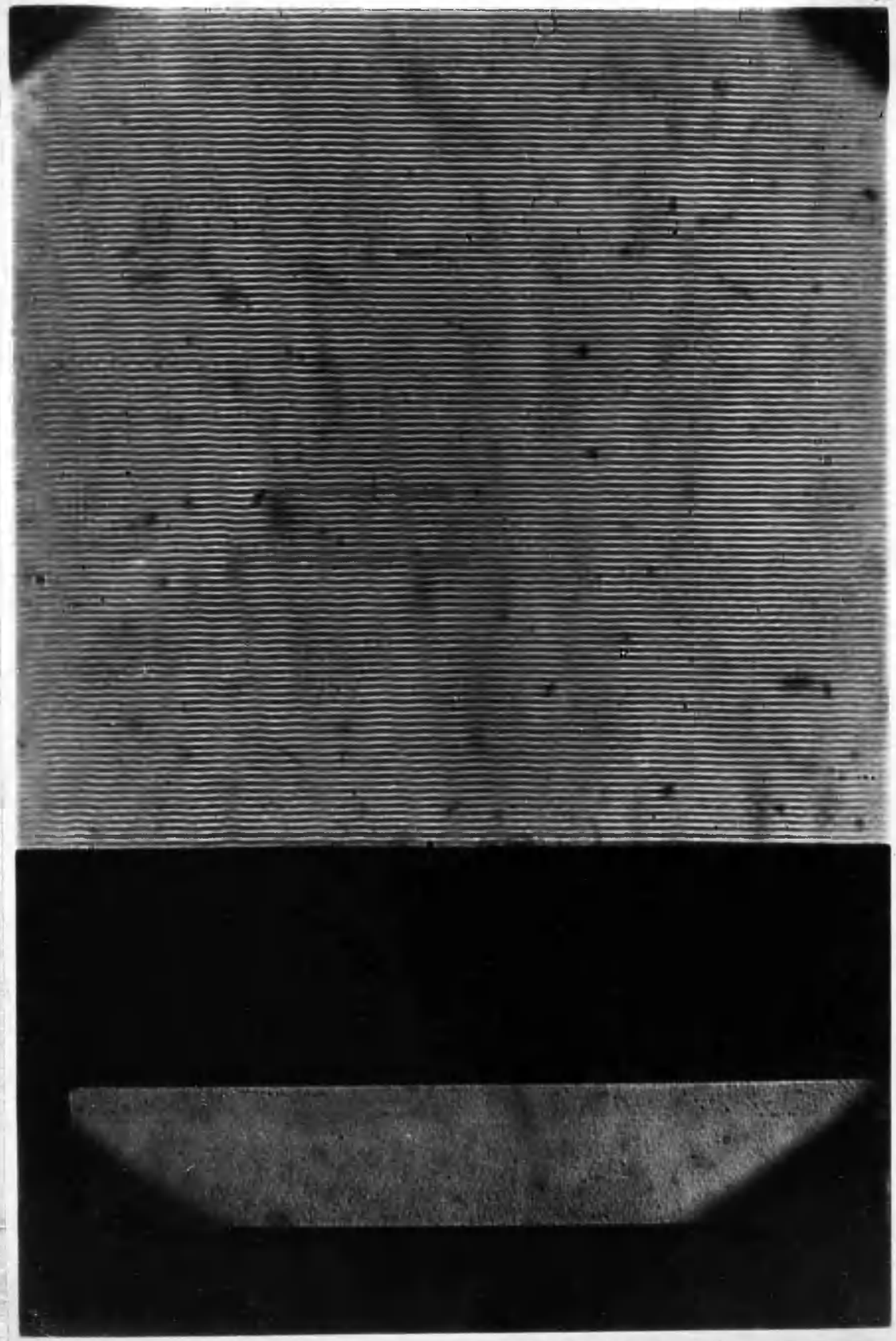

Pig.17 Aluminium transmission plate in xylol. Taken in Nomoto's manner.

able to use a more elaborate method which enables eertain conclusions to be drawn from the photographs. Fig. 17 shows standing waves between an aluminium transmission plate $6^{\circ} 1 \mathrm{~mm}$.thick and the surface of the Ilquid, which was in this case Iylol. The magnification was about $x 4 \cdot 9$, the time of exposure $1 / 50$ sec. 


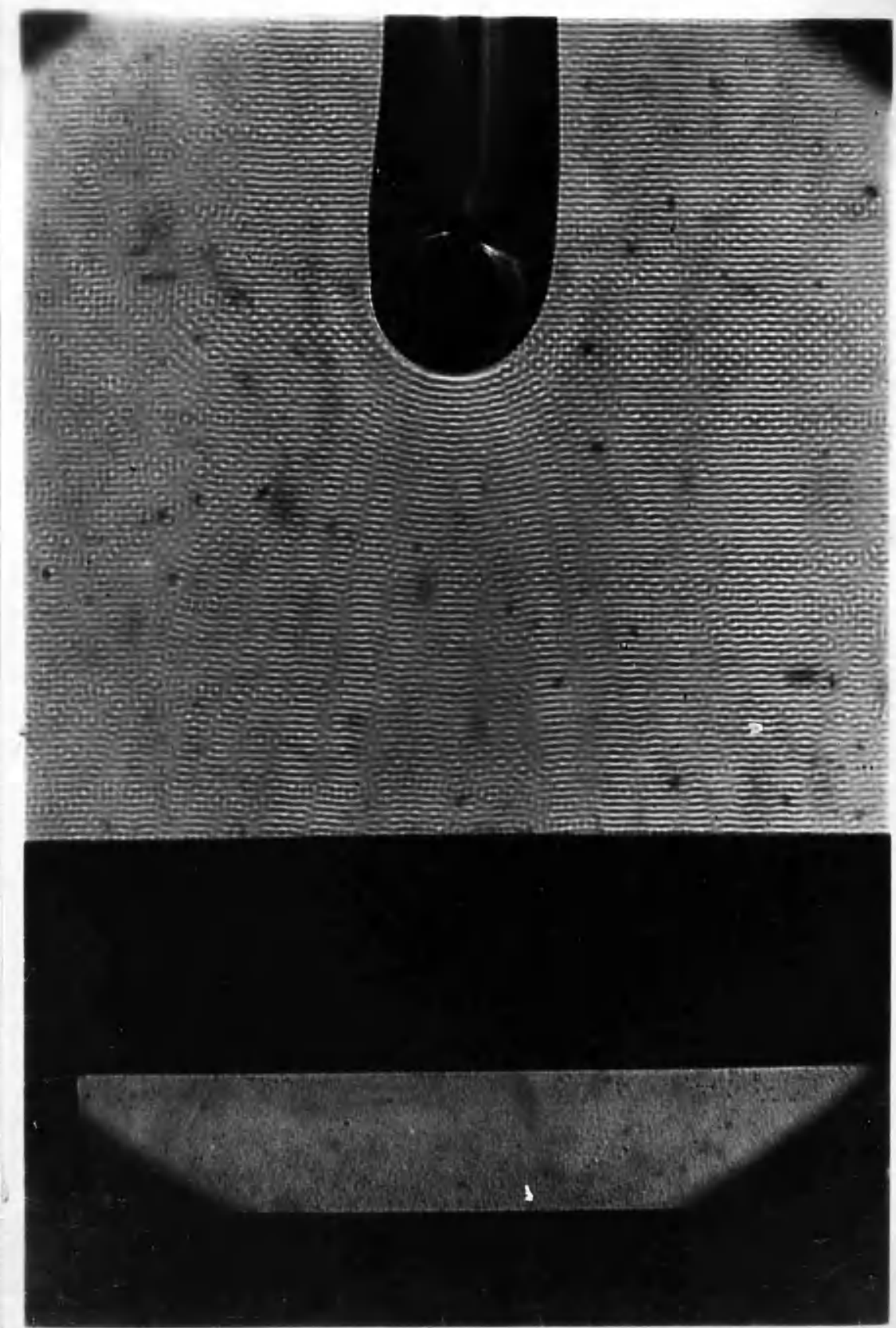

Fig. 18. The same conditions as in 1 ig.1\%, only an L-shaped glass rod is added as a reflector having its horizontal branoh parallel to the rays of light. The interference pattern is easily recognised. 

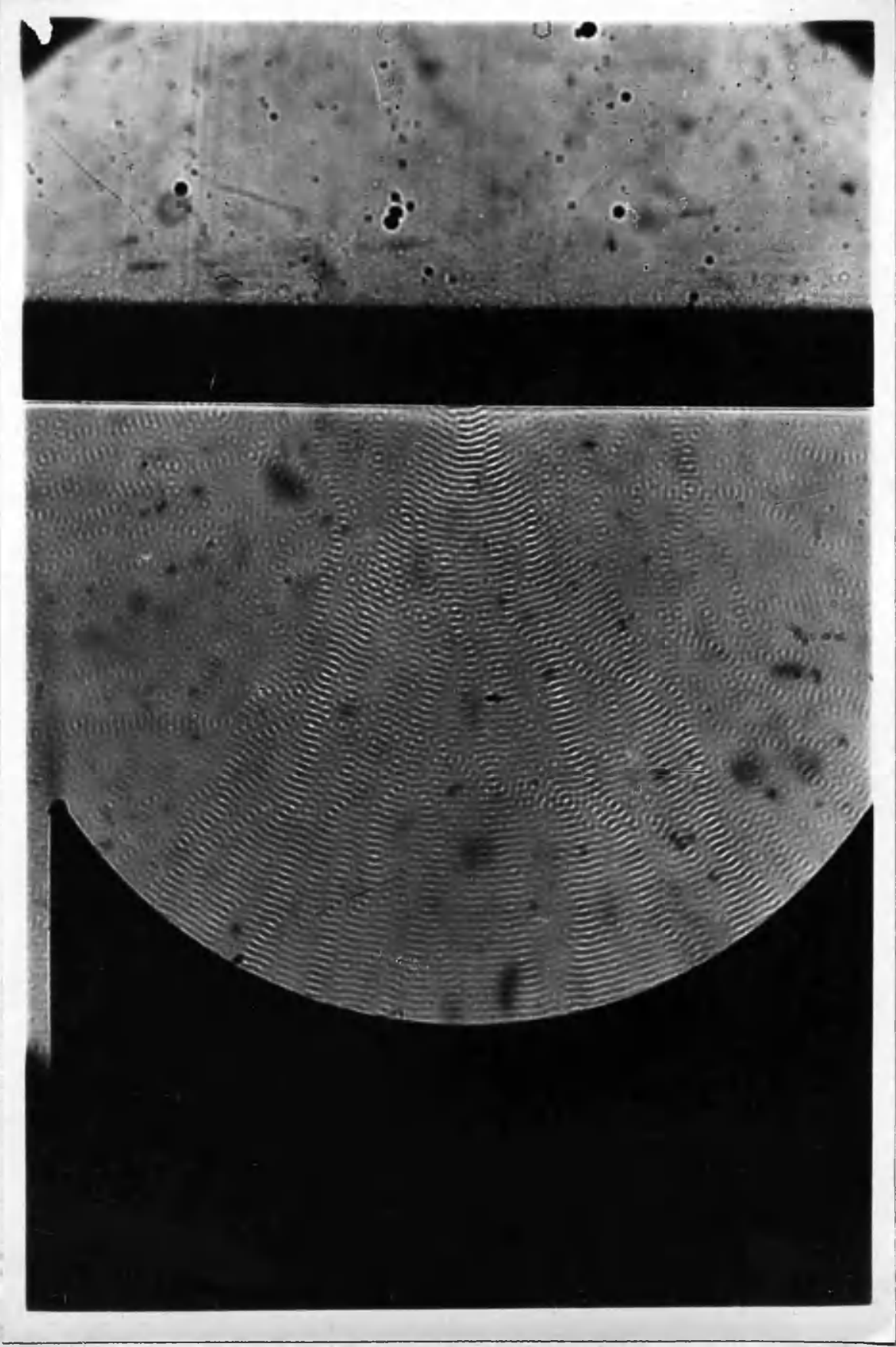

Fig. 19. The same arrangement as in $\mathrm{H}^{\prime} \mathrm{ig} .1 \%$, only the transmission plate is exchanged for a planocylinarical contact lens of aluminium the line focus of which is coinoldent with the surface of the liquid. 


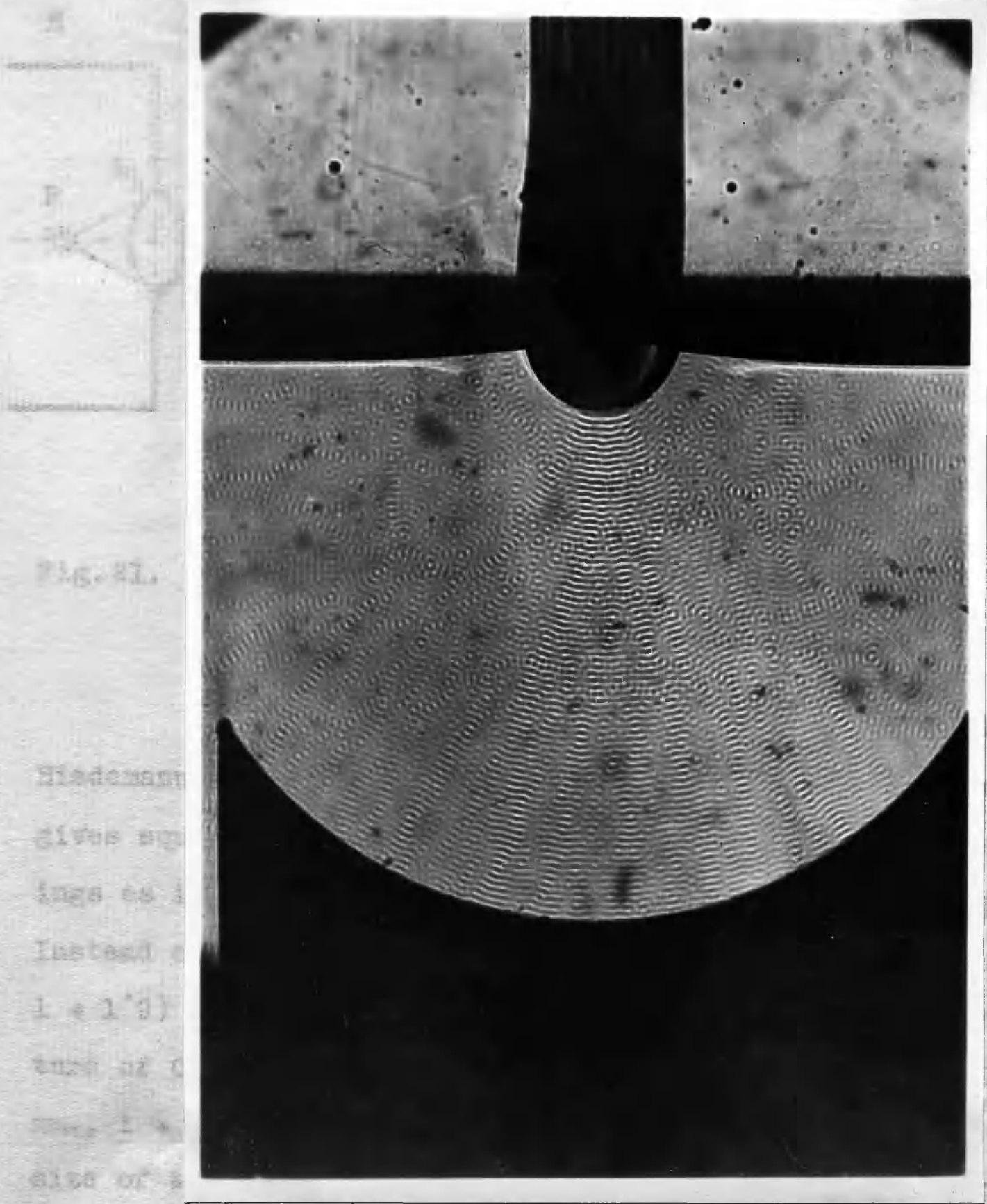

Fig. 20 is corresponding to Fig.18. The linefocus of the lens is coincident with the axis of the horizontal branch of the reflector rod.

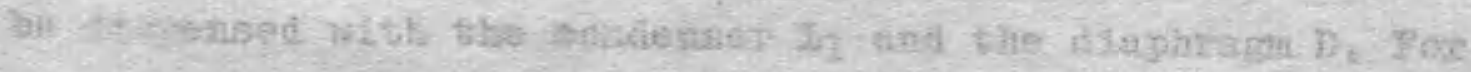


Pig. 2I Is a digram of the arrangement devised and then improved by Otohiko Nomoto $(49),(50)$.

$\mathrm{H}$

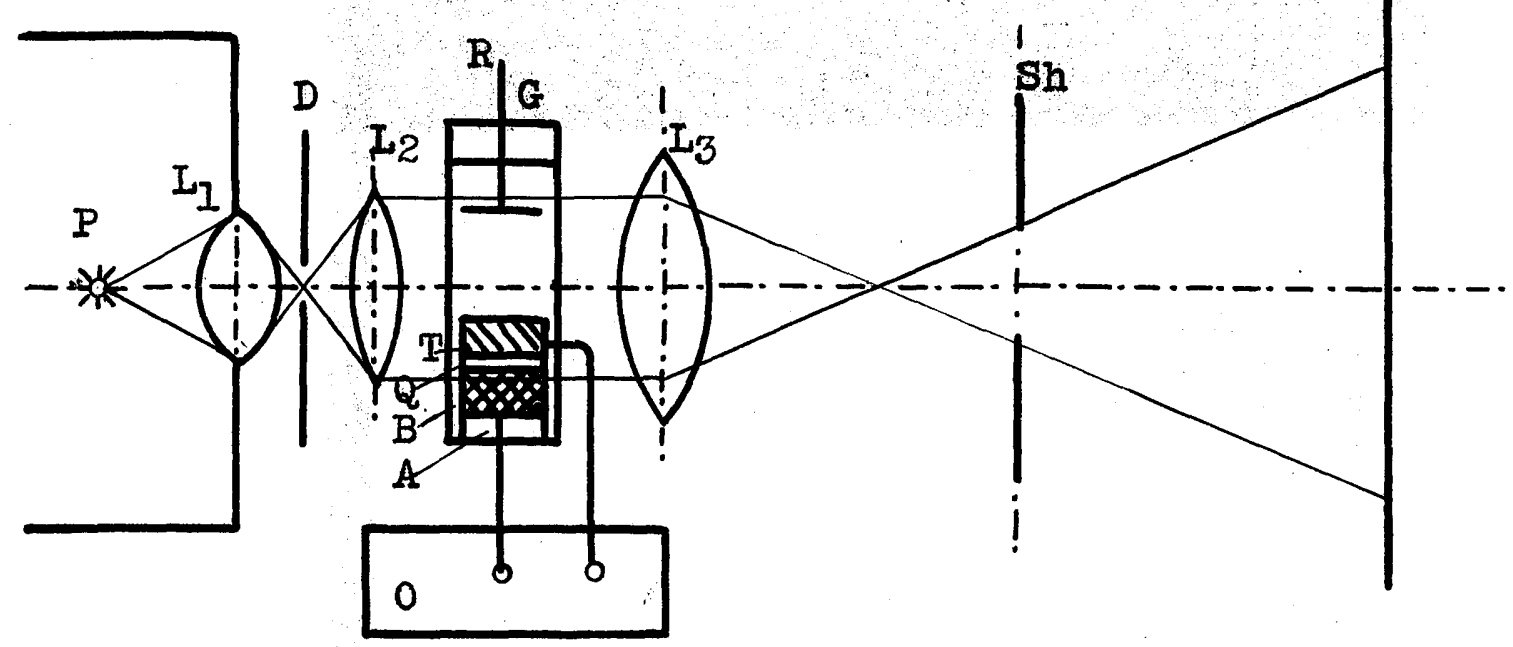

Fig.21. Experimental arrangement for rendering ultrasonic waves visible (Nomoto's improved method).

Nomoto's improved method differs but little from Hiedemann's ( $/ 6)$ method of secondary interferences, which gives equally good results. The letters have the same meanings as in Fig. 13, only $P$ is a 1000 c.p. Pointolite lamp.Instead of the diaphragm a double condenser $I_{1}(I=25.4 \mathrm{~mm}$. $\left.I+I^{\circ} 9\right)$ is used with a diaphragm $D$ having a circular aperture of $0.3 \mathrm{~m}$. A photographic lens $\mathrm{L}_{2}$ (Ernostar, $f=100$ m., $1 \div 2$ ), rendering the light parallel, is inserted. The size of the glass cell is $5 \times 5 \times 16 \mathrm{~cm}$. and the image on the screen is produced by a photographic lens $I_{3}$ (Dogmar, $I=180 \mathrm{~mm} ., 1 \div 4^{*} 51$. The use of the concentrated-arc lamp as light source would simplify the arrangement as it could be dispensed with the condenser $L_{l}$ and the diaphragm $D$. For $\frac{\text { Tig8. / the fifth harmonic of the vibrating quartz was appliod. }}{117,18,19,207}$ 
The most convincing photograph of the sound field in front of an ultrasonic lens is Fig.22.

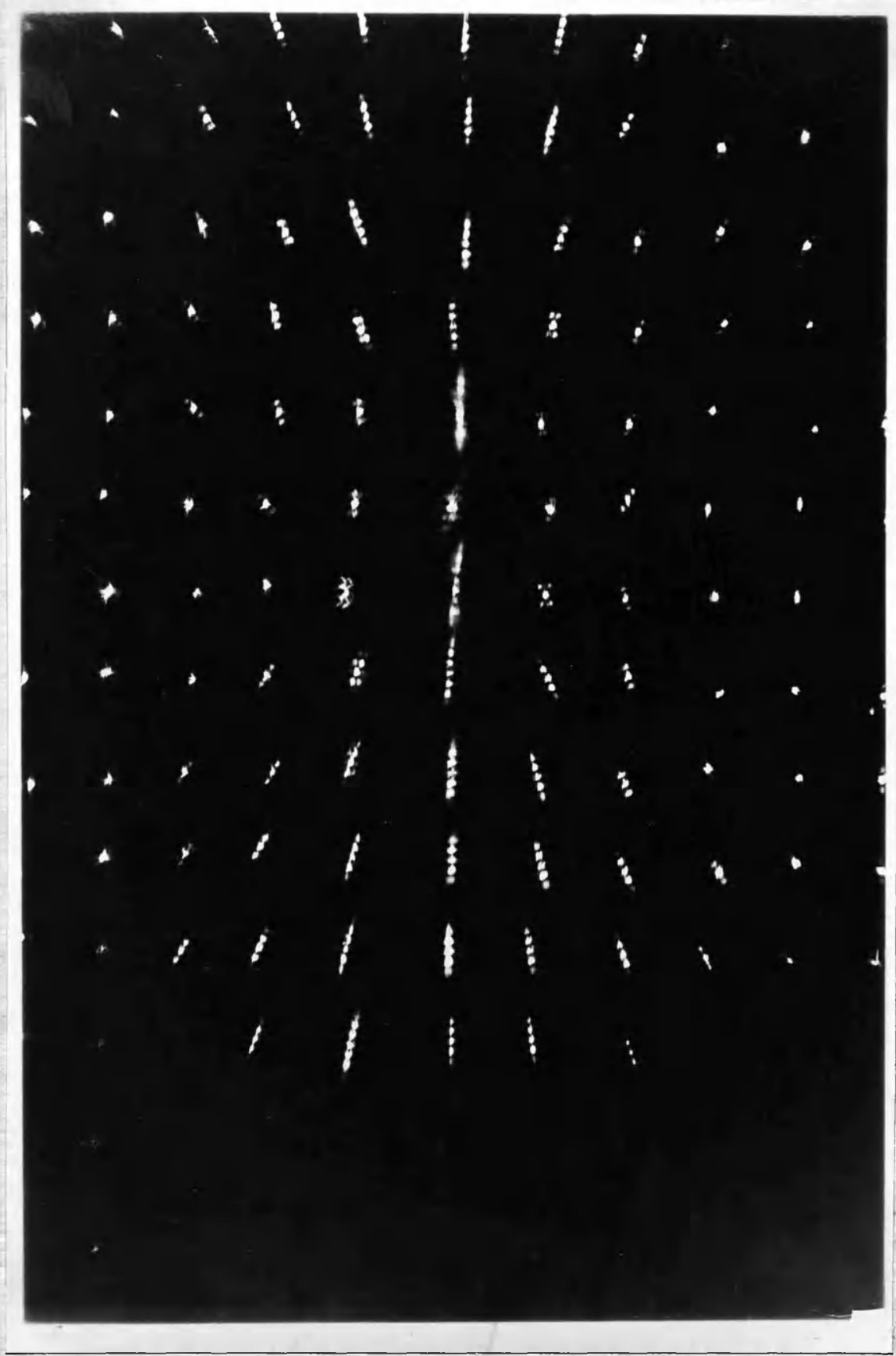

Fig.22. Plano-cylindrical aluminium contact lens in carbon tetrachloride. 
method ( 1 ) which can easily be expleined with the aid of Fig.23.

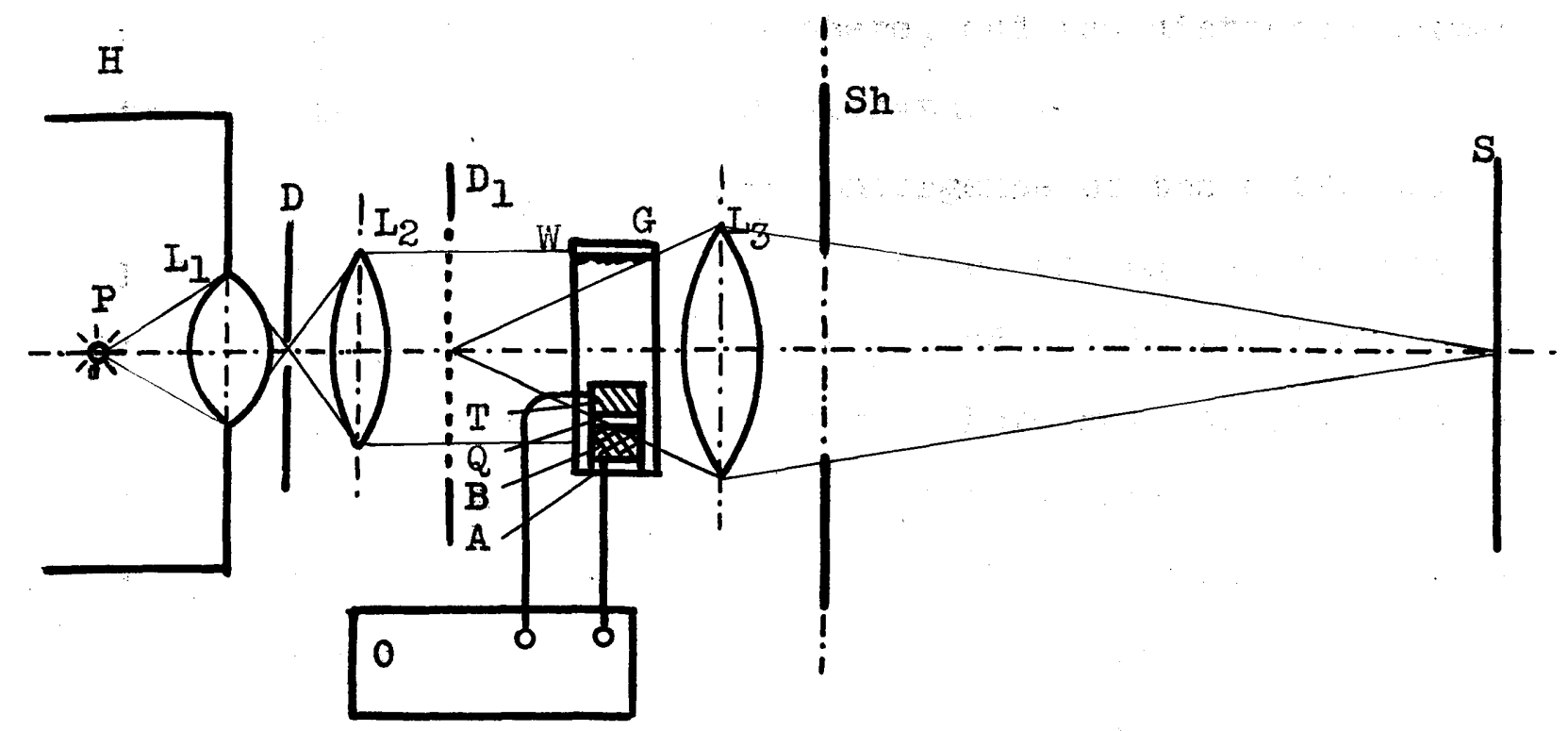

Fig. 23. Experimental arrangement for rendering ultrasonic waves visible (Bär and Meyer's method).

Here the letters have the same meanings as in the other optical arrangements. $D_{1}$ between $L_{2}$ and $G$ is a diaphragm with a great number of circular apertures at regular distances of a few m. Im. I gives sharp images of these apertures on the screen $S$. To make the most of the light available the image of the source of light should be produced in the plane of $I_{3}$. As the Pointolite lamp gives light in abundance the photographs (e.g. Fig22) could be taken with parallel light; thus a greater field could be evenly illuminated. If the ultrasonic waves are small enough they act as an optical grating and, on passing that, the light through each aperture of $D_{1}$ is diffracted. The line joining the diffraction spectra of an individual point lies in the difection of propagation of the yltra- 
sonic waves passing the corresponding point in the liquid, the number of orders of spectra depends on the amplitude of the wave, i.e. uItrasonic energy there, and the distances between the single orders on the wave-length.

In Fig.22 from the convergence of the diffraction patterns of the circular apertures the orthogonal projection of the line-focus can easily be traced, while the increase in intensity of the ultrasonic energy there may readily be detected from the growing number of diffraction images. To suppress the reflexion of ultrasonic waves at the boundary between carbon tetrachloride and air, in order to avoid the formation of standing waves, the surface of the liquid was covered with an irregular pad of wadding. As in the previous case the fifth harmonic $13.1 \mathrm{Mc} / \mathrm{sec}$.$) of the natural frequency of the crystal (600$ $\mathrm{kc} / \mathrm{sec}$.) was used. The magnification was $\times 3 \cdot 5$ approximately, the time of exposure $1 / 5 \mathrm{sec}$.

The application of a concentrated-arc lamp to this arrangement will also effect a considerable simplification. It makes, as in the previous case, dispensable the condenser $I_{1}$ and diaphragm $D$. The well-corrected photographic objective $\mathrm{L}_{2}$ can be replaced by a simple condenser.

A few words on how to make the diaphragm $D_{1}$ with the circular apertures. 'l'he ordinary advice is: by piercing, with a pin, a great number of holes/in a cardboard (Bär, Bergmann) or tinfoil (Hiedemann)/ at regular distances of 2 to $10 \mathrm{~mm} . /$ For Fig.22 such a perforated tinfoil was actually used. 'lhe diaphragms that I have made photographically are by far superior to the pricked ones. Their production is easy enough. 


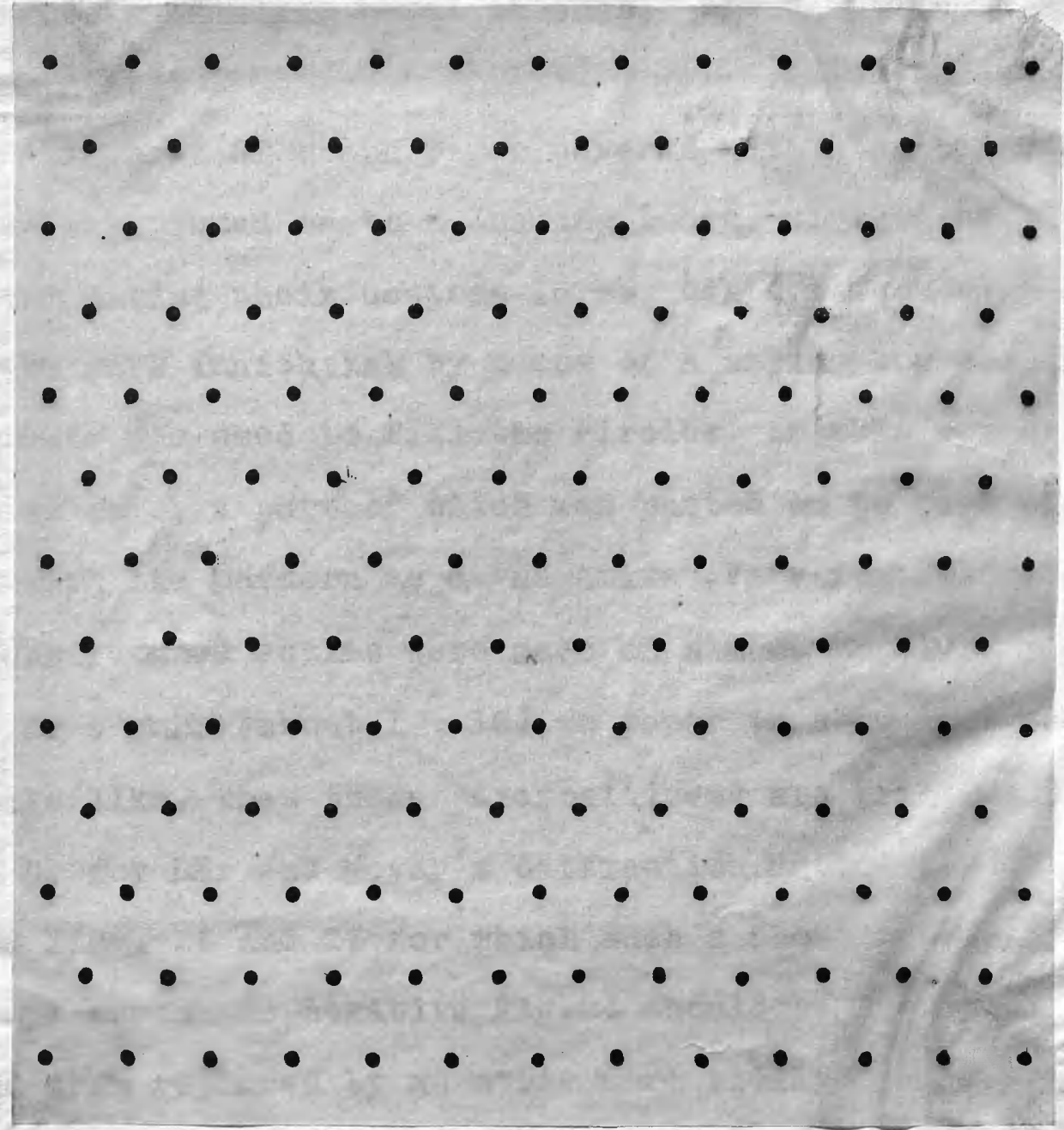

Fig. 24. Pattern for the photographic production of a diaphragm with circular apertures.

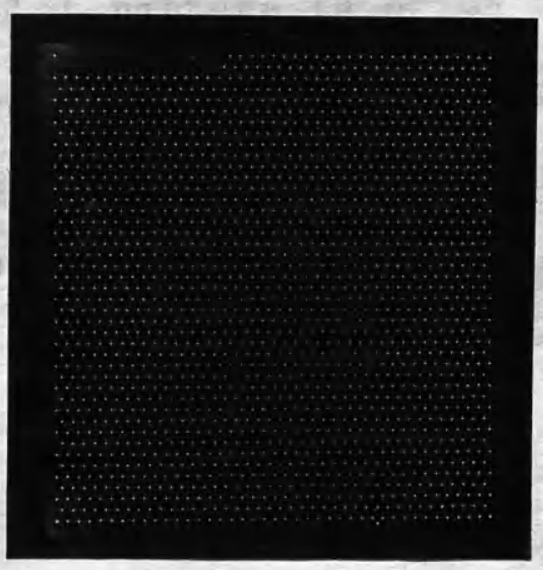

Fig. 25.

The pattern above reduced to $1 / 10$ approximately. 
After a few attempts, using thin ebonite plates or metal sheets with holes bored through, the following method has been adopted:

A sheet of graph paper covered with a sheet of tracing paper was pinned on to a drawing board. vircles of $1^{*} 5 \mathrm{~mm}$. radius and having their centres $10 \mathrm{~mm}$. distant from each other were drawn with Indiak ink by means of a spring bow compass. A fine pipette was used to fill the circles. In this way an areo. of $45 \times 45 \mathrm{~cm}^{2}$., a part of which was pasted on to page 51, was covered with the pattern as a "negative". Very contrasty copies to various reduced scales were made on almost grainless plates. Fig. 25 is a print (about $1: 10$ ) on paper to show what such a copy looks like. That these "diapositives" are brillant diaphragms $D_{1}$ for Bär and Meyer's diffraction method can be seen from the Figg: 26 and 27 for which such a photographic diaphragm was used. 'the negative Fig.24 should be used only for a test and then replaced by an other more tidily drawn; but, the results obtained by means of the first specimen were quite satisfactory and the diaphragm was not renewed. As, on the other hand, that pattern is offen seen on oil-cloth or similar materials one can be spared the trouble of drawing the negative.at all. Moreover, since these are made mechanically they will be more accurate than the hand-drawn patterns. 


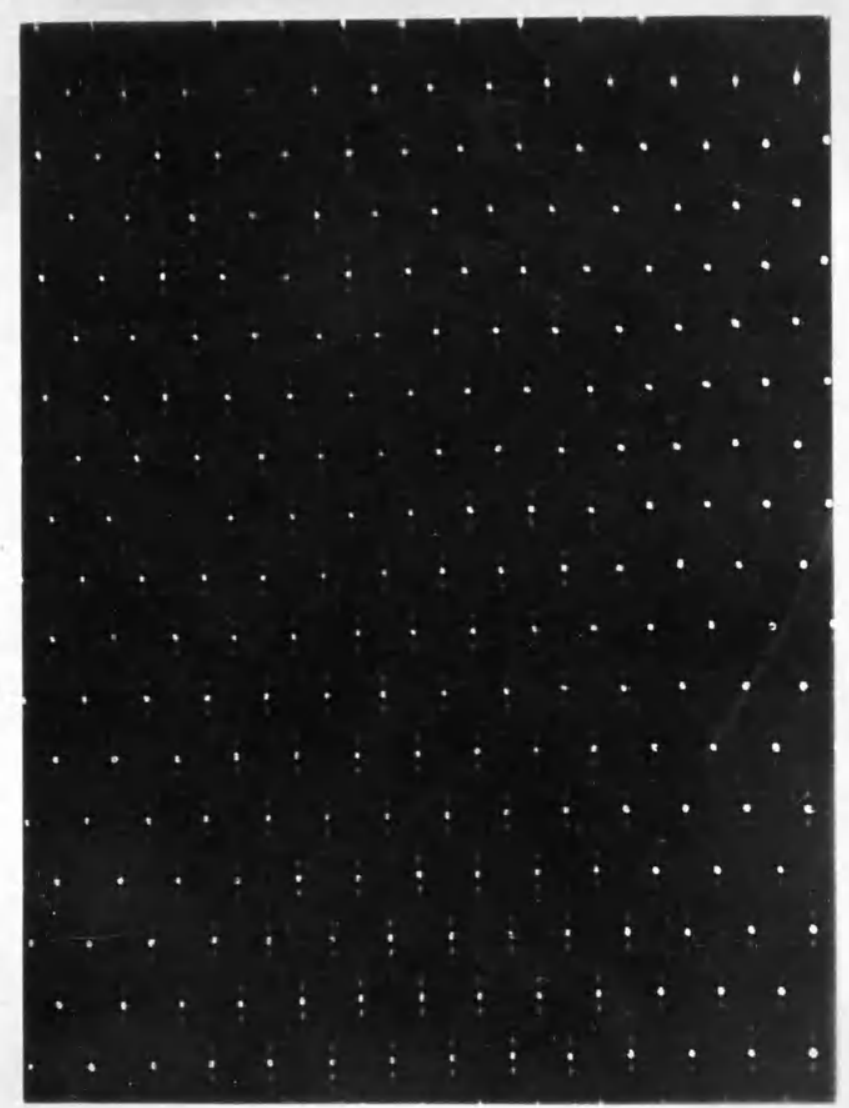

F1g. 26.

Diffraction method Quartz Crystal Photographically made diaphragm

Fig. 27.

The same as Fig. 26 only Rochelle salt crystal insteed of quartz

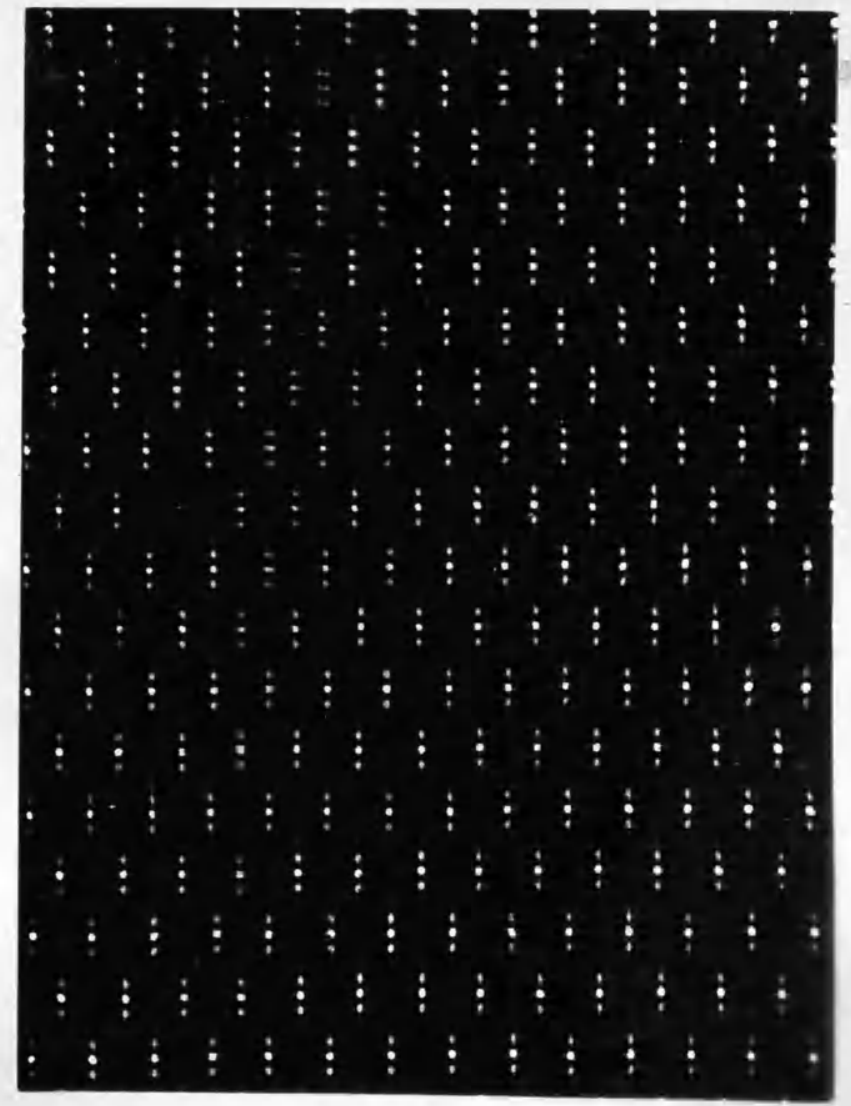




\section{Transmission Plates.}

It may be confidently expected that ultrasonic lenses and transmission plates will be put into practice very soon. It seems, therefore, to be opportune to suggest a method of specifying and measuring these devices.

That is quite easy in the case of transmission plates. The statement of shape, size, material, refractive and reflective indices or equivalent quantities and, if known, of the coefficient of absorption at the particular frequency is completely sufficient.

But also in the case of ultrasonic lenses this problem is not too hard because the approved methods used in optics can be similarly applied to acoustics. In one respect the treatment of ultrasonic lenses is even easier than that of optical lenses. Since, within the range of frequencies generable at present, no dispersion of sound velocity occurs either in solids or in liquids the acoustical focal length of an ultrasonic lens is independent of the frequency, in other words even a single ultrasanic lens is "achromatic" or rather "apochromatic".

For the "transcription" of methods from optios into acoustics, in addition to the radius of curvature and acoustical focal length of an ultrasonic lens their reciprocals, the curvature and focal power, have to be introduced. As the acoustical focal length and focal power of an ultrasonic lens depend on the medium of propagation 
a standard liquid must be chosen. It is convenient to use water as the standard because its properties are accurately known and stable.

It is suggested to take over the unit of curvature from optics, the dioptee $D$, and call it appropriately diacoustre $D_{\text {ac }}$ when used in ultrasonic work. The curvature of an ultrasonic lens expressed in $D_{a c}$ is, of course, the same as expressed in $D$

$$
\mathrm{R}=\frac{100}{\mathrm{r} \text { in } \mathrm{cm}}=\frac{39 \cdot 37}{\mathrm{r} \text { in inch }}
$$

Then, from the fundamental paraxial equation for the refraction at a spherical surface, it follows that the acoustical focal power is given in $D_{a c}$ by

$$
F_{\mathrm{ac}}=-(\mathrm{h}-1) \mathrm{R}
$$

where $\mu=v_{g} / \nabla_{I}, v_{S}$ being the ultrasonic velocity in the solid $\nabla_{1}$ that in the liquid.

Also an "acoustician s lens measure" can be built based on the same principle as the wide-spread "optician's lens measure" and more than that: the opticians lens measure itself can be used for supersonlo work if the values of the divisions are converted. 'the readings of the optician $s$ instrument are known to be calculated for $\mu=1.523$, therefore

$$
\mathrm{F}=0.523 \mathrm{R} \text {. }
$$

The acoustician's instrument has to show

$$
F_{a c}=-\left(\nabla_{S} / v_{I}-I\right) R \text {. }
$$

Conse quently

$$
F_{a c}=-\frac{\left(\nabla_{s} / \nabla_{I}-1\right)}{0.523} F
$$

A table, very easy to calculate, a simple graph or a sliderule will help to find the value without any trouble. 
A very convenient comparison of the concentrating effect of ultrasonic lenses or lens systems is made possible by the introduction of a quantity known as "aperture ratio" and used for the specification of photographic objectives. The aperture ratio is defined as the quotient of the entrance pupil of a lens system by its equivalent focal length or, in the case of a single lens, very nearly the quotient of the diameter of the lens by its posterior focal length. The aperture ratio is denoted as a quotient ... $1: 3 \cdot 5,1: 4 \cdot 5,1$ : $6^{\circ} 3,1: 9$ and so on or as a fraction $\ldots f / 2, f / 2 \cdot 8, f / 4$, $\mathrm{f} / 5 \cdot 6$ and so on.

The effects produced by two ultrasonic lenses under any given conditions are inversely proportional to the squares of their aperture ratios.

Improvement of Bergmann and Goehlich's method for measuring velocity of ultrasonics in liquids.

Bergmann and Goehlich $(5,6)$ have used their shadow projection of standing ultrasonic waves (cf. pp. 38-42) for the measurement of ultrasonic velocities in liquids as well.

The transparent cell in which the ultrasonic waves are generated in vertical direction is raised vertically upwards by a micrometer screw as shown in Fig. 16, p.42. At the same time the half-wave-lengths of ultrasonics are counted when passing a given point marked on the projection screen. The applied frequency multiplied by the elevation of the cell and divided by half the number of half-wave-lengths gives the velocity required. 
Bergmann and Goehlich's method involves the necessity of lifting the whole ultrasonic oscillator while oscillating and of counting stripes while moving which is a task trying to the eyes. An improvement of that method which avoids both disadvantages is based on the following observation:

The procedure described in the next few lines proved very satisfactory for the fine adjustment to the best visibility of standing waves produced in vertical direction in the transparent cell in the manner of Bergmann and Goehlich. By a siphon consisting of a u-shaped glass tube provided withla stopcock the surface of the liquid of propagation in the cell is very slowly lowered till the bright bands of the image on the screen are clearly defined. At this very moment the stop-cock is turned off. If this instant is missed all of a sudden the whole pattern on the screen is collapsing. Then the waves form again and the phenomenon is recurring after each half-wave. The change takes place most abruptly if an ultrasonic lens is inserted. Now the improvement:

Just when the pattern on the screen is disappearing the stop cock of the siphon is turned off and the height of liquid marked by a pointer similar as usual in experiments on capillarity. Then the stop cock is turned on again and a great number of "changes", say 200, counted. At the moment of the 200th disappearance the stop cock is turned off and the new position of the surface marked by another pointer. The difference of heights is measured microscopically. Supposing that the frequency is accurately known the result is correct to about $0.1 \%$ if the test ig/reliably/carried out.7 
The superiority of the solid lenses elaborated in this work over Pohlmann's Iiquid lenses is obvious; but it is oleimed that they also far surpass iruetzmacherss curved crystal.

A curved crystal has to be specially ground by a wasteful and expensive procedure ${ }^{+}$while lenses are easily and cheapIy made and can be used in connexion with every crystal already available. 'lhe curved crystal converges ultrasonics only to its centre of curvature, while sets of lenses of any desirable focal length can be provided for every ordinary crystal to focus ultrasonic energy towards any point required. The reflectivity of a curved crystal depending on the liquid in use cannot be diminished, contrary to the possibilities of reduction previously mentioned in the case of lenses.

by the above arguments on transmission plates and experimental evidence it has been proved that, contrary to the general opinion, there is no reason to design one of the electrodos of an oscillating quartz as a rectangular or circular frame, as a "window" through which the ultrasonic waxes are able to pass. On the contrary, a transmission plate of matching material without opening gives better results. Not the softness of lead, as Freunalich (26) thinks, but the fact that its acoustic resistivity is very nearly the same as that of quartz makes the effect of a "bed of lead" quite comprehensible, especially when propped up by an air cushion reflecting practically the whole incident energy. The same fact also explains Tumanski's success (68) when he was using lead foils as electrodes.

+ cr. the letter of The Edison Swan Electric Company Itd. p.50. where this difficulty is confirmed. 


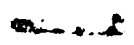

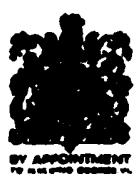

\section{THE EDISON SWAN ELECTRIC COMPANY L'.}

at.

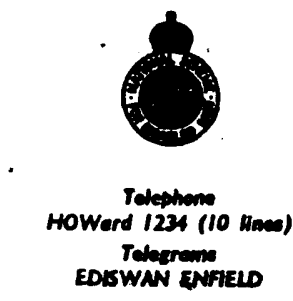

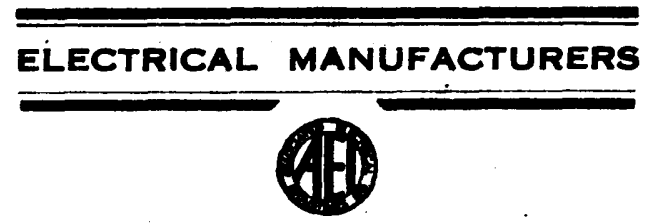

PONDERS END

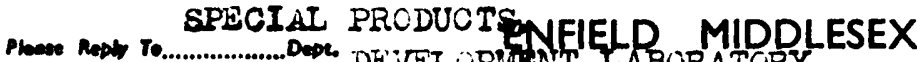

P.J. Ernst, Ph, D.

- Department of ipplied Fhysics,

University of Glasgow,

GLASGOW.

Dear Sir,

I noted your recent article in the Journal of Scientific Instruments, December 1945; with-great interest.

He are about to commence a series of experiments using ultrasonics, for medical purposes, and are working in conjuhction with ur. Grey Nalter, M. A. of Burden Neurological Institute.

ire had set out with the idea of using curved crystals of comparatively large diameter, but hate so far failed to find any-one wlling to grind concouc-sonvex crystals.

inile still exiloring the situation in this direction, we very interested in the idea of using flat crystals arid the suitable lenses. He would deom it a great favour if ycu would give us some guidance as to the bet proposition for our early experiments.

The conditions are approximately as follows:-

What follows has been omitted having no bearing upon the point in question. 
In the March 1946 1ssue of the J.Sci.Instrs. the following letter to the editor was published:

\begin{abstract}
if
Ultrasonic Lenses and Prisms

In your December 1945 issue, Dr Ernst has described methods of making ultrasonic lenses and recording their performance photographically. It may be of interest in this connexion to describe the simple procedure for achieving these objects which was adopted by the writer for the purpose of illustrating experiments carried out some time ago and described in a Discourse given at The Physical Society's Annual Exhibition in 1929 and published in the February r 929 issue of this Fournal.
\end{abstract}

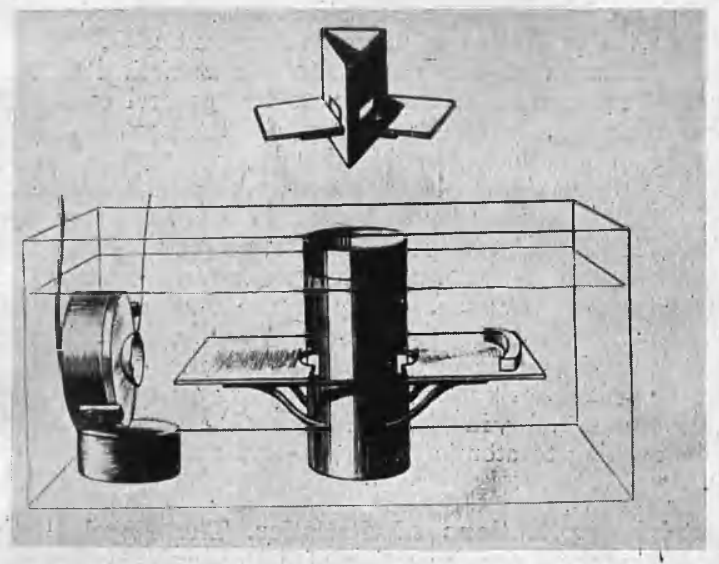

Fig. I. Experimental arrangement of ultrasonic lens and (above) prism

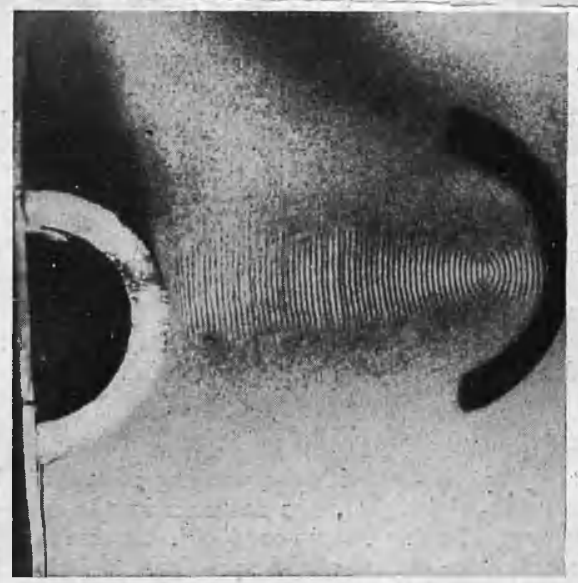

Fig. 2. Effect of hemispherical lens.

The experimental arrangement is shown in Fig. I. A brass cylinder having walls 7-10 mm. thick closed at one end and filled with pentane stands on the bottom of a trough containing transformer oil in which a piezo-electric ultrasonic generator is suspended so as to project a horizontal beam. Transmission through the pentane is achieved by milling horizontal slits at opposite ends of a diameter of the brass cylinder and covering them with very thin varnished paper. The path of the beam is rendered visible by the striae produced in a thin layer of coke dust deposited on horizontal opal glass sheets, using stationary waves produced by arranging for the convergent beam issuing from the lens to pass through the centre of curvature of a circular reflecting brass 'mirror'.

Fig. 2 shows the effect produced when using a hemispherical lens, the frequency of the generator being approximately 500,000 vibrations per second.

An ultrasonic prism of similar construction is shown in the upper part of Fig. 1.

F. L. Hopwood
(36)

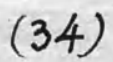

St Bartholomew's Hospital London 
It is interesting to learn of Prof. F. L. Hopwood's early experiments
on the uses of lenses and mirrors for ultrasonic work. The main
differences between his neat method and mine are as follows.
Prof. Hopwood used a liquid lens, working only in a horizontal
position, and applied R. W. Boyle's mechanical method of rendering
stationary ultrasonic waves visible, by dust figures of coke powder.
He used a $3 \mathrm{~kW}$. oscillator.
I employed solid lenses of high efficiency and optical methods
for the recording of either stationary or progressive waves, which
require less power for even better results; I used approximately
roo W. Also, optical methods are applicable to much shorter
waves and allow photographs to be taken at any instant during the
experiment.

Department of Natural Philosophy

University of Glasgow

But I should like to add the following comment to the

foregoing words:

1.

To the best of my knowledge Hopwood has never before

published anything about his experiments on ultrasonic lenses, nor has he mentioned them in the article quoted in his note.2. The only remark on ultrasonic lenses, I could find in his papers, was that in Nature,London, vol.128 p.748 (1931): "Thus by using plane and curved reflectors the well-known laws of reflection are verified. In the same way refraction of sound waves by prisms and lenses can be demonstrated." But exen there the illustrations of his present note are not shown. (35) 3. Those illustrations, however, are partly wrong, partly inconsistent with the Fig.28. words of his note.

In the upper part of th/sstetch Fig. I the prism is supposed to be filled with pentan $(v=1052 \mathrm{~m} / \mathrm{sec})$ while stand-

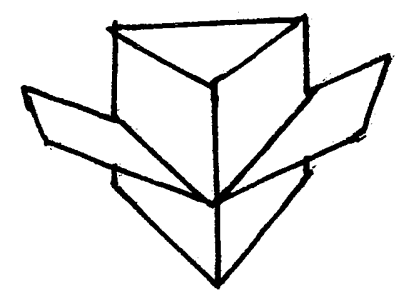

ing in a vessel containing transformer oil $(v=1370 \mathrm{~m} / \mathrm{sec}$ approximately $)$. MHepetä 
acoustically/

is/denser than the surrounding medium and ultrasonic waves passing it are therefore deviated away from the refractive edge. Consequently the horizontal opal glass sheets should lie in directions opposite to those sketched by Hopwood. A correct drawing is shown in Fig. 28. /Hopwood's/

4. In tha photograph Fig.2 the waves do not converge to the centre of curvature of the mirror but are concentrated towards a point near the focus of the mirror after having passed the lens and been reflected from the mirror. By that fact it is proved that the effect of Hopwood's lens is negligible, if existing at all. Fig.29.

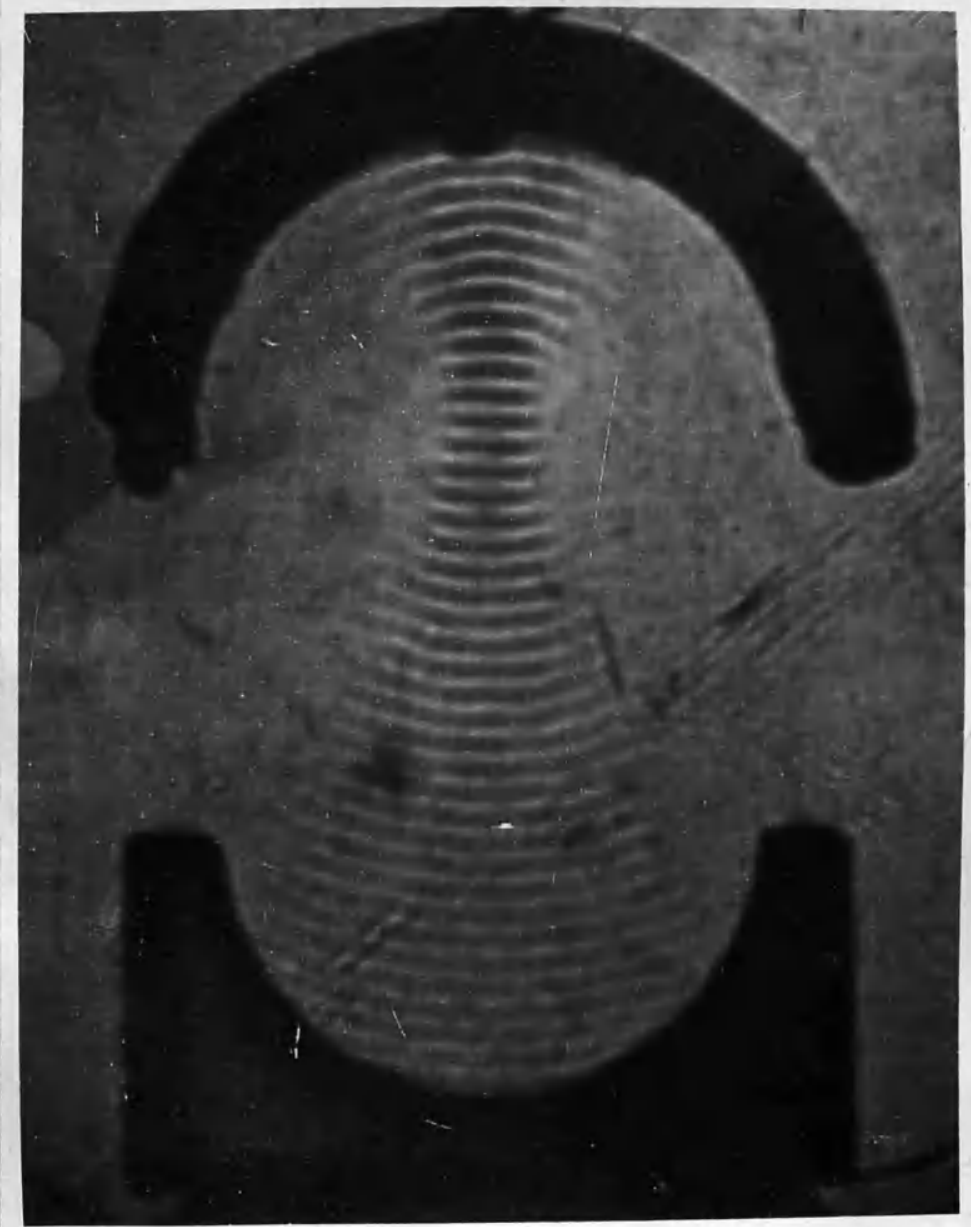

To produce an indireot proof that Hopwood's lens is ineffectual photographs are added of the same arrangement and taken with my apparatus. In Fig2g, oscillating orystal is a slab of Rochelle salt, L-cut, of $600 \mathrm{kc} / \mathrm{s}$ fundamental frequency. A eyliner drical lens of polymethyl methacrylate is used and a doublewalled and air-filled half-cylinder of glass as a oylindrical "mirror". Photo Fig.29 
shows exactly what Hopwood's should show.

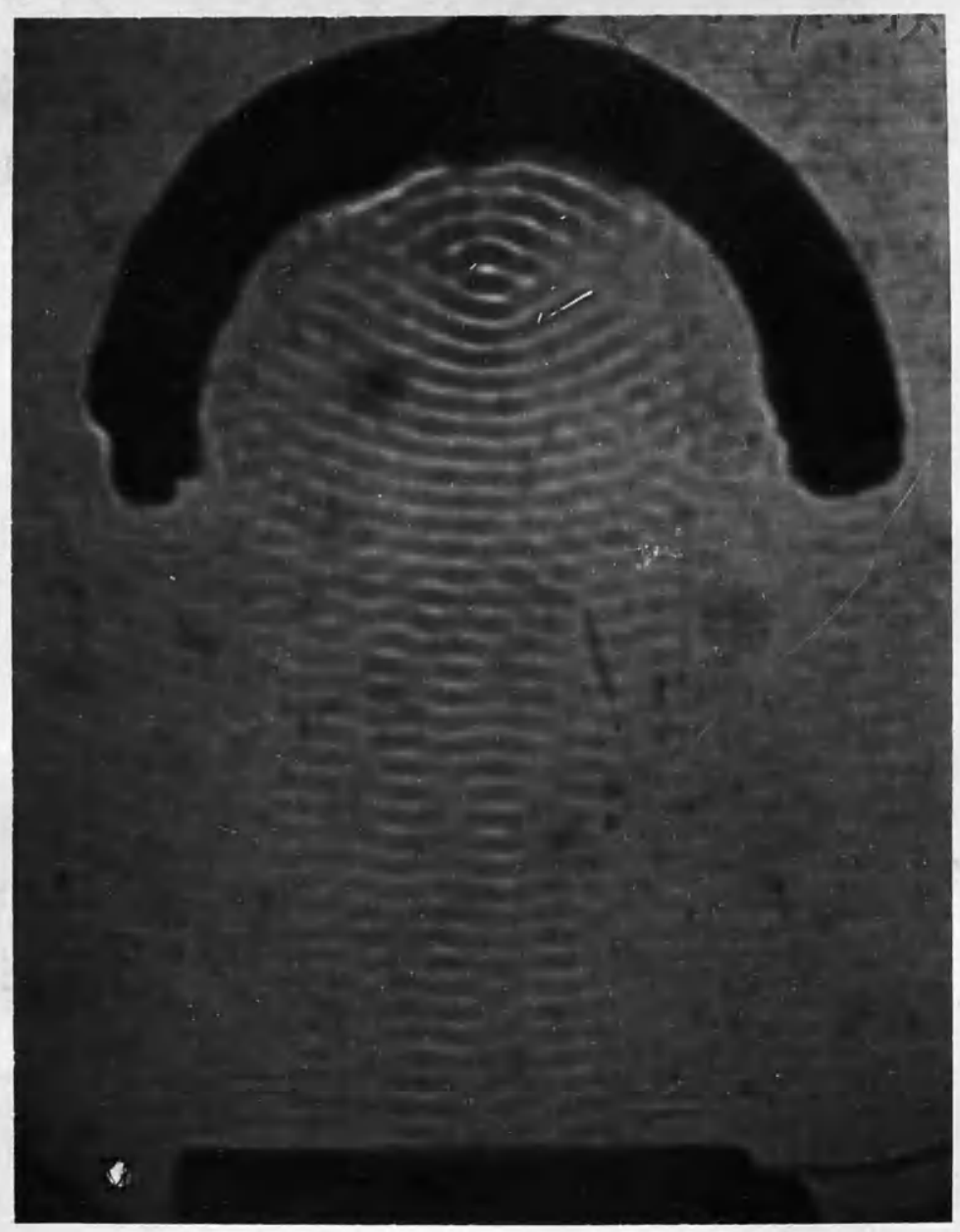

In Fig. 30 the

thle lens has been

removed; the pho-

tograph shows now,

without a lens, the

same as Hopwood's

doesxwith his lens: ${ }^{+}$

Figg. 31 and 32

on the next page

are photographs of

the same arrange-

ment as in Fig.29

only the lens of

poly-methyl meth-

acrylate is replaced

by a lens of poly-

Fig. 30. Reflexion of plane waves. styrene having the same curvature. The focal length of this is shorter since its refractive index with reference to liquids is higher.

The heating effect of ultrasonics in this arrangement is surprisingly large. Striae caused by it are visible even a considerable time after the generator is switched off. The photograph Fig.32 was taken about five minutes after the radiation had stopped.

+ In this way Hopwood's unjustified claim is incontrovertibly refuted. It is not clear why he tried to debase my work by his ill-founded pretension. 


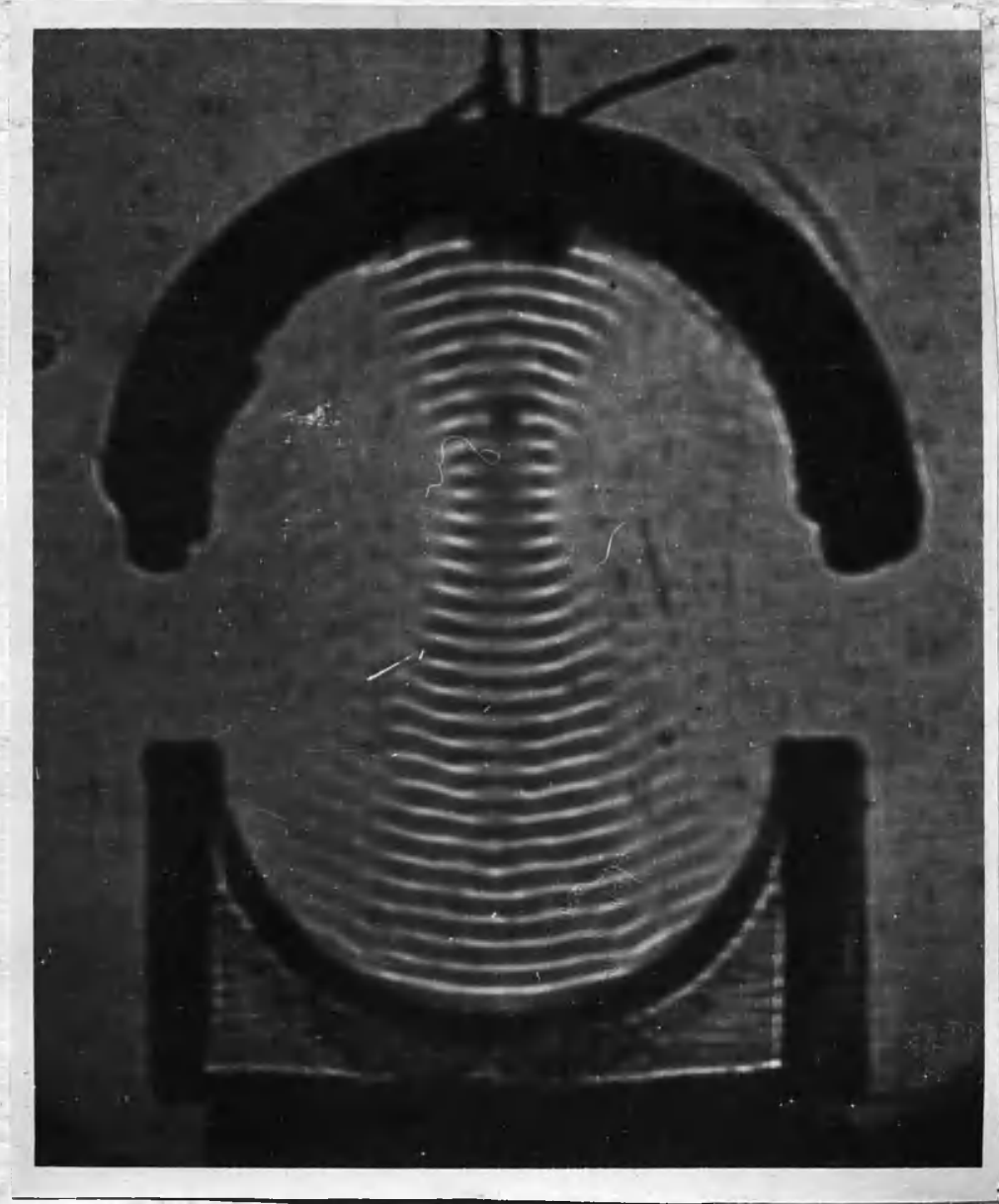

Fig. 31 .

Plano-cylindrical lens of polystyrene and

airfilled cylindrical "mirror"

with common line focus

Fig.32.

Arrangement as Fig.31

Photograph showing heatferfect

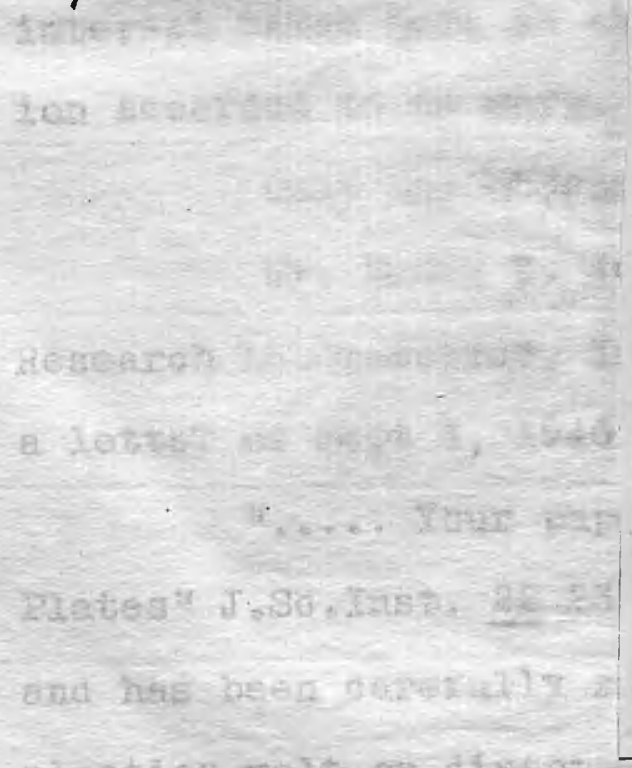

$-64-$ 
Hopwood's letter to the editor of J.Sci.Instr. was the only censure of my paper. Wany unsolicited appreciative letters of British, Canadian and American physicists encouraged me to continue the investigations. (Among others: Sir J.W.French of Barr \& Stroud, Ltd., Glasgow; R.W.Boyle of Ottawa, Canada; J.C.Hubbard of baltimore, Md.; H.K.Schilling of state College, $\mathrm{Pa}$; F.A.Firestone of Ann Arbor, Mich.) Several British and Amerioan firms made inquiries about particulars of the devices described. (Imperial Chemical Industries Limited, Winnington, Cheshire; The Edison Swan Rlectric Company Ltd., Middlesex; Central Scientific Company, Uhicago, Ill.; Messrs. Eimer \& Amend, New York, N.Y.) The editor of J. Acoust. Soc. Am. has accepted an article containing parts of the thesis not yet published and including a summary of the previous publication. I shall read a paper on Ultrasonic Lenses and Iransmission Plates before the Fall Acoustical Society theeting in Chicago (14-16th November, 1946). This facts prove the great interest taken here in the subject and the friendly reception accorded to my work.

Unly one objection has come to my knowledge:

Mir. Henry F. Jochim, Vice President of Crystal Research Laboratories, Inc., Hartford, Conn., is writing in a letter of sept 4,1946 :

".... Your paper "Ultrasonic Lenses \& Transmission Plates" J.Sc.Inst. 22238 (1945) has come to our attention and has been carefully read by our engineers. We find that plastics melt or distort at the extremely high power levels 
which we use. We also have not been able to get any lithium or lithium alloys such as suggested in your paper.

If you have any further thoughts on developments that could prove valuable to us we would appreciate hearing from you."

In rny answer I argued as follows: "..... In Great Britain I got lithium vithout any difficulty. ..... On the continent a lithium-magnesium alloy was very common, called "Bahnmetall (= railway metal)" and used mainly for the lining of bearings. I think this would be a very suitable substance and probably available here, too.

However, contact lenses of any material having an ultrasonic resistivity of between $130-150 \times 10^{4} \mathrm{~g} \cdot / \mathrm{cm} .^{2}$ sec. (quartz) and 15 (water) or 13 (Iiquid paraffin or transformer oil), best from 40 to $50 \times 10^{4} \mathrm{~g} \cdot / \mathrm{cm}^{2}$ sec., will satisfy you if its coefficient of absorption is not too high.

I am just trying to surmount the difficulty in a different way and shall furnish you further information as soon as the technical problem involved will be satisfactorily solved. ....."

In the last paragraph I am referring to the Phase-Reversal Zone-Plate treated on $\mathrm{p} .68$, ff.

unce Dr. Walter MCFarlane of Glasgow University has got a "heat-resistant piece of perspex" for the insulation of $x$-ray tubes in the western Infirmary of Glasgow. I guess that was not real perspex but a higher polymer or perhaps a phenolic. Anyhow, heat-resistaint plastics, as soon as it will be possible to produce some, will extend the field of application of plastic lenses to ultrasonics, even to such of very high power. 
Problems Awaiting the ir Final Solution.

An extended series of problems has arisen from observations made in the course of the foregoing investigations but not yet been treated. Many of them are quite simple and can be used for advanced students as introduction to independent research on ultrasonics. unly a few are mentioned below.

Velocity and absorption of ulträsonics in various plastics and akin substances.

Lead is known to sound in liquid air. A promising problem : Ultrasonic properties of lead at very low temperatures.

The natural frequency of Rochelle Salt L-cuts as a function of their thicknesses. (The value for an I-cut bar is $146 \mathrm{kc} . \mathrm{cm}$. , for an L-cut plate $207 \mathrm{kc} . \mathrm{cm}$. according to cady.) Influence of $X$-rays on the resonance frequency of a Rochelle salt I-cut. A change in frequency, similar to that in quartz crystals, was noticed during the experiments with irradiated crystals.

The velocity of sound in a molten metal is, as a rule, about half of its velocity in the solid metal. Bismuth seems to be an exception as the velocities are mentioned in literature: $v_{\text {solid }}=1810 \mathrm{~m} / \mathrm{sec}$. and $v_{\text {liquid }}=2180 \mathrm{~m} / \mathrm{sec}$. Three more difficult problems are fairly thoroughly discussed in the appendix on the following pages. The most fascinating problem seems to be the ultrasonic"imitation" of optical and electrical apparatus and methods from the single lens to the most intricated methods of Radar. 


\section{Ultrasonic Phase-Reversal Zone Plate.}

It is well known that a system of concentric circular rings, with radii proportional to the square roots of the natural numbers and transparent to light and opaque in alternate succession, acts as a series of convex and concave spherical lenses at the same time. Such a special circular diffraction grating is called Soret's or Fresnel's Zoneplate.(65). The fundamental focal length of a zone-plate is given by the formula

$$
f=r^{2} / \lambda,
$$

$r$ being the radius of the central circle and $\lambda$ the wavelength of light. Multiple foci are at distances $f / k$, where is stands for the successive odd numbers.

Wood ( $\eta 1$ ) improved the small efficiency of the zone-plate by an ingenious method of reversing the phase of the light through the alternate zones instead of cutting it out. His Phase-Reversal Zone-Plate is a practically colourless photographic print of an ordinary zone-plate on a thin sheet of plate-glass coated with dichomated gelatine (carbon print). After developing in hot water the print consists of only one system of rings of clear gelatine causing, at a suitable extreme thinness, the necessary retardation of exactly half a wave-length if monochromatic light is used. Thus, while a considerable amount of light is wasted in Soret's plate, theoretically no loss of energy takes place in Wood's plate. But despite their undeniable superiorities, neither one nor the other could replace optical lenses because of their inherent chromatic aberration. 
After some experimenting, in 1930 I succeeded in applying the zone-plate principle to the design of a device for focusing ultrashort electric waves (22). Here the chromatic aberration does not come in question since electric waves can be easily kept at $\boldsymbol{\alpha}_{\mathfrak{\alpha}}$ onstant frequency.

In 1939 Pohlmonn (55) developed a zone-plate for ultrasonic waves, consisting of 6 concentric brass rings of $0.8 \mathrm{~mm}$. thickness and having an outer diameter of $50 \mathrm{~mm}$.Its fundamental focal length is $80 \mathrm{~mm}$. at $2 \cdot 4 \mathrm{MC}$. in water.

To increase the efficiency of an ultrasonic zoneplate the phase-reversal principle can be applied similarly as in the case of light. To avoid the long-winded name of "ultrasonic phase-reversal zone-plate" the device described below will be called "acceleration-plate" in what follows. Here are the data of an acceleration-plate of 50 $\mathrm{mm}$. focal-length at $3 \mathrm{Mc} / \mathrm{sec}$. In water. In apircular disc of polymethyl methacrylate of $5 \mathrm{~mm}$. thickness and $28 \cdot 28 \mathrm{~mm}$. outer diameter a central circular and 3 concentric ringshaped grooves are cut of a depth of $1 \mathrm{~mm}$. The successive radii are: $r_{n}=5 \sqrt{n} \mathrm{~mm} ., n=1,2,3, \ldots 8$. As the velocities of ultrasonics in the above plastic and conductivity water are very nearly $\nabla_{\mathrm{p}}=2000 \mathrm{~m} / \mathrm{sec}$. and $\nabla_{\mathrm{W}}=1500 \mathrm{~m} / \mathrm{sec}$. respectively, the corresponding wave-length at $3 \mathrm{Mc}$. are $\lambda_{\mathrm{p}}=2 / 3 \mathrm{~mm}$. and $\lambda_{\mathrm{W}}=1 / 2 \mathrm{~mm}$. Consequently $1 \mathrm{~mm}$. corresponds to 3 half-wavelengths in polymethyl methacrylate and 4 half-wave-lengths in conductivity water, which fulfills the condition for an acceleration-plate. In addition the plate having a thickness of an even number of quarter-wave-lengths (30 the plate itself, 
24 the parts below the grooves) constitutes a transmission plate and transmits the whole incident energy provided that the loss by absorption is negligibly small.

An acceleration-plate was made of aluminium as well. Its thickness of $5 \mathrm{~mm}$. is equal to 12 quarter wave-lengths in aluminium at $3 \mathrm{Mc} / \mathrm{sec}$. and of $4.17 \mathrm{~mm}$. below the grooves to 10 quarter wave-lengths. The height of the ridges of $0.83 \mathrm{~mm}$. corresponas to half a wave-length in aluminium $\left(\lambda_{\mathrm{A} I}=1 \cdot 67 \mathrm{~mm}\right.$.), the depth of the grooves of $0^{\circ} 83 \mathrm{~mm}$. to 4 half wave-lengths in liquid paraffin $\left(\lambda_{\text {par }}=0.43 \mathrm{~mm}.\right)$ approximately. Pherefore the necessary phase-reversal is secured. The radii of the circles are the same as those of the plastic acceleration plate and so the focal-length of $f=58 \cdot 2 \mathrm{~mm}$.

Both acceleration plates worked quite satisfactorily, at least as weIl as lenses of the same aperture ratio about $f / 2$, if not even better.

To record the function of acceleration-plates photographically substitutes for plano concave cylindrical lenses 2 . 1 . were made both of aluminium and polymethyl methacrylate. They consist of rectangular transmission plates with a series of rectilinear grooves cut in parallel to the sides of the plates. The distances of the straight lines, considering their finite lengths, from the bisector of the rectangular plate is given by the formula

$$
O T_{n}=a \sqrt{4 n-I}
$$

The derivation of this formula is found in some text books of optics, for instance in schuster (78). The distances in the particular case were $\mathrm{OT}_{\mathfrak{n}}=4 \cdot 4,6 \cdot 72,8^{\bullet} 42 \ldots . .15^{\bullet} \mathrm{mm}$. The 
depth of the grooves (identical with the height of the ridges) was $0.7 \mathrm{~mm}$., that is equal to 3 half wave-length phn liquid paraffin or 2 half wave-lengths in polymethyl-methacrylate of ultrasonics at 3 Hidsec. A similar acceleration-plate was made of aluminium.

Both the plates worked excellently. But the heat developed from the very beginning of the oscillations was fairly great and the striae visible on the screen were rising to the surface of the liquid in curves like smoke above a flame. Ihe point of intersection of these curves was definitely higher than the pre-calculated focus which could not be clearly distinguished.

For a check the acceleration-plates were exchanged for plane plates of the same sizes and materials. Strangely enough, the effect was the same though considerably smaller. I am predisposed to the belief that the parallel edges of the rectangular plates act as single diffraction slit $\$$. When the phenomenon seen, using a plane circular disc, can be considered as the acoustical imitation of Arago"s "white spot experiment" in optics. But many more instances are necessary before this can definitely be: stated and further research is needed on this subject.

Anyhow, as long as the assertion that the devices under discussion act as true phase-reversal zone-plates is not backed with conclusive experimental evidence I would rather place the acceleration-plate problem among those awaiting their final solution. 
A Peculiar Ultrasonic Effect on a Binary Mixture of Liquids.

When I was searching for solids and liquids of much the same acoustic resistivities two problems presented themselves immediately: Is there any simple correlation between the ultrasonic velocities in 1. alloys, 2. mixtures (solutions) and those in their components? All available data were gone through but not much information was obtained from existing data. 'the problems seem to be very complicated and too large for an individual investigator. They were left aside because they are not directly connected with the subject of this thesis.

Anyway, one of the preliminary experiments on a mixture of two liquids was showing a peculiar supposedly unknown effect which was worthlohile mentioning.

Bergmann, on $p .185$ of his book, states explicitly: The velocity of sound of the mixture of two liquids having different velocities of sound lies between the single values of the components. (Translated from lerman: Mischt man zwei Hiüsigkeiten mit verschiedener schallgeschwindigkeit, so liegt die schallgeschwindigkeit der Mischung zwischen den beiden Einzelwerten der Komponenten.) (4). This statement is all the more surprising as Bergmann ( $\eta$ ) as early as in 1935 described an exception of this rule. Fig.33 is a copy of the graph in his paper. Curve I shows the velocity of sound in a mixture of amyl acetate (1237 $\mathrm{m} / \mathrm{sec}$ ) and bromoform $(929 \mathrm{~m} / \mathrm{sec}$.) over the whole range of concentration. (The values of the velocities are not in good agreement with those given by Parthasarathy) (52). Curve 2 shows the values for a mixture of methyl alcohol (1168 m/sec.) and water 
(1529 $\mathrm{m} / \mathrm{sec}$.$) . (Also those values are inaccurate.) At the per-$ centage of $25 \%$ methyl alcohol a maximum velocity is reached of about $1650 \mathrm{~m} / \mathrm{sec}$. which is higher than that of either component. I'o clear up this unexpected phenomenon Bergmann was promising further investigations but has not yet returned to this problem.

Since the mixture of methyl alcohol and water shows a volume contraction (negative deviation from Raoult's law) one easily supposes that the phenomenon could be connected in some way with the fulfilment of Raoult's law (33). Therefore, two preliminary experiments were made: The measurement of the velocity of sound in the mixture of chloroform and benzol and in that of carbon tetrachloride and liquid paraffin. The first, generally used for finding the specific gravity of the human blood (7g) (Hammerschlag's method) obeys Raoult's law, the second does it not.

The mixtures were made up by volume with suitable precautions against change in composition due to evaporation. "'he measurement has been made by bergmann and loehlich's method (cf. pp. 56/7) and extended over the entire concentration range. The results obtained are tabulated below and graphically represented in Figs.34,35. In the first case the velocity of ultrasonics in the mixture is a monotonous function of the composition while the second case shows a peculiar effect: For a composition of $20 \%$ carbon tetrachloride and 80\% liquid paraffin the velocity of sound increases to a maximum value of about $1550 \mathrm{~m} / \mathrm{sec}$. At the same time on the screen a pattern like a brick-wall appoases which changes to/honey- 
combs after intense ultrasonic treatment. (Cf. Fig.36 especially the upper part of the photograph.) The pattern remains "frozen" for some time, often even several hours, and then disappears slowly. Hig. 37 was taken just when the pattern was about to become blurred.

The effect occured at various frequencies between 470 and $720 \mathrm{kc} / \mathrm{sec}$. and is, of course, reproducible. It does not matter whether the mixture is newly made or has been kept for several months. Anyway, the investigation is admittedly incomplete and the problem still far from a definite solution. "lhe most obvious explanation would be a partial unmixing produced by ultrasonics. In course of an investigation concerning the occurence of a maximum absorption for a certain concentration $180) /$ of binary mixtures (170), Herzfeld/has calculated the amount of unmixing and found to be too small for observation. 'I'hus, for the moment, no satisfactory explanation can be offered but confirmation and expension of this highly interesting observation seems most desirable. Table 4. Velocity of ultrasonics in two binary mixtures.

\begin{tabular}{|c|c|c|c|c|c|}
\hline $\mathrm{CHCl}_{3}$ & $\mathrm{C}_{6} \mathrm{H} 6$ & $\mathrm{v}$ m/sec. & CCI4 & Iiqu.par. & v m/sec. \\
\hline 100 & 0 & 1003 & 100 & 0 & 927 \\
90 & 10 & 1008 & 90 & 10 & 940 \\
80 & 20 & 1026 & 80 & 20 & 970 \\
70 & 30 & 1061 & 70 & 30 & 1007 \\
60 & 40 & 1080 & 60 & 40 & 1103 \\
50 & 50 & 1102 & 50 & 50 & 1144 \\
40 & 60 & 1132 & 40 & 60 & 1188 \\
30 & 70 & 1172 & 30 & 70 & 1300 \\
20 & 80 & 1230 & 20 & 80 & 1550 \\
10 & 90 & 1246 & 10 & 90 & 1430 \\
0 & 100 & 1301 & 0 & 100 & 1390 \\
\hline
\end{tabular}




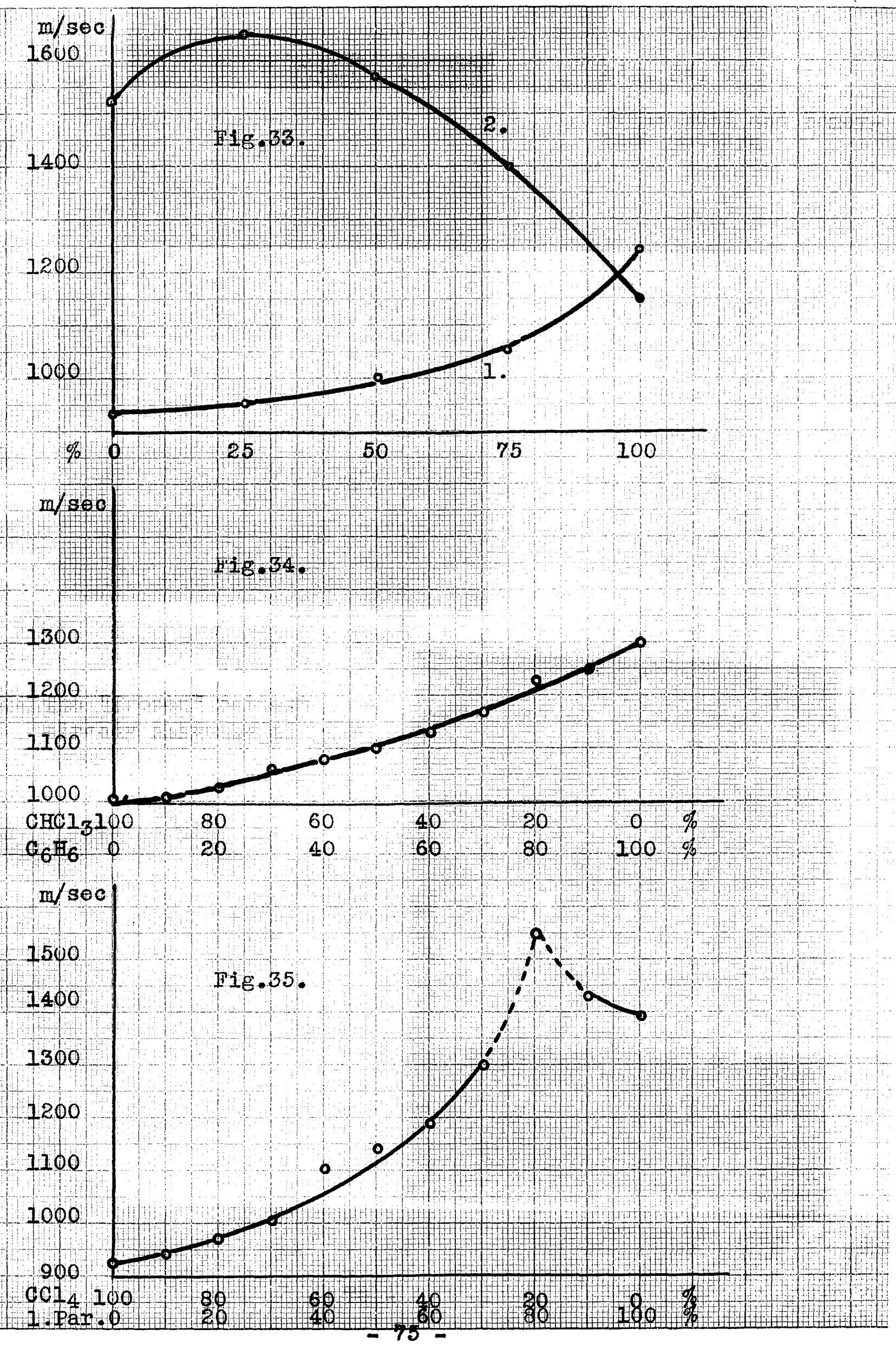




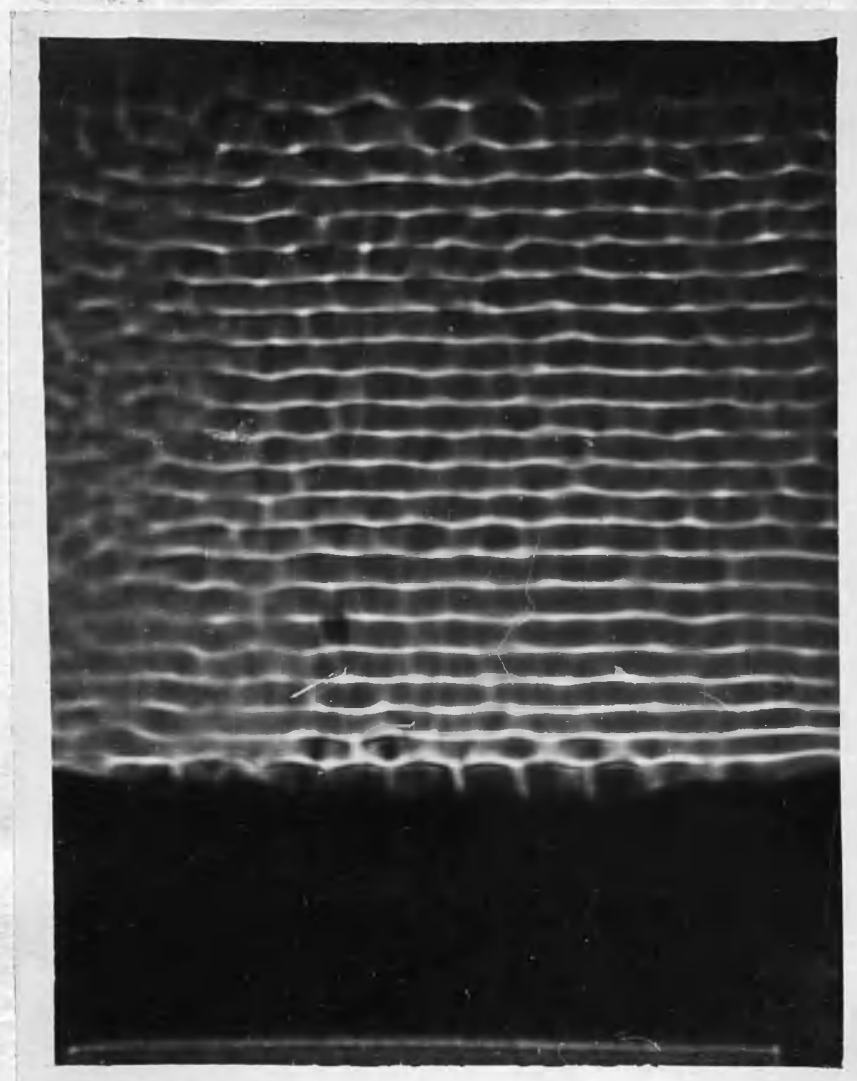

H'ig. 36.

Brick-wall and honeycomb pattern

Fig. 37.

The "frozen" pattern already slightly blurred 
The Blackening Effect of Ultrasonics on Photosensitive Emulsions.

Marinesco and Trillat were the first to ascertain the blackening action of ultrasonics on photographic films. In a paper "Action des Ultrasons sur les plaques photographiques" (48) they have stated the results of their experiments:-

"After a few minutes" action of powerful ultrasonics on unexposed photographic plates in pure distilled water, the plates, when developed in the ordinary way, show a slight fogging, while some material of the sensitized layer is colloidally dispersed through the water.'the slight fogging is already produced during the radiation by ultrasonics if developer is used as the medium for the propagation of the ultrasonic waves instead of distilled water. The blackening of exposed photographic plates is deepened by ultrasonic treatment before development."

In a second paper "Impression des plaques photographiques par les ultrasons" (47) Marinesco and Reggiani have corroborated the existence of the "photochemical effect" of ultrasonics by the following experiment:- They placed a photographic plate in a light-tight box filled with developer and put in a strong ultrasonic field for some minutes, the waves having met the plate obliquely. In this way they have obtained a system of bright and dark bands in alternate succession on the plate as a photograph of stationary ultrasonic waves analogous to wiener's ( $\frac{81}{2}$ ) photographic method of rendering stationary waves of light visible, harinesco and Reggiani have ascribed this phenomenon to "un processus d'activation par choc entre les molécules du sel d'argent". 
A third paper by Marinesco (46) "La loi du noircissement des plaques photographiques par les ultrasons" has shown that the blackening by ultrasonics of photographic plates obeyed the law of Hürter and Driffield (82) just as in the case of their being blackened by the action of light.

In No.523 of Actualités scientifiques et industrielles Marinesco (45) recapitulates his research on the blackening effect of ultrasonics on photosensitive emulsions without adaing any new particulars.

Since then it has neither been confirmed nor refuted by anyone that the effect under discussion existed. Fren Marinesco and his co-workers themselves did not revert to that subject. The only remark, referring to that natter, I have found in their subsequent papers was the following in Girard and Harinesco (27) "Centrifugeuse ultrasonore":

".. Un faisceau dóltrason ne peut Pranchir la limite métal-air subissant un grand nombre de réflexions jusqu' à I'extinction; les pellicules photogrephiques, qui sont sensibles aux ultrasons introduites dans le rotor en mouvement, montrent 1 absence de régime stationaire, la couche d’argent étant uniformement noircie."

The standard book on ultrasonics by Bergmann (3) makes, of course, mention of the investigations of Marinesco and his eoworkers; but Bergmann is doubtful whether the influence of ultrasonics on photographic films is a direct effect or an indirect.

"It is, however," he itiest on p. 220, "not impos- 
sible that in these experiments the plate may be blackened by a Iuminescence phenomenon which may appear in the liquid if it contains gas." In the third edition of his book Bergmann has omitted this remark.

wany series of experiments, concerning the blackening effect of ultrasonics on photosensitive emulsions, have been performed in the course of the research described above. Ilford HP3, Selochrome, Infrared, "R" and "Q" plates have been tried, immersed in liquid paraffin or other liquids, exposed to ultrasonic waves of frequencies between $100 \mathrm{kc} / \mathrm{sec}$. and $4 \mathrm{Mc} / \mathrm{sec}$. for from 250 to 1000 minutes without lenses or between 6 and 25 minutes with lenses. Unly the speediest plates, the HIP3, showed a blackening effect which seened to be connected in some way with a corona effect visible with the naked eye when dark-adapted.

It seems most likely that a blackening effect, either a direct or indirect one, of ultrasonics on photosensitive emulsions may lead to a practically important and powerful method for solving physical, chemical, biological and other scientific or technical problems in the next future :

the fundamental instrument for this purpose is the ultrasonic lens developed in the preceding chapters. 
1. Bär, R. und E. Meyer. Uber einige Versuche zur Beugung des Lichtes an Uitraschallwellen, relv.phys.Acta, $\underline{6}$, 570 (1933). Phys.Z., 34, 393 (1933).

2. Bahrs, S. und J. Engl. Zum piezoelektrischen tifekt an Ammoniumchloridkristalien beim Umwandlungspunkt $-30 \cdot 5^{\circ}$, z.Phys., 105, 470 (1937).

3. Bergmann, Lo Ultrasonics and their sicientific and Technical Applications, translated by St. Hatfield. John Wiley and sions, Inc. New York (1938).

4. Bergmann, I. Der Ultraschall und seine Anwendung in Wissenschaft und 'lechnik. 3. Aufl. VDI-Verlag, GABBH, Berlin, (1942). Lithoprinted by Edwards Brothers, Inc. (1944).

5. Bergmann, L. und H. J. Goehlich. Uber eine sehr einfache Methode zum Nachweis von Ultraschallwellen in Flüssigkeiten, Sitz.Ber.schles.Ges.f.vaterl.Kultur, 108, 47 (1936).

6. Bergmann, L. und H. J. Goehlich. Uber eine sehr einfache Hethode zum Nachweis von Ultraschallwellen in Hlüsigkeiten, thys.z.,38, 9 (1937).

7. Bergmann, I. und A. Jaensch. Schallgeschwindigkeitsmessungen in anorganischen und organischen H'lüssigkeiten, Sitz.Ber.Schles.Ges.f.vaterl.Kultur, 108, 34 (1936).

8. Blodgett, $K$. B. Use of Interference to Extinguish Reflexion of Light from Glass, Phys.Rev. 55, 391 (1939).

9. Bosch, W. C. and W. G. Allée,Jr. Circuit Details for a Small Supersonic Oscillator of the riezoelectric Type, Am.Phys.Teacher, 6 , 272 (1938).

10. Boyle, R. W. Transmission of sonic and ultrasonic waves through partitions, Nature, Lond., 121, 55 (1928).

11. Boyle, R. W., J. F. Lehmann and C. D. Reid. Vizualization and energy survey of a high frequency diffraction beam, Irans.roy.Soc.Canada, Sec.III, I9, 167 (1927).

12. Boyle, $\mathrm{K}$. W. and W. F. Rawlinson. 'l'heoretical Notes on the rassage of Sound through vontinuous Media, Trans.roy. soc.Canada, Sec III, 22, 55 (1928).

13. Buckingham, W. D. and C. R. Deibert. The ConcentratedArc Lamp, J.Opt.Soc.Am., 36, 245 (1946).

14. Busch, $G$. Neue seignette_elektriken, Helv.phys.Acta, 1I, $269 \cdot(1938)$.

15. Busch, G. Weitere Untersuchungen an Seignette-elektrischen substanzen, Helv.phys.Acta, Il, 359 (1938).

16. Cady, W. G. The Longitudinal Piezoelectric Effect in Rochelle Salt Crystals, Proc.Phys.Soc.,49, 646, (1937).

17. Cady, W. G. Piezoelectricity, Ist Ed., MoGraw-Hill Book Company, Inc. (1946) New York and London.

18. Cochrane, $\nu$. and $R$. W. Samsel. A Method of Determining the acoustic properties, absorption and velocity, for materials to be used as ultrasonic windows, lenses, and reflectors, Gen.EI.Rev.,47, 39, (1944).

19. Cremer, L., Ak. Z., 81 (1942). According to a quotation in Götz's paper (29). Just this volume of the Akustische Zeitschrift is not available here. 
20. David, I. :Beryllium X-Ray Tube Windows, Metal Treatment, Spring (1944).

21. Deans, J.: Optical rroperties of Thin Films, Math.Gazette, $29,57(1945)$.

22. Ernst, P. J.: Vorrichtung zum Sammeln und Zerstreuen, gerichtetem senden und Empfangen elektrischer Wellen. Austr. rat. Specific. No.132272 (1933).

23. Ernst, P. J.: Ultrasonic Lenses and Transmission Plates, J. Sci.Instr. 22, 238 (1945).

24. Fagan, C. P.: A new Type of Oscillatory Crystal, Electron. Hng. 468 (1945).

25. French, J.W.: Cryolite Hilms on Glass Surfaces, Nature, Lond., 146,687 (1942).

26. Freundlich, H., F. Rogowski and K. Söllner: phet Die Einwirkung von ultraschallwellen auf Gele, insbesondere tixotrope callerten. Koll. chem. Beihefte, 37, 223 (1933).

27. Girard, $r_{0}$ and $N$. Marinesco: Centrifugeux ultrasonore, U.R.Ac.Sci.Paris, 206, 2000 (1938).

28. Gmelin,A. Handbuch der 4 rganischen vhemie, 8.Aufl., Verlag Chemie GUBBH. System NO.22 Kalium (1935) il64-1222.

29. Götz, H.: Durchlässigkeit von wetallplatten in Flüssigkeiten gegenüber UItraschallwellen, H.T.Z., 64, 360 (1943).

30. Groth, E. J. and I. N. Liebermann: Precision Measurement of the Velocity of Sound at Supersonic Frequencies Using a microphone, Phys.Rev., 65, 350 (1944).

31. Gruetzmacher,J.: PiezoeIectrischer Kristall mit Ultraschallkonvergenz, Z.Phys. 96, 342 (1935).

32. Hesehus, N.: Uber Brechung und Geschwindigkeit des Schalles in porösen schalldurchlässigen Körpern, J.Russ.Phys.Chem. Ges., 22, 233 (1890). (From: Fortschritte d.Phys.(1891)389.)

33. Hildebrand, J.H.: Solubility, The Chem.Catalog Comp.,Inc. New York (1924).

34. Hopwood, F. I.: Experiments with High Frequency Sound Waves, J.Sci.Instr. 6,34 (.2929).

35. Hopwood F. I.: Some Properties of Inaudible Sound, Nature, Lond., 128, 48 (1931).

36. Hopwood, I. : Ultrasonic Lenses and Prisms, ,J. Sc1.Instr. $23,(1946)$.

37. International Critical Tables of Numerical Data.6 , 207ff., HicGraw-Hill Book Company, Inc., New York (1929).

38. Korndörfer, M.: Ther aje Berechnung von Drosselspulen, E.T. Z., 38, 521 (1917).

39. Kundt. A.: Uber eine neue Art akustischer Staubfiguren und über eine Anwendung derselben zur Bestinmung der Schallgeschwindigkeit in festen Körpern und Gasen. Pogg.Ann.Phys. 127,497 (1866).

40. Kundt, A.: Uber die Erzeugung von Klangfiguren in Orgelpfeifen etc., Pogg.Ann.Phys., 128, 337, 496 (1866).

41. Lubcke, E.: Houstik (in Geiger, H. und K.Scheel, Handbuch der rhysik, 8, Berlin, Julius springer (1927).)' 668 .

42. Lüdy, W.: Piezoelektrizität von lialiumphosphat, L.Phys., 113,302 (1939).

43. Ludy, W.: Der Einfluß der Hemperatur auf das dynamischelastische verhalten von Seignette-elektrika, Helv.phys. Hcta, 15, 527 (1942).

44. Lynn, J.'G., Zwemer, K. I., A. J. Chick and A.E. Miller: A New Method for the Generation and Use of Focused Ultrasoum 
sound in Experimental Biology, J.Gen.Physiol.,26, 179 (1942/3); repr.partly in Electr.Eng.,17, $122(\overline{1944})$.

45. Marinesco, N.: Propriétés piézochimiques, physiques et biophysiques des UItrasons. Act.Sc.et Ind., Vol 523. Paris (1937) Hermann \& Cie.

46. Marinesco, N.: Ia Ioi du noircissement des plaques photoFraphiques par les Ultrasons, C.R.Ac.Sci.Paris, 202, 757 $(1936)$.

47. Marinesco, N. and M. Reggiani: Impression des plaques photographiques par les ultrasons. C.R.Ac.Sc1.Paris, 200, 548 (1935).

48. Marinesco, $N$. and J.J.Trillat: Action des UItrasons sur les plaques photographiques, L.R.Ac.Sci.Paris, 196, 858 (1933).

49. Nomoto, 0. : Uber eine neue sichtbarmachungsmethode stehender schallwelien in Hlüssigkeiten, Proc.phys.math.Soc.Japan, (3) $18,402(1936)$.

50. Nomoto, U.: The same title and journal as(49), 19, 337 (1937) and 21,495 (1939).

51. Oyama, H.: Generation and Application of Intense supersonic Acoustic Waves, Rep.Radio Res. Japan, 4, 41 (1934).

52. Parathasarathy, s.: Ultrasonic Velocities in Organic Liquids, Proc.Ind.Acad.Sci. (A), 2, 3, 4 (1935/6).

53. Pierce, G.W.: Piezoelectric urystal Resonators and urystal Oscillators applied to the precision calibration of wavemeteres, proc.Am.Ac.Boston, 59, 81 (1923).

54. Pockels 'H', Uber den Hinflü dés elektrostatiachen Feldes auf das optische verhalten piezoelektrischer líristalle., Abh. d. Ges.d.Wiss., Göttingen, 39, 183 (1894).

55. Pohlmann, R.: tber die möglichkeit einer akustischen Abbildung in Analogie zur optischen, Z.Phys. 113 (1939) $697 f f$.

56. Porter, B. H.: The Supersonic Oscillator, Ind.Eng.Chem., 12, 748 (1940).

57. Rayleigh, Iord: The Theory of Sound, Macmillan \& Company, Ltd., Lond., (1926).

58. Rein, H. und $K$. Wirtz: Radiotelegraphisches Praktikum, 128, Berlin, Springer, 1922.

59. Scherrer, P.: Untersuchungen uber das dielektrische verhal-

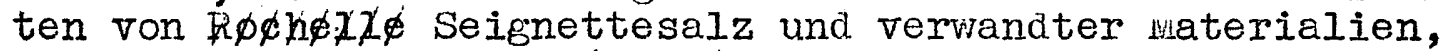
Z.Electrochem. 45, 171 (1939).

60. Schilling, H. K.: Acoustic lxperiments in the Teaching of Optics, Am.Phys.Teacher, 6, 156 (1938).

61. Sokoloff, S.: Uber die praktische Ausnützung der beugung des Iichtes an Ultraschallwellen., Phys.Z., 36, 142 (1935).

62. Sokoloff, S.:UItrasonic Oscillations and the $\overline{\mathrm{Ir}}$ application, lechn.Phys. USSR, 2, 522 (1935).

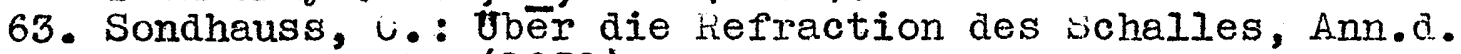
Phys , 85, 378, (1852).

64. Sondhauss, C.: On the Refraction of sound, Phil.Mag.5, 73 (1853)./Reprinted verbatim from 63./

65. Soret, : Hberdiedureltie Ann.Phys. $, 156,91(1875)$.

66. Stamford, N. C.: The Production of Rochelle Salt Piezoelectric Resonators having a rure Longitudinal Mode of vibration, Proc. I.R.E., 25, 4.56465 (1937). 
67. Straubel, H.: Schwingungsform und Temperaturkoeffizient von Quarzoseillatoren, Z.Hfr.T., 38, 14 (1931).

68. Tumanski, C.C.: The Generation of Ultrasonic Oscillations by Plezoelectric Quartz Lenses, (in Russian. I had the paper translated). J.Techn.Physik U.S.S.R., 7,2049$2052(1937)$.

69. Voigt, W.: Lehrbuch der Kristallphysik, 2.Aufl. B.G.Teubner, Ipz. 1928.

70. Willard, G. W.: Ultrasonic Velocity and Absorption in Liquids, Phys. Rev., (2) 57, 1057 (1940); J.A.S.A. 12, 438 (1941).

7l. Wood, R.W.: Phase-Reversal Zone-Plate, and DifiractionTelescopes, Phil. liag. (V) 45, 511 (1898).

72. Labaw, L. W.: Curved CrystaIs as Supersonic Generators, J.A.S.A., 16, $237(1945)$.

73. Weber, L. R. and F. F. Goeder: Phys.Rev. 61, 95 (1942). Velocity of Sound in Methyl Miethacrylate Polymer.

74. Greenland, $K_{\text {. }} M_{\text {. }}$ : Principles of the Use of Nonreflecting Films in Optical Instruments, Nature, Iond., 152, 290 $(1943)$.

75. Schmidt, H.: Schwingungs- und Wellenlehre, 410 ff.(1934) in: Handbuch der Ixperimentalphysik by Vien, W. and $F$. Harms, 17, Lpz. Akad. Verlagses. m.b.H.

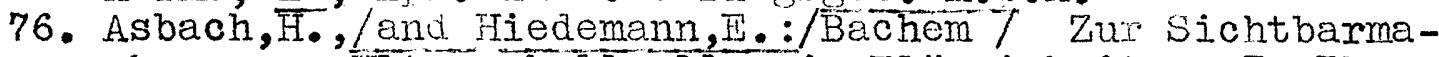
chung von Ultraschaliwellen in Hlüssigkeiten, Z. Phys. 88,395 (1934). Cf. 8.1so Z.Phys. 87, 442 (1933).

77. Houstoun, R.A.: A Treatise on Light, Longmann, Green \& Co., London (1938) 164f.

78. Schuster Sir A.: An Introduction to the Theory of Optics, London, Edw. Arnold \& Co. (1924) 3ra ed. 106.

79. Gray, R. C.: Examples on elementary Physics for Medical Students, Glasgow University, October 1944. p.10, No. 24.

80. Herzfeld, $K$. F.: The Unmixing Effect of Sound Waves on Liquid Mixtures, J.Ch.Ph., 9, 513 (1941).

31. Wiener, 0.: Stehende Lichtwellen und die Schwingungstotrhrichtung polarisierten Lichts, Wiedem. Ann., 40, 203 (1890). 